\title{
Comparing Favorable and Unfavorable Attachment of Colloids in a Discrete Sandstone Fracture
}

\author{
by
}

\author{
Sean Spanik
}

\begin{abstract}
A thesis submitted in conformity with the requirements for the degree of Master of Applied Science

Graduate Department of Civil Engineering University of Toronto
\end{abstract}

(C) Copyright by Sean Spanik 2017 


\title{
Comparing Favorable and Unfavorable Attachment of Colloids in a Discrete Sandstone Fracture
}

\author{
Sean Spanik \\ Master of Applied Science \\ Civil Engineering \\ University of Toronto
}

2017

\section{Abstract}

This study compares the results of cationic amine-modified latex (favorable attachment) and anionic carboxylate-modified latex (unfavorable attachment) microsphere transport through a discrete sandstone fracture. Two microsphere sizes (200 nm and $1000 \mathrm{~nm})$, two ionic strengths (5 $\mathrm{mM}$ and $10 \mathrm{mM})$, and two specific discharges $\left(0.35 \mathrm{~mm} \cdot \mathrm{s}^{-1}\right.$ and $\left.0.70 \mathrm{~mm} \cdot \mathrm{s}^{-1}\right)$ were tested to observe the impact on transport under both attachment conditions. The effect of ionic strength was significant for unfavorable attachment due to the presence of a secondary minimum, but not significant for favorable attachment conditions. The recovery of anionic microspheres resembled favorable attachment when cationic microspheres attached to the sandstone surface and created surface charge heterogeneities. For all conditions tested there was less separation between favorable and unfavorable attachment than would be expected in a comparable porous media study, which was attributed to less contact between the colloid and collector and higher specific discharge in fractured media. 


\section{Acknowledgments}

I would like to thank Dr. Brent Sleep for the opportunity to work on this project, and for providing me guidance throughout the process. This research would also not be possible without the help of Dr. Pulin Mondal who was always available to answer questions and provide assistance in the lab and with modeling. All the other members of the groundwater research group at the University of Toronto also deserve recognition for giving me notes on my presentations and providing support when needed. I also must acknowledge Ertiana Rrokaj, whose previous work with this fracture set up before my arrival was essential for this study. Other people at the University of Toronto that provided technical assistance include George Kretschmann at the Department of Geology and Olga Perebatova at the materials laboratory. I would like to thank Caitlin Corcoran at the University of Western Ontario and Dr. Ian Molnar for their help with operating the electrokinetic analyzer. Finally, I would like to thank Dr. Paul Henshaw and Dr. Nihar Biswas at the University of Windsor for their encouragement to pursue graduate studies. Outside of academics, I would like to thank

my girlfriend Emily for her support and for making the transition to Toronto much easier. Finally, I would not have had this opportunity without the support of my parents through the years. 


\section{Table of Contents}

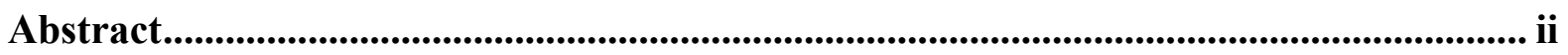

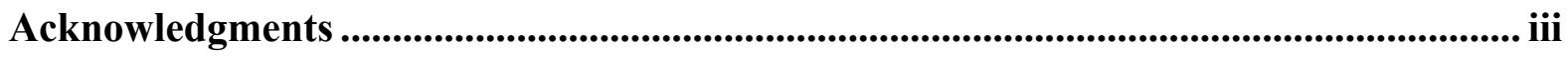

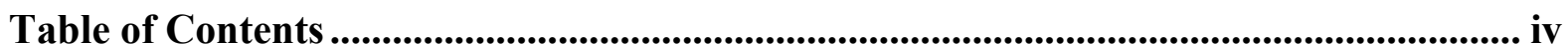

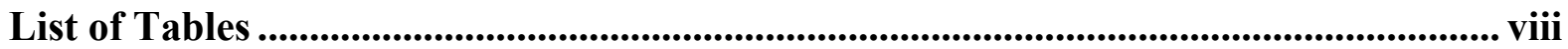

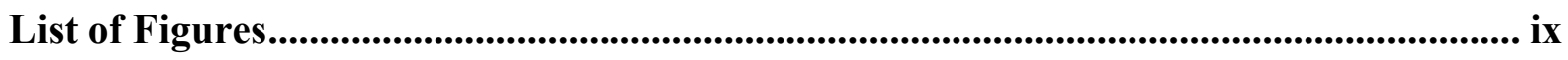

List of Appendices .............................................................................................................. xii

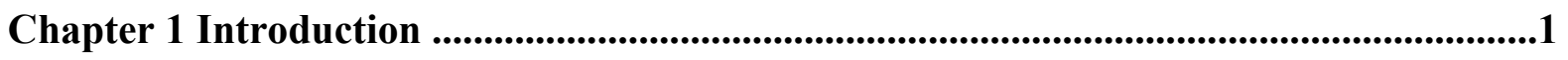

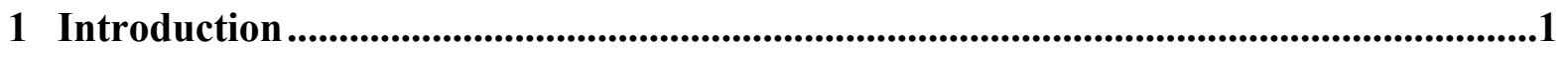

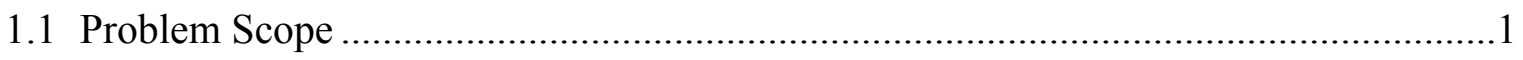

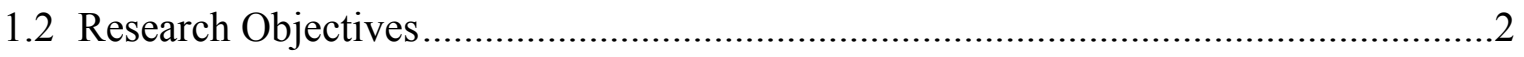

Chapter 2 Literature Review ......................................................................................................3

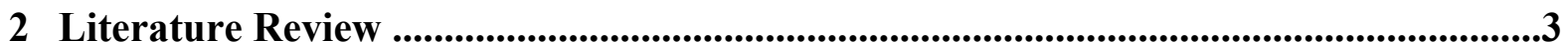

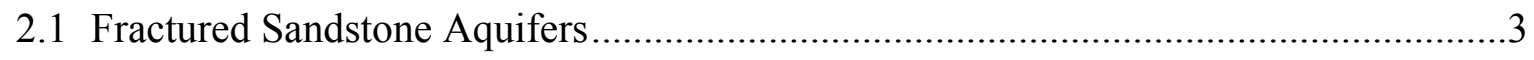

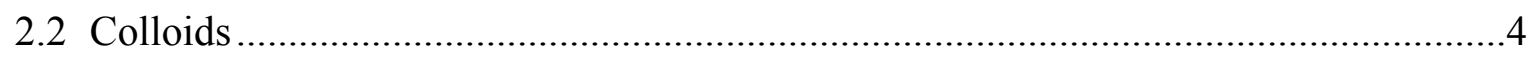

2.2.1 Electric Double Layer ............................................................................

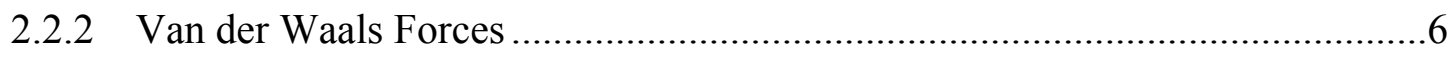

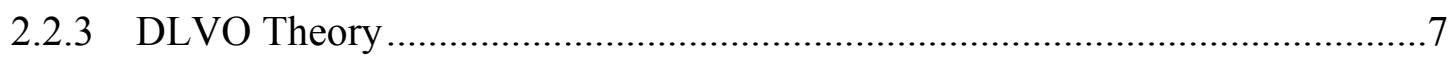

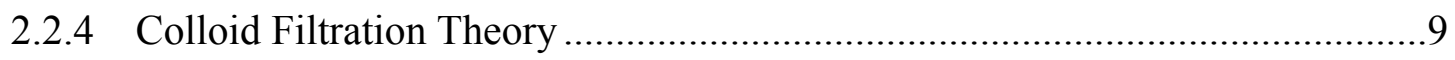

2.3 Unfavorable Attachment and Deviations from CFT ........................................10

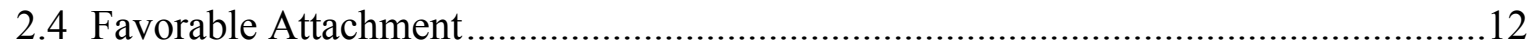

2.5 Solute Transport Through Fractured Rock ...................................................... 13

2.6 Colloid Transport Through Fractured Rock ..........................................................14

Chapter 3 Materials and Methods...............................................................................18

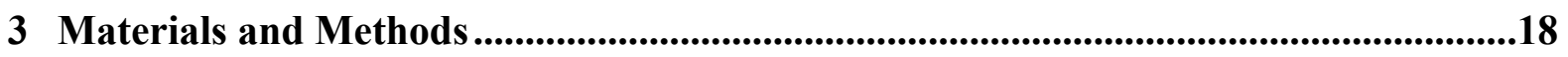

3.1 Sandstone Fracture Properties....................................................................... 18 


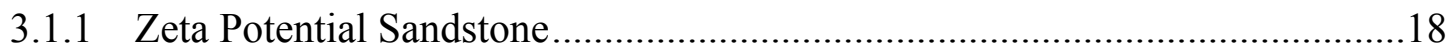

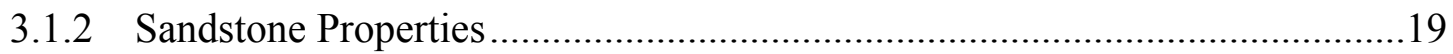

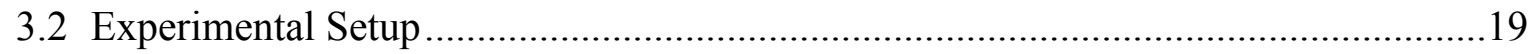

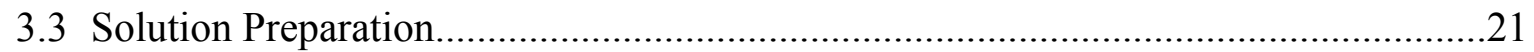

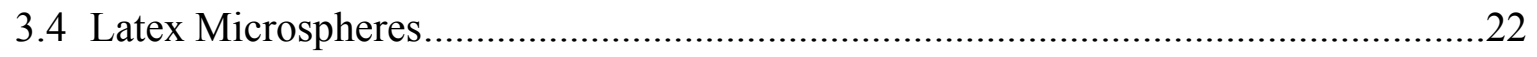

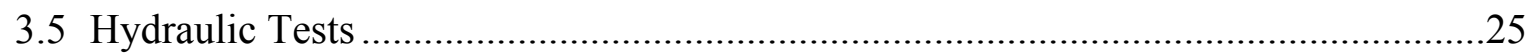

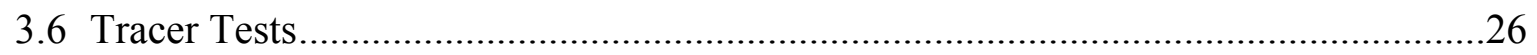

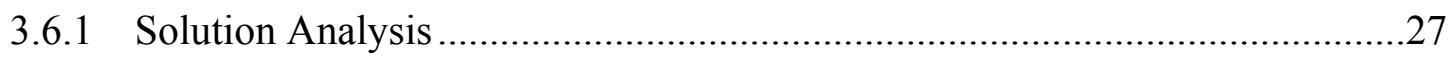

3.6.2 Bromide Analysis..................................................................................27

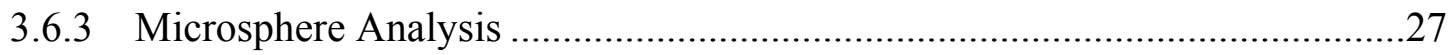

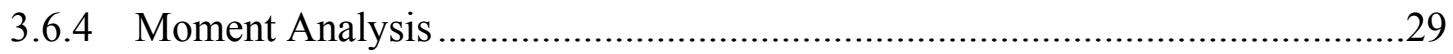

3.7 Hydrus-1D Parameter Estimation ………………….............................................29

3.8 Modeling with Compsim ..........................................................................................

Chapter 4 Results........................................................................................................................32

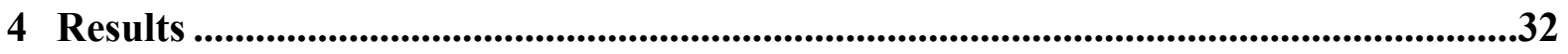

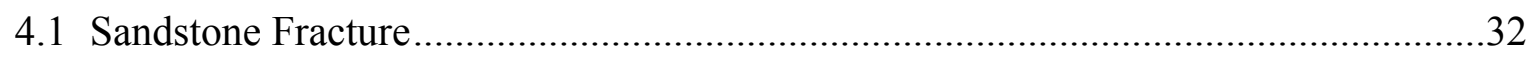

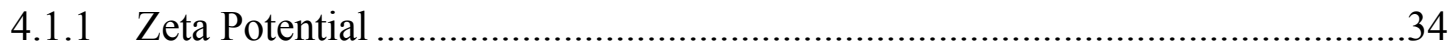

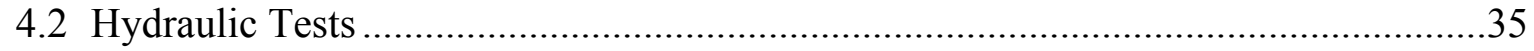

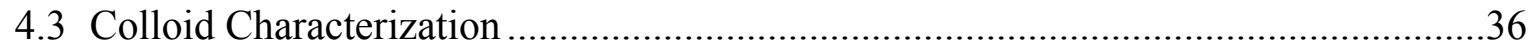

4.3.1 Buffer Selection .......................................................................................

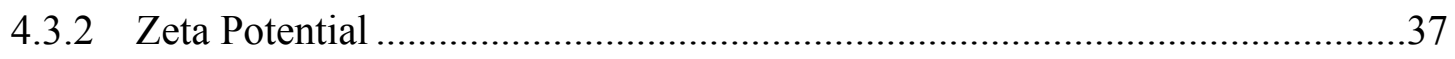

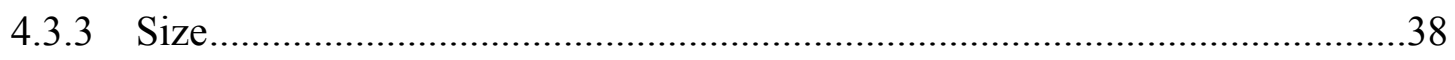

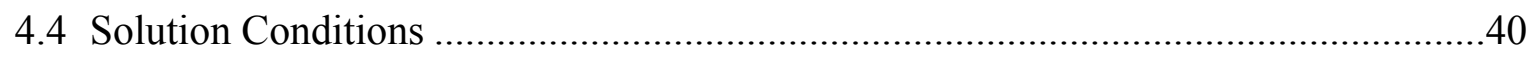

4.5 Bromide Transport ............................................................................................41

4.6 Unfavorable Attachment Tracer Tests ....................................................................42

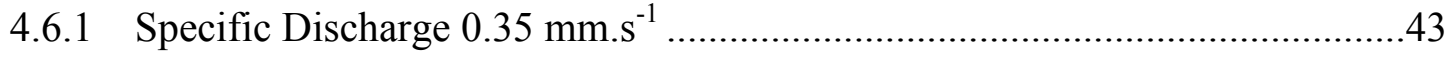


4.6.2 Specific Discharge $0.70 \mathrm{~mm} . \mathrm{s}^{-1}$

4.7 Favorable Attachment Tracer Tests ...................................................................46

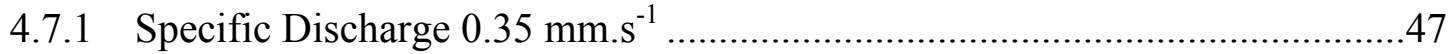

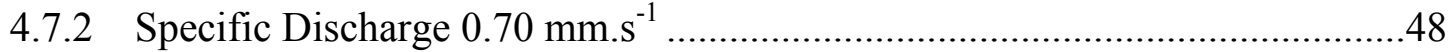

4.8 Comparisons and Hydrus-1D Parameter Estimation .........................................50

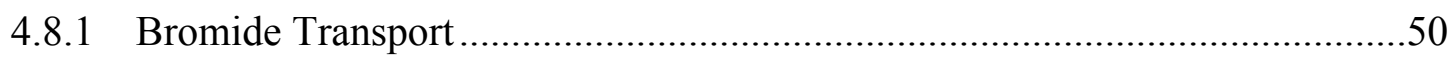

4.8.2 CML Microspheres Ionic Strength Comparisons ........................................52

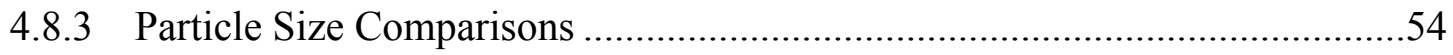

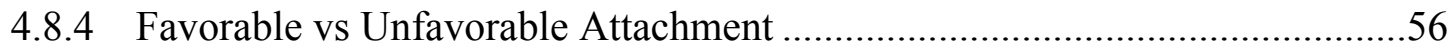

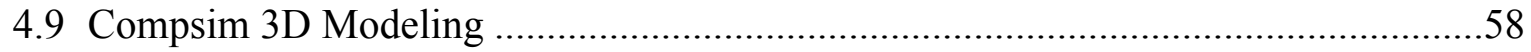

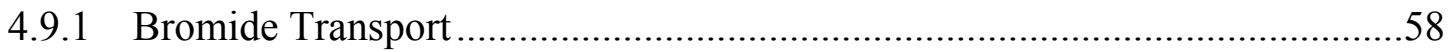

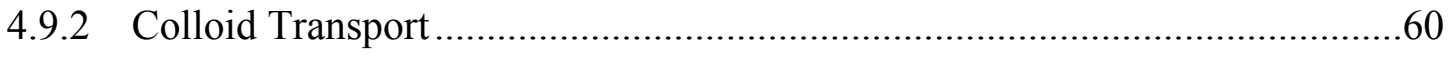

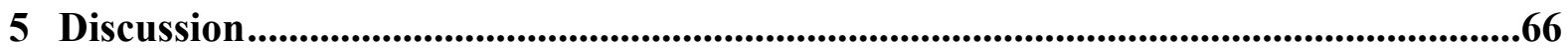

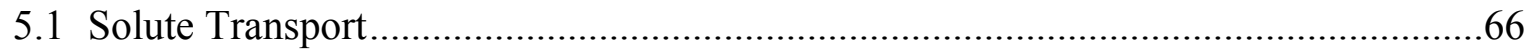

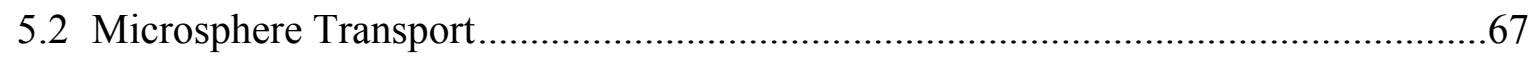

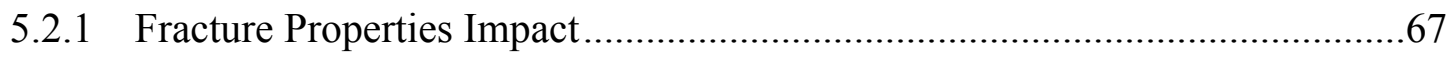

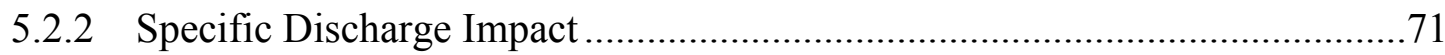

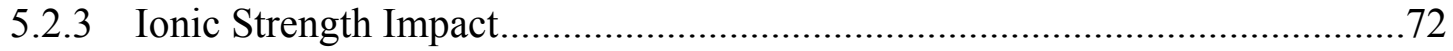

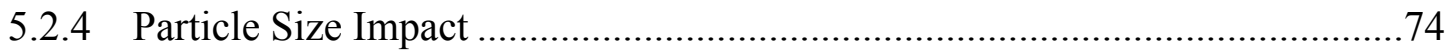

5.2.5 Comparing Favorable and Unfavorable Attachment .................................75

5.2.6 Comparison to Transport in Dolomite Fracture ............................................76

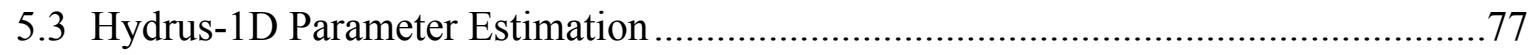

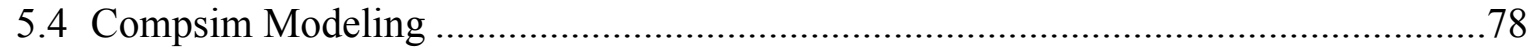

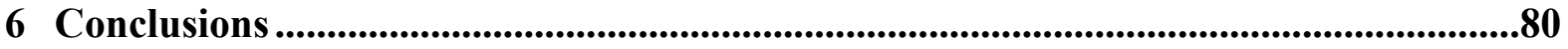

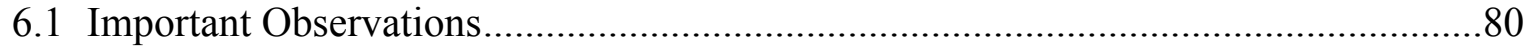

6.2 Recommendations for Future Work ................................................................... 81 


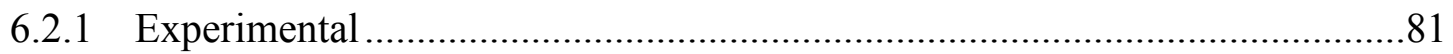

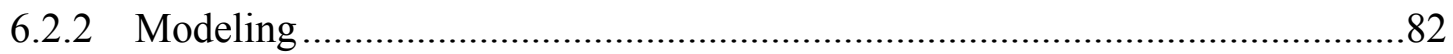

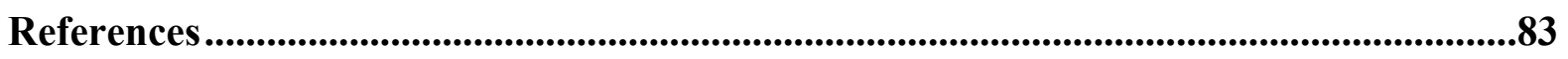

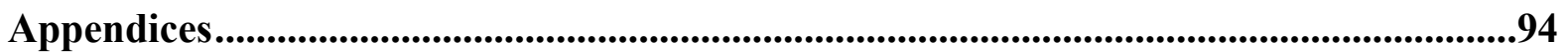




\section{List of Tables}

Table 2.1 Studies of colloid transport through fractured rock ................................................... 15

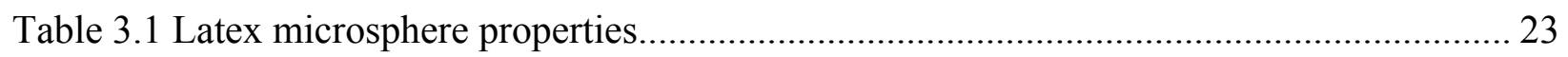

Table 4.1 Streaming potential results for crushed sandstone....................................................... 34

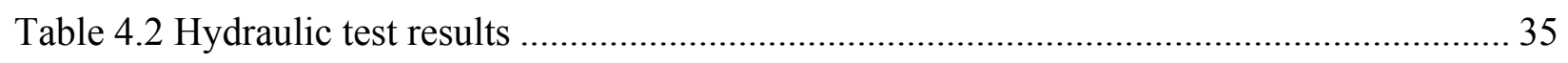

Table 4.3 Buffer comparison between citrate and bis-tris for AML microspheres ....................... 37

Table 4.4 Average Solution Conditions for Unfavorable Attachment Tests ................................. 40

Table 4.5 Average Solution Conditions for Favorable Attachment Tests .................................... 40

Table 4.6 Summary of Unfavorable Attachment Tracer Tests ................................................... 46

Table 4.7 Favorable Attachment Tracer Test Summary ……………………………................ 50

Table 4.8 Hydrus-1D Fitted Bromide Transport Parameters ...................................................... 52

Table 4.9 Hydrus 1D Parameter Estimation Unfavorable Attachment Ionic Strength Comparisons

Table 4.10 Hydrus 1D Parameter Estimation Particle Size Comparison for Favorable and

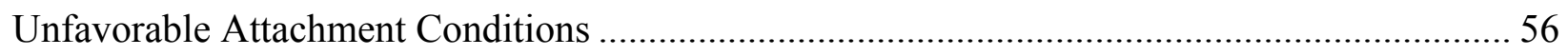

Table 4.11 Compsim Fitting Parameters for 0.35 and $0.70 \mathrm{~mm} \cdot \mathrm{s}^{-1} \mathrm{Br}$ Transport ....................... 59

Table 4.12 Compsim Fitting Parameters for Microsphere Transport ............................................ 62 


\section{List of Figures}

Figure 2.1: Example DLVO energy profile from Molnar et al. (2015) [58] .............................. 8

Figure 3.1 Diagram and photograph of fracturing process from Rrokaj (2015)....................... 19

Figure 3.2 Fracture setup (A) Photograph (B) Diagram ................................................... 21

Figure 3.3 Spectra for 200 and $1000 \mathrm{~nm}$ CML microspheres.............................................. 28

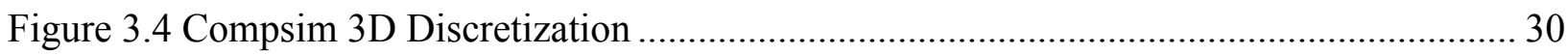

Figure 4.1 (A) 3D grayscale representation of bottom fracture surface (B) aperture distribution.

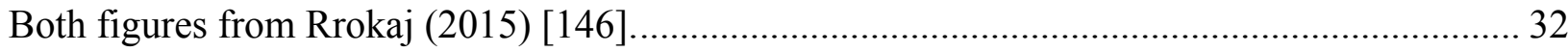

Figure 4.2 Permeability distribution from LCL .................................................................. 33

Figure 4.3 Mineral Phases in Sandstone Sample. Data from Rrokaj (2015) [146] ................... 34

Figure 4.4 Correlation between flow rate and head loss for hydraulic tests ............................ 36

Figure 4.5 (A) zeta potential AML microspheres; $\mathrm{NaCl}$ solutions also contain $5 \mathrm{mM}$ bis-tris buffer. (B) zeta potential CML microspheres; $\mathrm{NaCl}$ solutions also contain $1 \mathrm{mM} \mathrm{NaHCO} \mathrm{Huffer}_{3}$

Figure 4.6 SEM images of microspheres (A) $200 \mathrm{~nm}$ AML microsphere (B) $200 \mathrm{~nm}$ CML microsphere (C) $1000 \mathrm{~nm}$ AML microsphere (D) $1000 \mathrm{~nm}$ CML microsphere 39

Figure 4.7 Bromide BTC and semi-log plot of tailing at $0.35 \mathrm{~mm} . \mathrm{s}^{-1}$ S.D............................. 41

Figure 4.8 Bromide BTC and semi-log plot of tailing at $0.70 \mathrm{~mm} . \mathrm{s}^{-1}$ S.D.............................. 41

Figure 4.9 Unfavorable attachment BTC and semi-log plot of tailing at $5 \mathrm{mM} \mathrm{I.S.................} 43$

Figure 4.10 Unfavorable attachment BTC and semi-log plot of tailing at $5 \mathrm{mM} \mathrm{I.S...............} 43$

Figure 4.11 Unfavorable attachment BTC and semi-log plot of tailing at $5 \mathrm{mM}$ I.S................ 44

Figure 4.12 Unfavorable attachment BTC and semi-log plot of tailing at $10 \mathrm{mM}$ I.S.............. 45 
Figure 4.13 Favorable attachment BTC and semi-log plot of tailing at $5 \mathrm{mM}$ I.S.

Figure 4.14 Favorable attachment BTC and semi-log plot of tailing at $10 \mathrm{mM}$ I.S. 48

Figure 4.15 Favorable attachment BTC and semi-log plot of tailing at $5 \mathrm{mM} \mathrm{I.S.}$ 49

Figure 4.16 Bromide BTC and semi- $\log$ BTC at $0.35 \mathrm{~mm} . \mathrm{s}^{-1}$ with Hydrus-1D model fit 51

Figure 4.17 Bromide BTC and semi- $\log$ BTC at $0.70 \mathrm{~mm} . \mathrm{s}^{-1}$ with Hydrus-1D model fit ......... 51

Figure 4.18 Ionic strength effects $200 \mathrm{~nm}$ CML microspheres with Hydrus-1D model fit. BTC and semi- $\log$ BTC at $0.35 \mathrm{~mm} . \mathrm{s}^{-1} \mathrm{SD}$

Figure 4.19 Ionic strength effects $1000 \mathrm{~nm}$ CML microspheres with Hydrus-1D model fit. BTC and semi-log BTC at $0.35 \mathrm{~mm} . \mathrm{s}^{-1} \mathrm{SD} \quad 0.35 \mathrm{~mm} . \mathrm{s}^{-1} \mathrm{SD}$ 53

Figure 4.20 Particle size effects under unfavorable attachment conditions with Hydrus-1D model

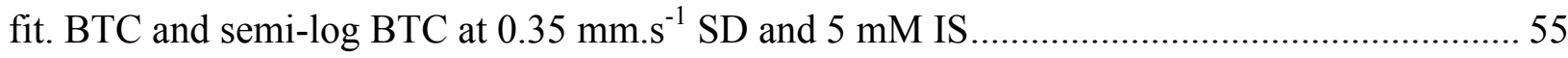

Figure 4.21 Particle size effects under favorable attachment conditions with Hydrus-1D model fit. BTC and semi-log BTC at $0.35 \mathrm{~mm} . \mathrm{s}^{-1} \mathrm{SD}$ and $5 \mathrm{mM}$ IS. 55

Figure 4.22 Favorable vs Unfavorable attachment conditions for $200 \mathrm{~nm}$ microspheres with Hydrus-1D model fit. BTC and semi- $\log$ BTC at $0.35 \mathrm{~mm} . \mathrm{s}^{-1} \mathrm{SD}$ and $5 \mathrm{mM}$ IS.

Figure 4.23 Favorable vs Unfavorable attachment conditions for $1000 \mathrm{~nm}$ microspheres with Hydrus-1D model fit. BTC and semi- $\log$ BTC at $0.35 \mathrm{~mm} . \mathrm{s}^{-1} \mathrm{SD}$ and $5 \mathrm{mM}$ IS. 57

Figure 4.24 Bromide experimental and semi-log BTC with Compsim model fit at $0.35 \mathrm{~mm} . \mathrm{s}^{-1}$ SD

Figure 4.25 Bromide experimental and semi-log BTC with Compsim model fit at $0.70 \mathrm{~mm} . \mathrm{s}^{-1}$ SD 59

Figure 4.26 CML microsphere (unfavorable attachment) experimental BTC and semi-log BTC with Compsim model fit at $0.35 \mathrm{~mm} . \mathrm{s}^{-1} \mathrm{SD}$ and $5 \mathrm{mM}$ IS 
Figure 4.27 AML microspheres (favorable attachment) experimental BTC and semi-log BTC with Compsim model fit at $0.35 \mathrm{~mm} . \mathrm{s}^{-1} \mathrm{SD}$ and $5 \mathrm{mM}$ IS

Figure 4.28 Effect of collector diameter on Compsim model fit

Figure 4.29 Unfavorable (left) and favorable (right) concentration distribution in middle fracture layer (layer 4) for $200 \mathrm{~nm}$ microspheres at $0.35 \mathrm{~mm} . \mathrm{s}^{-1} \mathrm{SD}$ and $5 \mathrm{mM}$ IS 63

Figure 4.30 Unfavorable (left) reversible attachment (layer 3) and favorable (right) irreversible attachment (layer 5) attached microsphere distribution for $200 \mathrm{~nm}$ microspheres at $0.35 \mathrm{~mm} . \mathrm{s}^{-1}$ SD and $5 \mathrm{mM}$ IS.

Figure 5.1 CML microsphere transport test at $0.35 \mathrm{~mm} . \mathrm{s}^{-1} \mathrm{SD}$ and $5 \mathrm{mM}$ IS for $200 \mathrm{~nm}$ particle size before and after AML microsphere transport tests

Figure 5.2 CML microsphere transport test at $0.35 \mathrm{~mm} . \mathrm{s}^{-1} \mathrm{SD}$ and $5 \mathrm{mM}$ IS for $1000 \mathrm{~nm}$ particle size before and after AML microsphere transport tests 69

Figure 5.3 (a) 3 consecutive $200 \mathrm{~nm}$ CML transport tests showing increasing recovery as favorable sites are filled. (b) Comparing $200 \mathrm{~nm}$ BTCs before attached AML microspheres and after favorable sites are filled. 


\section{List of Appendices}

Appendix A : Rock Fracture Properties from Rrokaj (2015) [146] ..................................94

Appendix B : Tracer Calibration Curves ..............................................................................98 


\section{Chapter 1 \\ Introduction}

\section{Introduction}

\subsection{Problem Scope}

Contamination of groundwater is a major concern as many people around the world rely on aquifers as their source of drinking water. In fact, in Canada more than 9 million people (almost $1 / 3$ of the population) rely on groundwater as their primary drinking water source with the majority of these users being located in rural areas [1]. In the United States the proportion of the population that relies on groundwater for domestic purposes rises to $51 \%$, with rural areas again being more reliant at $63 \%$ of total water use [2]. Sandstone aquifers are a widespread source of drinking water; for example, the province of Prince Edward Island is completely reliant on a fractured sandstone aquifer for all of their water supply [3]. In many locations, especially in rural areas, septic tanks and underground storage tanks are commonly used alongside drinking water wells. Contaminants such as viruses and bacteria can migrate from these sites and contaminate drinking water. Colloids are capable of being a contaminant on their own (viruses and bacteria), but also can mobilize sorbed contaminants. The potential health risk of mobile contaminants reaching drinking water supplies makes it imperative to understand the transport of these colloidal particles, and special consideration should be given to transport through fractures.

Colloid transport through fractured rock is not as well studied as colloid transport through porous media, and even fewer investigations have been conducted in fractured media under favorable attachment conditions (oppositely charged colloid and collector). There have been several studies in porous media that examine favorable attachment conditions (e.g. Elimelech (1994) [4] and Cai et. al (2015) [5]), but to the best of the author's knowledge, no studies have been conducted that compare favorable and unfavorable attachment transport tests in a discrete sandstone fracture. With the limited investigation of favorable attachment conditions in fractured media, this study will provide insight into whether cationic colloids can be mobile in a sandstone fracture. Another objective of this study is to develop a better understanding of unfavorable attachment by directly comparing the results of favorable and unfavorable transport tests. Although much of the experimental work on colloid transport is focused on unfavorable attachment conditions, a lot of 
the theory is more effective at describing transport under favorable attachment conditions. For example, colloid filtration theory (CFT) is a commonly used model for predicting colloid transport, but it is a better predictive tool under favorable attachment conditions [6]. Unfavorable attachment, such as in the transport of bacteria and viruses, causes deviations from the classical filtration theory because of factors such as deposition in the secondary minimum and surface charge heterogeneities

[7]. Analyzing the differences in how ionic strength, specific discharge, and particle size impact transport under both attachment conditions will result in a more thorough understanding of phenomena such as secondary minimum attachment and surface charge heterogeneity.

\subsection{Research Objectives}

1. Perform unfavorable attachment tracer tests with negatively charged carboxylate-modified latex (CML) microspheres. Determine the impact of ionic strength, specific discharge, particle size, and fracture properties on transport.

2. Perform favorable attachment tracer tests with positively charged amine-modified latex (AML) microspheres. Determine the impact of ionic strength, specific discharge, and particle size, and fracture properties on transport.

3. Compare the BTCs of AML microspheres, CML microspheres, and a conservative solute (Br) to develop a better understanding of the mechanisms governing colloid and solute transport through fractures.

4. Fit the experimental BTCs with Hydrus-1D to estimate transport parameters and investigate the effect of changing particle size, solution conditions, and attachment conditions.

5. Use a 3D model (Compsim) to simulate the transport of bromide and the $200 \mathrm{~nm}$ AML and CML microspheres. 


\section{Chapter 2 \\ Literature Review}

\section{Literature Review}

\subsection{Fractured Sandstone Aquifers}

Sandstone aquifers are a common drinking water source in Canada and around the world. For example, the province of Prince Edward Island (PEI) is completely dependent on a highly permeable fractured sandstone aquifer for all of their industrial, domestic, agricultural, and potable uses [3]. Sandstone aquifers transmit most of their water through joints, fractures, and bedding planes [8].

Sandstone has a porosity that varies approximately between $0.05-0.25$ [9], which results in matrix diffusion being an important consideration for transport studies in fractured sandstone. The importance of porosity for matrix diffusion was shown by Boving and Grathwohl (2001) [10], with their experiments on geologically varied sandstone and limestone indicating that there was a close relationship between total porosity and the effective diffusion coefficient of the rock. Several studies have shown that the porosity of sandstone decreases with depth [11], [12]. Ramm and Bjorlkke (1994) [12] also showed that there is a negative correlation between clay content and porosity at depths $<2.5-3 \mathrm{~km}$. The presence of swelling clays such as kaolinite can cause significant reductions in permeability by reducing pore cross-sectional area [13]. According to Domenico and Schwartz (1998) [14] a representative value for hydraulic conductivity of sandstone rock is $3 \times 10^{-10}$ to $6 \times 10^{-6} \mathrm{~m} / \mathrm{s}$.

Sandstone has a negative zeta potential under most groundwater conditions with an isoelectric point (IEP) of 2.2-2.8 [15]. The zeta potential of sandstone varies with changes in salinity, $\mathrm{pH}$, and temperature. A study by Vinogradov and Jackson (2015) [16] demonstrated that in low ionic strength conditions $(0.01 \mathrm{M})$ the zeta potential of the sandstone decreases in magnitude with increasing temperature. The explanation for this change is that the $\mathrm{pH}$ decreases with increasing temperature, and it is well understood that a lower $\mathrm{pH}$ leads to a less negative zeta potential. 


\subsection{Colloids}

Colloids are described as micro-sized suspended particles in the size range of $1 \mathrm{~nm}$ up to $1 \mu \mathrm{m}$ in diameter [17]. The size range varies in the literature, with some sources defining the range as up to $10 \mu \mathrm{m}$ [18], [19]. Colloids are not considered a solution, as their size is much larger than that of ions. When a particle falls below $1 \mathrm{~nm}$ it begins to behave more like a molecule with van der Waals forces, Brownian motion, and diffusion being some of the dominant forces. When the size of the particle reaches 5-10 $\mu \mathrm{m}$ the dominant forces affecting the particles become that of gravity and fluid drag [20]. A colloidal suspension is characterized by an electrostatic stability because of repulsive forces between particles. In the absence of an electrostatic repulsion between colloids the instability would cause aggregation.

Colloids have been found in a variety of different geological conditions in concentrations as high as $100 \mathrm{mg} . \mathrm{L}^{-1}$ [21]. In a fractured granitic aquifer in Switzerland Degueldre et al. (1989) [22] reported colloid concentrations of $10^{10}$ particles per liter. There are several varieties of colloids that may exist in the subsurface including inorganic, organic, biocolloids, and engineered nanoparticles (ENPs). Examples of these are clays and mineral precipitates (inorganic), macromolecular components of natural organic matter (organic), as well as bacteria and viruses (biocolloids) [23]. Sources of colloids include infiltration, mineral precipitation, and injection into the subsurface for remediation. The generation of colloids in groundwater can occur as a result of changes in geochemistry [24] such as a change in $\mathrm{pH}$ or a sudden decrease in ionic strength due to rain infiltration. Several studies have shown that a decrease in ionic strength can lead to colloid re-entrainment [25], [26]. Rapid changes in flow velocity and increased shear due to pumping can also result in an increase in colloid concentration. Groundwater sampling can be impacted by the generation of colloids from flow perturbations as noted by Backhus, et al. (1993) [27] when they observed orders of magnitude higher concentrations of colloids in bailed samples when compared to samples collected by slow prolonged pumping.

Colloids can be either positively or negatively charged which results in either favorable or unfavorable attachment conditions depending on the charge of the collector. When the colloid and collector have like charges the result is unfavorable attachment, and when they have opposite charges the result is favorable attachment. Unfavorable attachment is the most common condition in aquifers as most environmentally relevant particles are negatively charged [28]. Colloids such 
as organic materials, viruses, bacteria, and clays are negatively charged at near neutral or higher $\mathrm{pH}$. Minerals present in many rocks such as sandstone, limestone, and others are also negatively charged at near neutral $\mathrm{pH}$ conditions.

One of the primary motivations behind studying colloid transport in groundwater is that contaminants that would otherwise be immobile can become mobile due to being adsorbed to a mobile colloid particle. The phenomenon of contaminants sorbed to colloidal particles has been noted by studies such as McDowell-Boyer et al. (1986) [29] and Magee et al. (1991) [30]. Many other studies have reported that colloids can travel at a much faster rate than solutes at both the lab [31], [32] and field [33] scale. Colloid facilitated transport becomes environmentally significant if four conditions are met: mobile colloids are present in sufficiently large concentrations, particles are transported over significantly large distances through uncontaminated zones of the porous medium, contaminants sorb strongly to the colloids and desorb slowly, and the contaminant is highly toxic [34].

\subsubsection{Electric Double Layer}

The theory of electrical double layer interaction is an important concept in colloid science that was established over 150 years ago by Helmholtz (1853) [35] with modifications by Guoy-Chapman (1910-1913) [36], [37] and Stern (1924) [38]. The double layer is a cloud of ions that forms around the dispersed colloidal particle. The electric double layer consists of the Stern layer and the Diffuse layer. The Stern layer consists of oppositely charged ions to the surface that are bound tightly, and the Diffuse layer contains loosely bound ions that are mostly of opposite charge to the Stern layer [39]. The thickness of the double layer is known as the Debye length $(1 / \kappa)$, which is the distance from the particle surface to the outer edge of the Diffuse layer (shear plane).

The Gouy-Chapman model of the electric double layer states that the surface charge of the particle must be exactly balanced by counterions [40]. The Diffuse layer is formed due to counterions being attracted towards the surface while like charged ions are repelled from the surface. Diffusion forces act in the opposite direction, with the result being an increasing concentration of counterions closer to the surface [41].

The major change with the Stern model of the electric double layer compared to the GouyChapman model, is that the Gouy-Chapman model assumed that the ions acted as point charges, 
whereas the Stern model considers the finite size of the ions [42]. The size of the ions impacts the model because if the charge is assumed to be located at the center of the ion then it cannot touch the surface and is instead located at a distance of one ion radius away [43]. Another modification to the Stern model was introduced by Grahame (1947) which divides the Stern layer into two regions, with the inner region consisting of specifically adsorbed ions [44].

Electrical interaction between colloidal particles is one of the most important determiners of particle stability, aggregation and deposition [43]. The stability of colloidal solutions is dependent on the combination of attractive van der Waals forces and repulsive electrostatic forces between colloid particles. The interaction of electrostatic and van der Waals energy form the basis for the classical DLVO theory that was developed separately by Derjaguin \& Landau (1941) [45] and Verwey \& Overbeek (1948) [46]. The details of DLVO theory and how it relates to both favorable and unfavorable attachment conditions will be discussed in later sections of the literature review.

\subsubsection{Van der Waals Forces}

The existence of adhesive van der Waals forces has a major impact on colloid stability. There have been several important contributions to the theory of van der Waals forces including early contributions by London (1937) [47] and Hamaker (1937) [48]. The problem with applying early theories of van der Waals forces to macroscopic bodies is that the force is not additive. Lifshitz (1956) [49] developed a more comprehensive theory that treats matter as a continuum [50]. Attractive van der Waals forces are always present and exist between all atoms, molecules, and macroscopic bodies. Van der Waals forces act over short distances of less than about $10 \mathrm{~nm}$ [51].

The magnitude of van der Waals forces between spherical particles is computed as a function of the separation distance and diameters of the particles [48]. The van der Waals force between two spherical particles $\left(\mathrm{W}_{\mathrm{ss}}\right)$ and between a spherical particle and a flat surface $\left(\mathrm{W}_{\mathrm{sf}}\right)$ can be calculated according to the following equations [52]:

$$
\begin{gathered}
W_{s s}=-\frac{A}{6 D}\left(\frac{R_{1} R_{2}}{R_{1}+R_{2}}\right) \\
W_{s f}=-\frac{A R}{6 D}
\end{gathered}
$$


Where A is the Hamaker constant, D is the separation distance, and $\mathrm{R}$ is the radius of the sphere. The Hamaker constant in the equation for a flat surface and a sphere was originally developed for interaction between two flat plates, so the following is a corrected equation that was proposed by Gregory (1981) [53] and has been used by several studies [7], [26], [54]:

$$
W_{s f}=-\frac{A R}{6 D}\left(1+\left(\frac{14 D}{\lambda}\right)^{-1}\right)
$$

Where $\lambda$ is the characteristic wavelength and is commonly assumed to be $100 \mathrm{~nm}$ [53]. The conventional Hamaker constant can be calculated with the following equation [55]:

$$
A=\pi^{2} C \rho_{1} \rho_{2}
$$

Where $\rho_{1}$ and $\rho_{2}$ are the number of atoms per unit volume in the two bodies and $\mathrm{C}$ is the coefficient in the atom-atom pair potential. The value of the Hamaker constant depends on the materials, but is generally in the range of $10^{-19}$ to $10^{-20} \mathrm{~J}[56]$.

\subsubsection{DLVO Theory}

The fate and transport of colloids and contaminants is dependent on the interaction energy between colloid and collector. Classical DLVO theory was developed by summing van der Waals and electric double layer forces, which were discussed in the previous two sections of this review. Van der Waals forces are generally attractive, whereas double layer forces can be either attractive or repulsive depending on chemical structure, supporting media properties, and surface potential [57]. The DLVO energy profile is developed by summing adhesive and repulsive energies over a range of separation distances. An example of a DLVO energy profile from Molnar et al. (2015) [58] is shown for both favorable (silver colloid-iron oxide) and unfavorable (silver colloid-quartz sand) attachment conditions is shown in Figure 2.1. 


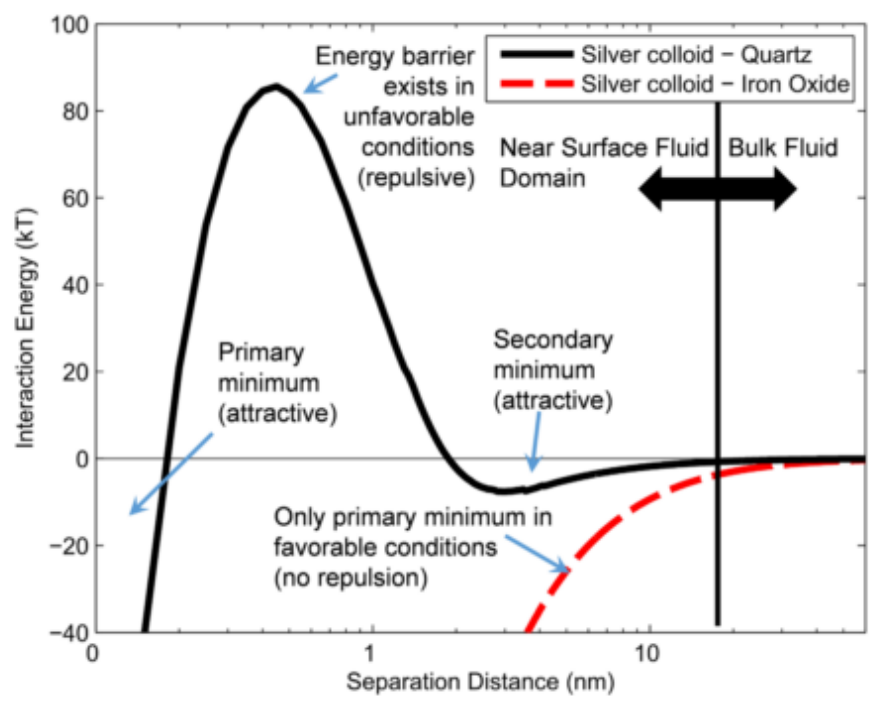

Figure 2.1: Example DLVO energy profile from Molnar et al. (2015) [58]

Figure 2.1 shows that under unfavorable attachment conditions there is a primary minimum and a secondary minimum, while under favorable attachment conditions there is only a primary minimum. As shown by Kuznar and Elimelech (2007) [59], the secondary minimum depth increases and the separation distance from the collector surface decreases with increasing ionic strength because raising the ionic strength decreases the range of the double layer forces. Another difference between the favorable and unfavorable profiles is that there is an energy barrier to attachment in the primary minimum when conditions are unfavorable. The height of the energy barrier is proportional to particle size, which was shown in a study by Litton and Olson (1996) [60], where the size of the energy barrier between latex microspheres and quartz increased from $30 \mathrm{kT}$ for the smallest particles to $1000 \mathrm{kT}$ for the largest particles. The energy barrier decreases as the ionic strength increases, and eventually disappears at high ionic strength (Kuznar and Elimelech (2007) [59] showed disappearance of the barrier at $100 \mathrm{mM}$ ionic strength). The ionic strength at which the energy barrier no longer exists is known as the critical coagulation concentration. Other factors such as surface roughness, colloid shape, and electrolyte valence can also have an impact on the DLVO interactions [61]-[63].

In recent years, DLVO theory has been modified to include non-DLVO interactions including Lewis acid/base interaction, steric interaction, and structural forces (hydrophobic interaction and 
hydration pressure) [57]. The inclusion of these non-DLVO forces is necessary because at small separation distances of closer than a few nanometers attractive van der Waals and repulsive double layer forces often fail to predict the interaction [64].

Two of the primary forces that are not considered by classical DLVO theory are hydration and hydrophobic interaction. Repulsive hydration forces can occur at short separation distances, and originate due to adsorbed hydrated ions being prevented from desorbing as two surfaces approach one another [65]. Hydrophobic interactions are attractive and occur between nonpolar molecules. At separation distances of 1-4 $\mathrm{nm}$ hydrophobic effects can be stronger than van der Waals forces and cause colloidal suspensions to coagulate more quickly than predicted by DLVO theory [66]. The short range nature of hydrophobic forces results in a reduced height for the potential energy barrier, but does not impact the depth of the secondary minimum [67].

\subsubsection{Colloid Filtration Theory}

Colloid filtration theory (CFT) was developed by Yao et al. (1971) [68] to describe wastewater filtration processes, and is still commonly used to model colloid transport in the subsurface. CFT is based on a single isolated spherical collector surrounded by an infinite fluid. CFT uses a twostep filtration process that incorporates transport to the collector and attachment. The three mechanisms involved in transporting the particles to the collector are interception, sedimentation, and diffusion. Yao et al. (1971) [68] was the first to develop an equation for collector efficiency; the equation is based on the summation of the three analytical expressions for particle transport: interception, sedimentation, and diffusion. The single collector contact efficiency $\left(\eta_{0}\right)$ is defined as the fraction of transported particles that contact the collector surface. The single collector removal efficiency $(\eta)$ represents the fraction of transported particles that are captured on the surface. The $\eta$ value is generally smaller than the $\eta_{\mathrm{o}}$ value under most groundwater conditions (unfavorable conditions), so an empirically derived scaling factor called the collision efficiency $(\alpha)$ is used [69]. The $\alpha$ value represents the percentage of collisions that are successful. Under favorable attachment conditions, the $\alpha$ value can be assumed to be 1 and the $\eta$ and $\eta_{\mathrm{o}}$ values are equal [70]. The collision efficiency can be calculated by analyzing particle break through curves from column experiments. The single collector removal efficiency $(\eta)$ is the product of the single collector contact efficiency $\left(\eta_{\mathrm{o}}\right)$ and the collision efficiency $(\alpha)$. The equations for $\eta$ and $\eta_{\mathrm{o}}$ are as follows: 


$$
\begin{gathered}
\eta_{o}=\eta_{D}+\eta_{I}+\eta_{G} \\
\eta=\alpha \eta_{o}
\end{gathered}
$$

Where $\eta_{D}, \eta_{I}$, and $\eta_{G}$ are the transport efficiencies by diffusion, interception, and sedimentation respectively. Filtration theory is still applicable for predicting colloid transport when the colloidcollector interactions are attractive [71], but when unfavorable attachment conditions are present standard filtration theory is not as effective of a tool. Over the last few decades several attempts to develop an improved correlation equation for $\eta$ have been made [72]-[79]. The Rajagopalan and Tien (1976) [72] equation (RT) used the Happel sphere-in-cell porous media model [80] to provide a more realistic representation of porous media than the isolated sphere model. The RT model incorporated van der Waals forces and hydrodynamic retardation to the mechanisms of sedimentation and interception, but treated diffusion the same as CFT. More recently, Tufenkji and Elimelech (2004) [73] (TE) improved on the RT model by considering the influence of hydrodynamic interaction and van der Waals forces on the deposition of Brownian particles. The Long and Hilpert (2009) [75] model (LH) built upon the TE model by adopting their sedimentation and interception terms directly and using a numerical Lattice-Boltzmann simulation in random packings of spheres of uniform diameter to develop a correlation for Brownian particles. Ma et al. (2009) [77] (MPFJ) used a "hemispheres-in-cell" geometry that represented grain to grain contact better than the Happel sphere-in-cell geometry, to develop a correlation equation. Most recently, the range of applicability for the correlation equation was increased by Nelson and Ginn (2011) [78] (NG) to provide better approximations in the low fluid flow regime.

\subsection{Unfavorable Attachment and Deviations from CFT}

There are several issues when attempting to apply filtration theory to predict transport especially under unfavorable attachment conditions. Even under favorable conditions CFT sometimes overpredicts the retention of smaller nanoparticles [81]. Some of the primary causes for the

observed deviations from CFT predictions are: collector surface charge heterogeneity, heterogeneity in colloid population, straining, blocking, secondary minimum attachment and detachment, and other simplifying assumptions. 
Surface charge heterogeneity is one of the most common explanations for deviations from CFT [7], [21], [54], [82]-[84]. As described by Tufenkji et al. (2004) [7], surface charge heterogeneity can develop due to the presence of surface impurities such as metal oxides. Song et al. (1994) [85] showed that unfavorable surfaces with even minor surface charge heterogeneity can result in deposition rates that are orders of magnitude larger than a homogeneous surface. Elimelech et al. (2000) [83] demonstrated the effects of patchwise heterogeneity very well by using different fractions of aminosilane modified quartz sand (positively charged) to show that the average zeta potential was a poor predictor of observed retention. The CFT based models often predict zero attachment under unfavorable conditions because they assume mean surface characteristics (zeta potential) are consistent across the entire surface [86].

In addition to the surface charge heterogeneity of the collector, surface charge heterogeneity among colloid populations has also been shown to cause deviation from the log-linear retention profile that is predicted by CFT [54], [87]-[90]. Microorganisms in particular can show significant variation in surface properties among the population, which studies have shown can have a major impact on transport [91]-[93]. Tong and Johnson (2007) [88] showed that even experiments run with microspheres can have heterogeneity among the colloid population and cause hyperexponential profiles of retained colloids.

Deposition in the secondary minimum of the DLVO energy profile another major cause that is cited for causing deviation from CFT [7], [26], [54], [94], [95]. The secondary minimum exists under unfavorable attachment conditions, and is the result of adhesive van der Waals forces overcoming repulsive double layer forces. The most common method used to show that particles are being retained in the secondary minimum is to flush with a low ionic strength solution [25], [26], [54], [94]-[96]. The low ionic strength solution eliminates the secondary minimum so particles become detached and a spike in effluent concentration is generated.

Colloid retention from straining is caused by particles becoming stuck in downgradient pore throats that are too small to allow them to pass [29]. There have been several studies that have suggested that straining might be a significant factor in controlling colloid transport [97]-[100]. Bradford et al (2003) [99] showed that straining impacts colloid transport so that it can no longer be described by CFT when the ratio of colloid diameter to the median grain diameter is greater 
than 0.005. Zvikelsky and Weisbrod (2006) [101] applied a similar concept to transport through fractured rock by comparing the diameter of the colloids to the minimum aperture of the fracture.

Blocking is a process that can cause an unexpected BTC shape that is either delayed or asymmetric [102]. Blocking is the result of favorable attachment sites being filled by previously deposited colloids, which causes that site to be "blocked" for future attachment. CFT assumes that there is a constant rate of retention over time which would mean there is an infinite retention capacity [21]. Real systems have a finite maximum concentration of attached colloids $\left(\mathrm{S}_{\max }\right)$, which depends on physiochemical conditions such as water velocity, solution chemistry, colloid size and shape, pore structure, surface roughness, and physical and chemical heterogeneity [103].

Other explanations for CFT being unable to predict colloid transport in many situations are that it does not include particle detachment [104] and the geometry is simplified. The typically used Happel sphere-in-cell geometry may cause CFT models to often overpredict $\eta$ [105]. Surface roughness of colloids and collectors is another CFT simplification that may explain the discrepancy between predictions and observed results [61], [106]-[108].

\subsection{Favorable Attachment}

Colloid transport under favorable attachment conditions is a topic that is not as extensively researched as transport under unfavorable conditions due to unfavorable conditions being more common in nature and more difficult to model. Although not as extensively researched, transport under favorable conditions can provide important insight into the role of colloidal and hydrodynamic interactions in transport [81]. There have been some studies involving colloid transport under favorable conditions in porous media [4], [110], but this is not a well explored area in fractured media.

Favorable attachment conditions develop in the absence of repulsive electrostatic forces between the colloid and collector. Materials such as titanium oxide, iron oxide, and magnesium oxide have a point of zero charge (PZC) near neutral or above causing them to have a positive charge under most groundwater conditions [43]. The positive charge of these materials leads to favorable attachment sites. Attachment under favorable conditions generally happens in the primary minimum of the DLVO energy profile, and is irreversible under normal conditions. Although considered irreversible, factors such as increased hydrodynamic shear (as shown by Bergendahl 
and Grasso (2000) [111]), reduced ionic strength for colloids attached at nanoscale protruding asperities (as shown by Shen et al. (2012) [112]), and charge reversal by reduction in $\mathrm{pH}$ (shown by several studies [28], [54], [113]) can cause particles to detach from the primary minimum.

\subsection{Solute Transport Through Fractured Rock}

Understanding the factors that impact solute transport through fractured rock is essential to better predict the movement of contaminants in the subsurface. Flow through fractures is controlled by both advective and diffusive processes with the relative importance of each being determined by the Peclet number $\left(P_{e}\right)$. The advective and diffusive processes involved here are dispersion (macrodispersion and Taylor dispersion) and molecular diffusion respectively. The equation for the Peclet number is:

$$
P_{e}=\frac{v_{m} l}{D_{m}}
$$

Where $v_{m}$ is the mean solute velocity, $l$ is the characteristic length (mean fracture aperture), and $D_{m}$ is the molecular diffusion coefficient. Diffusion will dominate for low $\mathrm{P}_{\mathrm{e}}$ numbers $\left(P_{e}<<1\right)$, macrodispersion dominates for intermediate $P_{e}$ numbers, and Taylor dispersion dominates for high $\mathrm{P}_{\mathrm{e}}$ numbers [114].

Although the fracture contains most of the fluid flow, the matrix and stagnant water zones are still important factors in solute transport because of molecular diffusion. Diffusive transfer of solutes between flowing water in the fracture and the rock matrix or stagnant water zones can significantly retard the transport of contaminants. The impact of matrix diffusion on solute transport through fractures has been noted by several studies [115]-[119]. The effect of matrix diffusion is also evident in the delayed breakthrough of conservative tracers compared to colloids in transport tests [31], [33], [120], [121].

Although matrix diffusion is the most common explanation for BTC tailing, advective processes such as dispersion can also have a significant influence on tailing. The two mechanisms that lead to dispersion in a fracture are Taylor dispersion and macrodispersion. Taylor dispersion is due to velocity variation across the fracture aperture, and macrodispersion is due to velocity variation in the plane of the fracture caused by aperture variability. Studies such as Becker and Shapiro (2000) [122] have found that advective mechanisms such as dispersion were the only way to explain the 
late time behavior of the tracers in a field test in fractured crystalline rock. Separating the effects of dispersion and diffusion can be difficult to do in fractured rock. The velocity flow fields can be so heterogenous that diffusion into a neighboring streamline can have a major impact on tracer transport [123]. One method that was used by Callahan et al. (2000) [124] to distinguish advective and diffusive processes was to use multiple solutes with different diffusion coefficients to effectively separate matrix diffusion and dispersion in the tracer test.

A dual porosity (mobile-immobile) model is often used to represent solute transport through fractured rock [125], [126]. The dual porosity model assumes that the system can be divided into a highly mobile preferential flow zone (fracture) and a significantly less mobile zone (matrix) [127]. The assumption is often made that there is a mobile (fracture) and immobile (matrix) zone with diffusive transport between the two due to concentration gradients [128]. Another model that can be used to represent solute transport is the dual permeability (mobile-mobile) model. The difference in the dual permeability model compared to the dual porosity model, is that in the dual permeability model the solute can move through the rock matrix by advection and diffusion, whereas in the dual porosity model the matrix acts as a sink for diffusion with the fracture [129]. Dual permeability models are not applied as often in the field because it can be challenging to determine the large scale effective properties for both the matrix and fracture [130].

\subsection{Colloid Transport Through Fractured Rock}

Numerous studies related to colloid transport in porous media have been conducted, and recently transport through fractures has gained interest due to the fractures' ability to create preferential pathways for contaminant migration. Fractures generate preferential pathways because they have large flow paths, have high velocity flows compared to surrounding matrix, have low diffusion from the fracture aperture into the matrix, and have less colloid-collector interaction especially in unfavorable attachment conditions [101]. Lab studies [32], [121], [131], [132], field studies [133][135], modeling [136]-[138], and reviews [23] of colloid transport through fractures have been increasing in recent years, but it is still a topic that requires further investigation. Table 2.1 below presents some examples of lab and field studies that study colloid transport through fractured rock. 
Table 2.1 Studies of colloid transport through fractured rock

\begin{tabular}{|c|c|c|c|c|}
\hline Reference & Collector & Tracers & Study Information & Study Results \\
\hline $\begin{array}{l}\text { Alaskar et al. } \\
\text { (2015) [132] }\end{array}$ & $\begin{array}{l}\text { greywacke } \\
\text { and Berea } \\
\text { sandstone }\end{array}$ & $\begin{array}{l}\text { negatively } \\
\text { charged silica } \\
\text { particles larger } \\
\text { than } 2 \mu \mathrm{m} \\
\text { diameter. }\end{array}$ & $\begin{array}{l}\text { Investigation of the } \\
\text { mechanisms for } \\
\text { transport of silica } \\
\text { particles through } \\
\text { fractured rock }\end{array}$ & $\begin{array}{l}\text { - Gravitational } \\
\text { sedimentation was } \\
\text { prominent }\end{array}$ \\
\hline $\begin{array}{l}\text { Becker (1999) } \\
\text { [139] }\end{array}$ & $\begin{array}{l}\text { tuff and } \\
\text { granite }\end{array}$ & $\begin{array}{l}\mathrm{CML} \\
\text { microspheres } \\
\text { (0.19 to } 0.98 \\
\mu \mathrm{m} \text { diameter) }\end{array}$ & $\begin{array}{l}\text { Field and laboratory } \\
\text { tracer tests } \\
\text { performed }\end{array}$ & $\begin{array}{l}\text { - Small recovery of CML } \\
\text { microspheres in all but } \\
\text { smallest scale lab tests } \\
\text { - Smaller microspheres } \\
\text { had a higher recovery }\end{array}$ \\
\hline $\begin{array}{l}\text { Cumbie, McKay } \\
\text { (1999) [140] }\end{array}$ & $\begin{array}{l}\text { shale } \\
\text { saprolite }\end{array}$ & $\begin{array}{l}\mathrm{CML} \\
\text { microspheres } \\
(0.05 \mu \mathrm{m} \text { to } \\
4.25 \mu \mathrm{m} \\
\text { diameter })\end{array}$ & $\begin{array}{l}\text { Tracer tests } \\
\text { performed to } \\
\text { determine optimum } \\
\text { diameter for } \\
\text { recovery of particles }\end{array}$ & $\begin{array}{l}\text { - Optimum diameter } \\
\text { was } 0.5 \text { um } \\
\text { - Bigger more } \\
\text { gravitational settling } \\
\text { - Smaller more diffusion }\end{array}$ \\
\hline $\begin{array}{l}\text { Harvey et al. } \\
\text { (2008) [141] }\end{array}$ & $\begin{array}{l}\text { karst } \\
\text { limestone }\end{array}$ & $\begin{array}{l}\mathrm{SF}_{6} \text { and } \mathrm{CML} \\
\text { microspheres } \\
(1.6,2.9, \text { and } \\
4.9 \mu \mathrm{m} \\
\text { diameter })\end{array}$ & $\begin{array}{l}\text { Field study accessing } \\
\text { the susceptibility of a } \\
\text { well to } \\
\text { contamination using } \\
\text { forced gradient } \\
\text { injection and } \\
\text { recovery }\end{array}$ & $\begin{array}{l}\text { - Microspheres arrived } \\
\text { threefold earlier than } \\
\text { SF6 } \\
\text { - Microspheres } \\
\text { underestimated the } \\
\text { attachment potential } \\
\text { of oocysts } \\
\text { - Lower recovery was } \\
\text { for larger diameter } \\
\text { microspheres }\end{array}$ \\
\hline $\begin{array}{l}\text { McCarthy et al. } \\
\text { (2002) [32] }\end{array}$ & $\begin{array}{l}\text { shale } \\
\text { saprolite }\end{array}$ & $\begin{array}{l}\mathrm{CML} \\
\text { microspheres } \\
(0.1,0.5,1.0, \\
2.1 \mu \mathrm{m} \\
\text { diameter })\end{array}$ & $\begin{array}{l}\text { Tracer tests with } \\
\text { varying solution } \\
\text { chemistry and } \\
\text { particle size used to } \\
\text { determine the effect } \\
\text { on transport through } \\
\text { fractured rock }\end{array}$ & $\begin{array}{l}\text { - Recovery decreased } \\
\text { with increasing ionic } \\
\text { strength } \\
\text { - Ca bigger impact than } \\
\mathrm{Na} \\
\text { - Earlier arrival time of } \\
\text { microspheres } \\
\text { compared to bromide } \\
\text { - } 0.5 \mu \mathrm{m} \text { had the } \\
\text { highest recovery }\end{array}$ \\
\hline
\end{tabular}




\begin{tabular}{|c|c|c|c|c|}
\hline Reference & Collector & Tracers & Study Information & Study Results \\
\hline $\begin{array}{l}\text { McKay et al. } \\
(2000) \text { [120] }\end{array}$ & $\begin{array}{l}\text { weathered } \\
\text { shale } \\
\text { saprolite }\end{array}$ & $\begin{array}{l}\text { bacteriophage } \\
\text { PRD-1, MS-2, } \\
\text { INA, and } 0.1 \\
\mu \mathrm{m} \text { diameter } \\
\text { latex } \\
\text { microspheres }\end{array}$ & $\begin{array}{l}\text { Tracers introduced } \\
\text { into well and their } \\
\text { transport was } \\
\text { monitored with } \\
\text { downgradient } \\
\text { monitoring wells }\end{array}$ & $\begin{array}{l}\text { - tracers appeared as a } \\
\text { pulse suggesting } \\
\text { transport through } \\
\text { fractures } \\
\text { - Arrival was } 500 \text { times } \\
\text { faster than solute } \\
\text { - Microspheres } \\
\text { exhibited the least } \\
\text { retention }\end{array}$ \\
\hline $\begin{array}{l}\text { Mondal and } \\
\text { Sleep (2013) [142] }\end{array}$ & dolomite & $\begin{array}{l}\mathrm{CML} \\
\text { microspheres } \\
\text { (0.2 and } 0.02 \\
\mu \mathrm{m} \text { diameter) } \\
\text { bacteriophage } \\
\text { MS-2 and } \\
\text { PR772 }\end{array}$ & $\begin{array}{l}\text { Compared the } \\
\text { transport of viruses } \\
\text { and virus sized } \\
\text { microspheres. }\end{array}$ & $\begin{array}{l}\text { - retention and } \\
\text { transport of MS-2 and } \\
\text { PR772 closer to } 200 \\
\text { nm particles than } \\
\text { similarly sized } 20 \mathrm{~nm} \\
\text { particles } \\
\text { - Microspheres were } \\
\text { more affected by } \\
\text { changes in ionic } \\
\text { strength } \\
\text { - Microspheres not } \\
\text { suitable surrogates for } \\
\text { viral pathogens }\end{array}$ \\
\hline $\begin{array}{l}\text { Neukum et al. } \\
\text { (2014) [143] }\end{array}$ & Sandstone & $\begin{array}{l}\text { silver } \\
\text { nanoparticles } \\
(0.05 \mu \mathrm{m} \\
\text { diameter })\end{array}$ & $\begin{array}{l}\text { Analyzed transport } \\
\text { and fate of } \\
\text { engineered silver } \\
\text { nanoparticles in } \\
\text { partially fractured } \\
\text { sandstone }\end{array}$ & $\begin{array}{l}\text { - physiochemical } \\
\text { filtration was a major } \\
\text { transport process } \\
\text { - important factors are } \\
\text { solute chemistry, } \\
\text { mineralogy and } \\
\text { surface heterogeneity } \\
\text { - Divalent cations had } \\
\text { larger effect than } \\
\text { monovalent cations on } \\
\text { hindering AgNP } \\
\text { transport. }\end{array}$ \\
\hline $\begin{array}{l}\text { Reimus et al. } \\
\text { (1994) [31] }\end{array}$ & tuff & $\begin{array}{l}\text { iodide, } 0.3 \\
\text { and } 1.0 \mu \mathrm{m} \\
\text { diameter } \mathrm{CML} \\
\text { microspheres }\end{array}$ & $\begin{array}{l}\text { Tracer tests } \\
\text { performed in three } \\
\text { natural tuffs. }\end{array}$ & $\begin{array}{l}\text { - colloids arrived earlier } \\
\text { than solute } \\
\text { - smaller effective } \\
\text { volume of the fracture } \\
\text { due to larger particles } \\
\text { not being able to enter } \\
\text { dead zones } \\
\text { - less diffusion for larger } \\
\text { particles. }\end{array}$ \\
\hline
\end{tabular}




\begin{tabular}{|c|c|c|c|c|}
\hline Reference & Collector & Tracers & Study Information & Study Results \\
\hline $\begin{array}{l}\text { Rodrigues et al. } \\
\text { (2013) [144] }\end{array}$ & $\begin{array}{l}\text { dolomitic } \\
\text { limestone } \\
\text { and granite }\end{array}$ & $\begin{array}{l}\text { E. coli and } \\
\text { conservative } \\
\text { tracer }\end{array}$ & $\begin{array}{l}\text { Quantified the } \\
\text { number of E. coli } \\
\text { retained in a single, } \\
\text { saturated, variable- } \\
\text { aperture fracture } \\
\text { extracted from the } \\
\text { natural environment }\end{array}$ & $\begin{array}{l}\text { - Fracture } \\
\text { characteristics } \\
\text { important for } \\
\text { understanding } \\
\text { retention mechanisms } \\
\text { - Higher specific } \\
\text { discharge and/or } \\
\text { smaller apertures do } \\
\text { not always facilitate } \\
\text { particulate transport }\end{array}$ \\
\hline $\begin{array}{l}\text { Stoll et al. (2016) } \\
\text { [131] }\end{array}$ & $\begin{array}{l}\text { granodiorite } \\
\text { and acrylic } \\
\text { glass }\end{array}$ & $\begin{array}{l}0.025 \mu \mathrm{m} \text { and } \\
1.0 \mu \mathrm{m} \\
\text { diameter } \mathrm{CML} \\
\text { microspheres }\end{array}$ & $\begin{array}{l}\text { Effect of residence } \\
\text { time, colloid size and } \\
\text { collector material is } \\
\text { examined in artificial } \\
\text { fracture }\end{array}$ & $\begin{array}{l}\text { Larger colloids more } \\
\text { affected by } \\
\text { sedimentation } \\
\text { whereas smaller } \\
\text { colloids more affected } \\
\text { by surface roughness }\end{array}$ \\
\hline $\begin{array}{l}\text { Zhang et al. } \\
\text { (2015) [135] }\end{array}$ & $\begin{array}{l}\text { mudrock } \\
\text { and } \\
\text { sandstone }\end{array}$ & $\begin{array}{l}\text { natural } \\
\text { colloids }\end{array}$ & $\begin{array}{l}\text { Field study about } \\
\text { impact of rainfall on } \\
\text { colloid transport }\end{array}$ & $\begin{array}{l}\text { - Max colloid } \\
\text { concentration prior to } \\
\text { arrival of flow } \\
\text { discharge peak } \\
\text { - Rainfall intensity main } \\
\text { factor dictating colloid } \\
\text { concentration }\end{array}$ \\
\hline $\begin{array}{l}\text { Zvikelsky and } \\
\text { Weisbrod (2006) } \\
{[101]}\end{array}$ & $\begin{array}{l}\text { natural } \\
\text { discrete } \\
\text { fractured } \\
\text { chalk cores }\end{array}$ & $\begin{array}{l}\mathrm{CML} \\
\text { microspheres } \\
(0.02,0.1,0.2, \\
\text { and } 1.0 \mu \mathrm{m} \\
\text { diameter) }\end{array}$ & $\begin{array}{l}\text { Tracer tests analyzed } \\
\text { BTCs, first arrival, } \\
\text { mass recovery, and } \\
\text { peak C/Co }\end{array}$ & $\begin{array}{l}-0.2 \mu \mathrm{m} \text { microspheres } \\
\text { had highest recovery } \\
-1.0 \mu \mathrm{m} \text { microspheres } \\
\text { had slightly lower } \\
\text { recovery } \\
-0.1 \mu \mathrm{m} \text { lower recovery } \\
\text { than both previous } \\
-0.02 \mu \mathrm{m} \text { lowest } \\
\text { recovery }\end{array}$ \\
\hline $\begin{array}{l}\text { Vilks et al. (1997) } \\
\text { [145] }\end{array}$ & granite & $\begin{array}{l}0.02 \mu \mathrm{m} \\
\text { diameter silica }\end{array}$ & $\begin{array}{l}\text { Tested if colloid } \\
\text { tracer can provide } \\
\text { additional } \\
\text { information over a } \\
\text { solute tracer }\end{array}$ & $\begin{array}{l}\text { - Silica can migrate } \\
\text { through fractures over } \\
\text { distances of } 17 \mathrm{~m} \\
\text { - Significant transport } \\
\text { differences between } \\
\text { colloids and solutes }\end{array}$ \\
\hline
\end{tabular}




\section{Chapter 3 \\ Materials and Methods}

\section{Materials and Methods}

\subsection{Sandstone Fracture Properties}

To get a more complete understanding of the tracer test results the properties of the sandstone fracture need to be characterized. The properties that were important in this study include the matrix porosity, elemental composition, aperture distribution, and zeta potential. Much of this analysis, excluding the zeta potential, was performed during the thesis work of Rrokaj (2015) [146] who was a previous graduate student working with the sandstone fracture set up. The zeta potential analysis was performed by myself at the University of Western Ontario with the help of Caitlin Corcoran and Dr. Ian Molnar.

\subsubsection{Zeta Potential Sandstone}

The zeta potential of the sandstone rock was measured by SurPASS Electrokinetic Analyzer (Anton Paar ${ }^{\circledR} \mathrm{GmbH}$ ). The samples were prepared by crushing left over sandstone pieces that were generated from cutting the rock for the fracture setup. The rock samples were crushed by hand using a mortar and pestle to a size less than $1.7 \mathrm{~mm}$. The crushed rock was then sieved through $1.7 \mathrm{~mm}, 0.6 \mathrm{~mm}$, and $0.1 \mathrm{~mm}$ sieves to be separated into two size distributions of $0.6 \mathrm{~mm}$ to $1.7 \mathrm{~mm}$ and $0.1 \mathrm{~mm}$ to $0.6 \mathrm{~mm}$. The crushed samples were washed thoroughly with distilled water and dried overnight in an oven at $110^{\circ} \mathrm{C}$. The zeta potential of the samples was measured at each of the solution conditions used for the tracer tests. The solution conditions that were tested included $5 \mathrm{mM}$ and $10 \mathrm{mM}$ total ionic strengths, with both $1 \mathrm{mM}$ sodium bicarbonate $\left(\mathrm{NaHCO}_{3}\right)$ and $5 \mathrm{mM}$ bis-tris $\left(\mathrm{C}_{8} \mathrm{H}_{19} \mathrm{NO}_{5}\right)$ buffers.

For the measurement of zeta potential, approximately $1.5 \mathrm{~g}$ of the crushed sandstone was packed into the cylindrical measurement cell. A duplicate measurement was performed for each solution condition. The electrokinetic analyzer operates by measuring the zeta potential using the streaming potential method. The electrolyte solution is pumped through the measuring cell containing the sample. The pressure difference and relative movement of the charges in the double layer allow the streaming potential to be detected by electrodes on either side of the sample. The temperature, 
conductivity, and $\mathrm{pH}$ are determined simultaneously and the software automatically calculates the zeta potential.

\subsubsection{Sandstone Properties}

The sandstone properties were determined during the initial setup of the sandstone fracture system, and are presented in Rrokaj (2015) [146]. The methods used were as follows: ATOS II 3D scanner (aperture distribution and surface profile), X-ray diffusion (XRD) and X-ray fluorescence (XRF) spectroscopy (mineral and elemental composition respectively), scanning electron microscope (matrix porosity).

\subsection{Experimental Setup}

A sandstone rock block was artificially fractured using a Forney Compression Testing Machine. A uniaxial compression load was applied to $12 \mathrm{~mm}$ diameter steel bars on either side of the rock block to induce the fracture. A diagram and photograph of the fracturing process from Rrokaj (2015) [146] is shown in Figure 3.1.
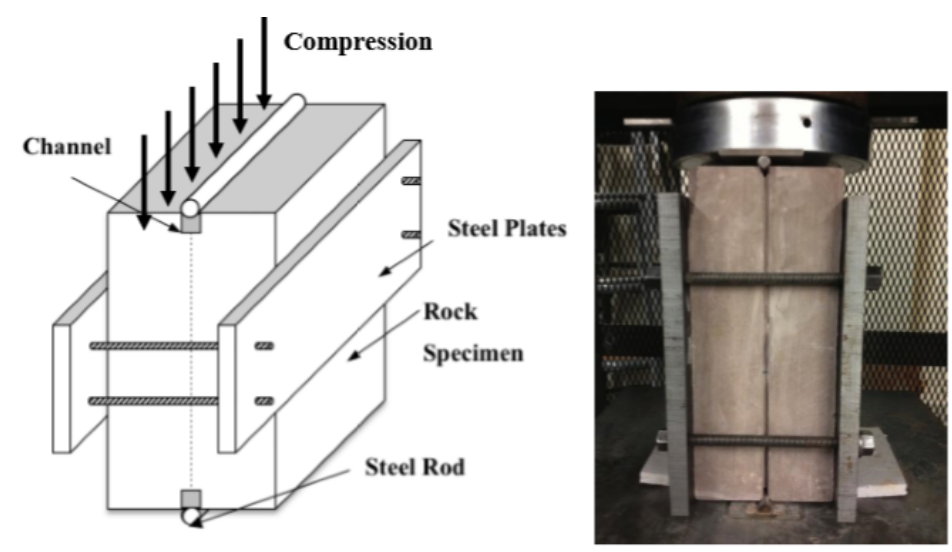

Figure 3.1 Diagram and photograph of fracturing process from Rrokaj (2015).

The bench top sandstone fracture consisted of the following parts: (a) sandstone fracture rock block (280mm x $210 \mathrm{~mm} \times 70 \mathrm{~mm})$, (b) acrylic inlet chamber block $(210 \mathrm{~mm} \times 80 \mathrm{~mm} \times 40 \mathrm{~mm})$, (c) stainless steel holding frame, (d) dual-head peristaltic pump (MasterFlex ${ }^{\circledR}$ L/S drive with Easy Load $^{\circledR}$ II pump heads 77201-60) to pump water continuously and keep fracture saturated, (e) syringe pump (74900 Series Syringe Pump, Cole-Parmer ${ }^{\circledR}$ ) to inject solutions during tracer test, 
(f) gear pump with Micropump ${ }^{\circledR}$ head (Model 120-000-110) to flush the solution in the inlet chamber, (g) fraction collector (Pharmacia LKB Redifrac) installed with $10 \mathrm{~mL}$ polypropylene vials for sample collecting from the outlet manifold, (h) $30 \mathrm{~cm}$ glass tube piezometers ( $3 \mathrm{~mm}$ I.D.) connected on the inlet chamber and outlet manifold for hydraulic head measurement, (i) steel frame to support the rock holding cell.

Rubber gaskets (Global Rubber Products Ltd. Ontario) were used along the long sides of the rock block to provide no flow boundaries. An acrylic block and a rubber gasket were used at the downstream short side (outlet) to create a no flow boundary. The upstream short side of the rock block was connected to a channel (volume $20 \mathrm{~mL}$ ) that was cut into an acrylic inlet chamber block and surrounded by a rubber gasket. The inlet chamber was connected to the fracture, which allowed fluid to flow into the system. Screws that were tightened over stainless steel plates provided uniform pressure on the rubber gaskets and helped to prevent leaks. Five glass piezometers were installed at the outlet manifold and one glass piezometer was installed at the inlet to measure head difference. The five outlet needle ports were connected to form one outlet manifold. The fracture was oriented horizontally and level for all tests.

The sandstone fracture system was used previously by another student, but was not operated for a period of about 12 months. The system was completely sealed, but no water was being pumped through the fracture during this time so it needed to be re-saturated. Before any water was pumped into the system, carbon dioxide was flushed through the fracture and tubing for approximately an hour to displace any air. The valves in the system were systematically opened and closed to ensure that the carbon dioxide reached all areas of the system. Following the flush with carbon dioxide, autoclaved Milli- $\mathrm{Q}^{\circledR}$ water was pumped through the system to displace or dissolve all the carbon dioxide. The valves were opened and closed systematically to ensure that the entire system would be saturated. Over the next several weeks, hydraulic tests were performed daily until the results started to stabilize, at which time it was assumed that the fracture was fully saturated. Figure 3.2 (A) and (B) show a picture and schematic diagram of the bench-top setup. 


\section{(A)}

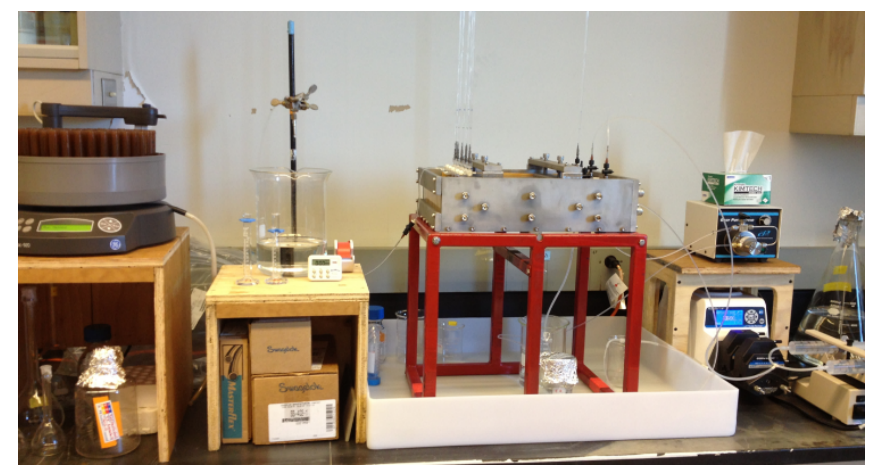

(B)

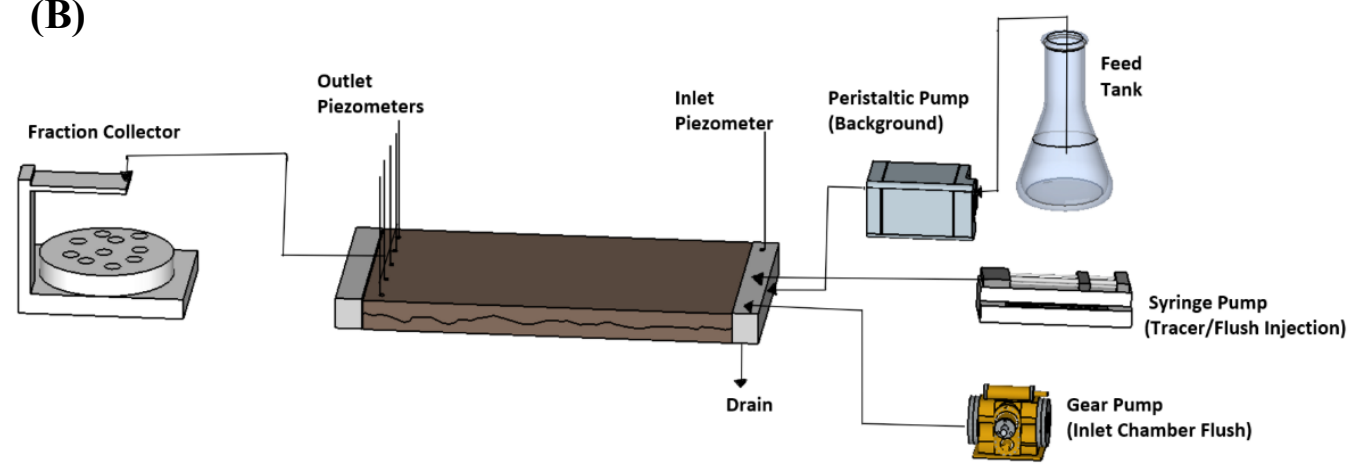

Figure 3.2 Fracture setup (A) Photograph (B) Diagram

\subsection{Solution Preparation}

The tracer tests were run under several different solution conditions by varying parameters such as the ionic strength and $\mathrm{pH}$. The ionic strength of the solution was varied between $5 \mathrm{mM}$ and 10 $\mathrm{mM}$ and the $\mathrm{pH}$ of the solution was kept at either 6 or 8 depending on the microspheres that were being used for the test. A pH of 6 was used for the AML microspheres because the microspheres were not as stable at more basic $\mathrm{pH}$ conditions. The same reasoning applied to the decision to use a $\mathrm{pH}$ of 8 for the CML microspheres because they were stable in this $\mathrm{pH}$ range. The $\mathrm{pH}$ of the CML and AML microsphere solutions were kept as close as possible while ensuring stability of the particles to limit the effect of changing $\mathrm{pH}$ on the sandstone surface charge. The $\mathrm{pH}$ was also selected to be a realistic value for groundwater.

Each of the tracer solutions contained $1 \mathrm{mM}$ of $\mathrm{NaBr}$, which was used as a non-reactive tracer. The other components of the solution were the buffer, $\mathrm{NaCl}$ to achieve the desired ionic strength, and the microspheres. A flush solution was prepared the same as the tracer solution, but without the tracers (microspheres and $\mathrm{NaBr}$ ). An additional $1 \mathrm{mM} \mathrm{NaCl}$ was added to the flush solution to replace the $1 \mathrm{mM} \mathrm{NaBr}$ and keep the ionic strength the same as the tracer solution. A low ionic 
strength flush solution was prepared with $1 \mathrm{mM}$ sodium bicarbonate to be used in a final high velocity flush of the fracture.

The AML microsphere solution was prepared by using a bis-tris buffer at a concentration of $5 \mathrm{mM}$. Bis-tris was selected as the buffer because a cationic buffer was more effective at maintaining a positive zeta potential, and the buffering range (5.8-7.2) was ideal. The concentration of $5 \mathrm{mM}$ was selected because if the concentration was any lower the buffer would not be effective causing the $\mathrm{pH}$ to rise significantly as the solution passed through the fracture. An additional $1 \mathrm{mM} \mathrm{NaBr}$ and $0 \mathrm{mM}$ or $5 \mathrm{mM} \mathrm{NaCl}$ was added to the solution depending on the ionic strength required. Although the concentration of the buffer that was added was $5 \mathrm{mM}$, this only corresponded to an ionic strength of about $4 \mathrm{mM}$ when the $\mathrm{pH}$ of bis-tris was adjusted to 6 using $\mathrm{HCl}$. Thus, when 1 $\mathrm{mM}$ or $6 \mathrm{mM} \mathrm{NaCl} / \mathrm{NaBr}$ was added to the $5 \mathrm{mM}$ bis-tris buffer the result was two ionic strength conditions of $5 \mathrm{mM}$ and $10 \mathrm{mM}$ respectively. A higher ionic strength solution was not tested because of the possibility of the colloids becoming less stable at higher ionic strengths.

The CML microsphere solution was prepared with $1 \mathrm{mM} \mathrm{NaHCO}_{3}$ to buffer the $\mathrm{pH}$ at 8 along with $1 \mathrm{mM} \mathrm{NaBr}$, and 3 or $8 \mathrm{mM} \mathrm{NaCl}$ depending on the total ionic strength required. The result of the addition of $3 \mathrm{mM} \mathrm{NaCl}$ is a solution with a total ionic strength of $5 \mathrm{mM}$, and the $8 \mathrm{mM} \mathrm{NaCl}$ results in a solution with a $10 \mathrm{mM}$ ionic strength. The total ionic strength of these solutions was selected to be the same as the AML microsphere tracer solution to allow for a more accurate comparison between favorable and unfavorable conditions.

\subsection{Latex Microspheres}

Latex microspheres were used as surrogates for natural colloids. Two different sizes were used $(200 \mathrm{~nm}$ and $1000 \mathrm{~nm})$ as well as two different surface modifications (amine modified and carboxylate modified). The carboxylate modified latex (CML) microspheres (200 nm F8805 and 1000 nm F8819 FluoSpheres ${ }^{\circledR}$ microspheres from Molecular Probes, Invitrogen Canada Inc.) are negatively charged tracers, which were used to simulate an unfavorable attachment condition when paired with the negatively charged sandstone surface. The amine modified latex (AML) microspheres (200nm F8763 FluoSpheres ${ }^{\circledR}$ microspheres from Molecular Probes, Invitrogen Canada Inc. and $1000 \mathrm{~nm}$ L1030 from Sigma Aldrich) are positively charged so they were used to simulate favorable attachment conditions when paired with the negatively charged sandstone surface. Both the CML and AML microspheres are relatively hydrophobic and sensitive to changes 
in $\mathrm{pH}$ and ionic strength. The AML microspheres should be used in a $\mathrm{pH}$ of less than 9.0 and the CML microspheres should be used in a $\mathrm{pH}$ greater than 5. The ionic strength of the buffer should be kept as low as possible.

A working stock solution of microspheres was prepared by diluting the stock microsphere solution 100 times in Milli- $Q^{\circledR}$ water. The working stock was then further diluted 40 to 72 times depending on the size of the microspheres. The $200 \mathrm{~nm}$ microspheres were diluted 72 times to a concentration of $6.37 \times 10^{8}$ Particles. $\mathrm{mL}^{-1}$, the $1000 \mathrm{~nm}$ microspheres were diluted 40 or 50 times to a concentration of $9.09 \times 10^{6}$ Particles. $\mathrm{mL}^{-1}$. The following formula used to calculate the concentration of particles in a solution:

$$
N=\frac{\left(6 C \times 10^{12}\right)}{\rho \times \pi \times \emptyset^{3}}
$$

Where, $\mathrm{C}$ is the concentration of suspended beads in $\mathrm{g} \cdot \mathrm{mL}^{-1}(0.02 \mathrm{~g} \cdot \mathrm{mL}-1$ for a $2 \%$ suspension $), \emptyset$ is the diameter of particles in $\mu \mathrm{m}$, and $\rho$ is the polymer density in $\mathrm{g} \cdot \mathrm{mL}^{-1}$ (1.05 for polystyrene). Table 1 below summarizes the properties of the colloid particles that were used.

Table 3.1 Latex microsphere properties

\begin{tabular}{|c|c|c|c|c|}
\hline Particles & \multicolumn{2}{|c|}{$\begin{array}{l}\text { Anionic Carboxylate- } \\
\text { Modified Particles }\end{array}$} & \multicolumn{2}{|c|}{$\begin{array}{c}\text { Cationic Amine-Modified } \\
\text { Particles }\end{array}$} \\
\hline Mean Diameter $(\mu \mathrm{m})$ & 0.2 & 1.0 & 0.2 & 1.0 \\
\hline Manufacturer & $\begin{array}{l}\text { Thermo } \\
\text { Fisher }\end{array}$ & $\begin{array}{l}\text { Thermo } \\
\text { Fisher }\end{array}$ & $\begin{array}{l}\text { Thermo } \\
\text { Fisher }\end{array}$ & $\begin{array}{l}\text { Sigma } \\
\text { Aldrich }\end{array}$ \\
\hline Colour & Blue & Nile Red & Red & Yellow-Green \\
\hline Suspension & $2 \%$ & $2 \%$ & $2 \%$ & $2.5 \%$ \\
\hline $\begin{array}{l}\text { Working Stock Conc. } \\
\left.\text { (Pts.mL } L^{-1}\right)\end{array}$ & $4.55 \times 10^{10}$ & $3.64 \times 10^{8}$ & $4.55 \times 10^{10}$ & $4.55 \times 10^{8}$ \\
\hline $\begin{array}{c}\text { Peak Wavelengths } \\
\text { (excitation/emission) }(\mathrm{nm})\end{array}$ & $365 / 415$ & $535 / 575$ & $580 / 605$ & $470 / 505$ \\
\hline Tracer Conc. (Pts.mL $\left.{ }^{-1}\right)$ & $6.37 \times 10^{8}$ & $9.09 \times 10^{6}$ & $6.37 \times 10^{8}$ & $9.09 \times 10^{6}$ \\
\hline Detection Limit & $1.28 \times 10^{6}$ & $3.75 \times 10^{4}$ & $1.28 \times 10^{6}$ & $4.14 \times 10^{4}$ \\
\hline
\end{tabular}


The zeta potential and size of the microspheres was analyzed using the Horiba SZ-100 Nano Particle Analyzer. The zeta potential and size of the microspheres was measured under all solution conditions that would be used for the tracer tests. In addition, the zeta potential of the AML microspheres was monitored before entering and after exiting the fracture to ensure that favorable attachment conditions were consistent throughout the test.

The size of the particles was measured by adding approximately $3 \mathrm{~mL}$ of sample to a disposable cuvette and inserting it into the Nano Particle Analyzer. A measurement was taken four times for each sample to ensure that the results were consistent. The Nano Particle Analyzer can measure particle sizes between $0.3 \mathrm{~nm}$ and $8 \mu \mathrm{m}$. A laser light is input to the sample particles and the light scattered by the particles at $90^{\circ}$ or $173^{\circ}$ is collected by a detector. The particles in the sample are subject to Brownian motion with the larger particles moving slower than the smaller ones. The scattering light intensity is detected as pulses. When the phase of the scattering light is the same the intensity becomes strong. Small particles require a short delay time between measurements for their intensity to be correlated, whereas larger particles require a larger delay time. An autocorrelation function is developed which can calculate the size of the particles.

The size of the microspheres was also verified by using a Scanning Electron Microscope (SEM). A small volume $(20 \mu \mathrm{L})$ of each microsphere solution was placed on a glass slide and gold coated. The microspheres were then placed under the SEM and several individual spheres were measured using the sizing function of the instrument. The SEM was used to confirm the reported manufacturers size of the microspheres especially for situations where the Horiba particle size analyzer provided unexpected results.

The zeta potential of the microspheres was measured by adding approximately $0.5 \mathrm{~mL}$ to an electrode cell using a $1 \mathrm{~mL}$ disposable syringe. After it was confirmed that no air bubbles were present in the cell, it was inserted into the sample holder of the Nano Particle Analyzer. A measurement was taken three times for each sample to ensure that the results were consistent. The range of measurement for the SZ-100 zeta potential is $-200 \mathrm{mV}$ to $200 \mathrm{mV}$. The zeta potential of the particles is a measurement of the surface potential at the shear plane of the electric double layer. The measurement is performed by using Electrophoretic Light Scattering (ELS) and applying an alternative potential to the solution. The alternative potential causes oscillation of the particles and a shift of the frequency of scattered light compared to the fundamental beam (Doppler 
effect). By detecting the frequency variation, the electrophoretic mobility of the particles is determined, and with that the zeta potential can be calculated.

\subsection{Hydraulic Tests}

Hydraulic tests were run periodically on the fracture set up to determine the hydraulic aperture, specific discharge, and Reynolds number at different flow rates. The hydraulic test was performed by pumping autoclaved buffered Milli- $Q^{\circledR}$ water using a dual-head peristaltic pump. The dual-head pump helps to eliminate water pulsation and keep the water flow constant. The pump inlet tubing splits into two channels for the dual heads and then the channels are joined back together at the pump outlet to provide continuous flow.

The equivalent aperture was calculated by finding the cubic law aperture [147], [148]. The cubic law aperture is defined as the equivalent parallel plate aperture which would permit a certain flow rate at a given pressure drop. Based on this definition it was necessary to determine the head loss across the fracture as well as the flow rate. To measure head loss an inlet piezometer along with 5 outlet piezometers were located on the fracture and the inlet and outlet heads were measured to the nearest $0.5 \mathrm{~mm}$. The average outlet head value was subtracted from the inlet head value to determine the head loss across the fracture. The flow rate was measured to the nearest $0.5 \mathrm{~mL}$ by collecting the water from the outlet for one minute in a volumetric cylinder. The equivalent hydraulic aperture $\left(b_{c}\right)$, specific discharge $\left(v_{c}\right)$, and Reynolds number $\left(R_{e}\right)$ were calculated using the following equations:

$$
\begin{gathered}
v_{c}=\frac{Q}{W b_{c}} \\
b_{c}=\left(\frac{12 \eta Q L}{\gamma W|\Delta h|}\right)^{\frac{1}{3}} \\
R_{e}=\frac{\rho v_{c} b_{c}}{\eta}
\end{gathered}
$$

Where $\eta$ is the dynamic viscosity of water $\left(\mathrm{kg} \cdot \mathrm{m}^{-1} \cdot \mathrm{s}^{-1}\right)$, $\mathrm{Q}$ is the volumetric flow rate of water $\left(\mathrm{m}^{3} \cdot \mathrm{s}^{-1}\right), \mathrm{L}$ is the length of the fracture $(\mathrm{m}), \gamma$ is the specific weight of water $\left(\mathrm{kg} \cdot \mathrm{m}^{-2} \cdot \mathrm{s}^{-2}\right), \mathrm{W}$ is the width of the fracture $(\mathrm{m}), \Delta h$ is the piezometric head difference in the fracture $(\mathrm{m})$, and $\rho$ is the density of water $\left(\mathrm{kg} \cdot \mathrm{m}^{-3}\right)$. 
Hydraulic Tests were performed at three flow rates $\left(6.67 \times 10^{-8} \mathrm{~m}^{3} . \mathrm{s}^{-1}, 1.0 \times 10^{-7} \mathrm{~m}^{3} . \mathrm{s}^{-1}, 1.33 \times 10^{-7}\right.$ $\left.\mathrm{m}^{3} \cdot \mathrm{s}^{-1}\right)$. The Reynolds number at each of these flow rates was below unity because the cubic law is only valid under laminar flow conditions. Several hydraulic tests were conducted during the saturation process for the fracture to ensure that conditions were stabilized before any experiments were run. Hydraulic tests were also conducted before every tracer test to confirm that nothing was causing the hydraulic aperture to deviate (e.g. air bubbles).

\subsection{Tracer Tests}

Tracer tests were performed under both favorable (positively charged colloids) and unfavorable (negatively charged colloids) conditions with bromide as a conservative tracer. The $\mathrm{pH}$ and ionic strength of the tracer solution was varied depending on the conditions that were being tested and the microspheres that were being used. A lower $\mathrm{pH}(\mathrm{pH}$ 6) was used for the AML microspheres compared to the $\mathrm{CML}$ microspheres $(\mathrm{pH} 8)$ to keep both particles stable during the experiments. The fracture was flushed with tracer-free background solution of equal ionic strength and $\mathrm{pH}$ to the test solution for 24 to 48 hours before the test was started. The purpose of this process was to equilibrate the fracture to the conditions that would be used in the tracer test. The favorable attachment tests required 48 hours to allow for the $\mathrm{pH}$ of the water exiting the fracture to stabilize at approximately 6 because the sandstone had a natural buffering capacity at a more basic $\mathrm{pH}$. The $\mathrm{pH}$ of the effluent was tested prior to starting a favorable attachment tracer test to ensure that it had stabilized. The unfavorable tests were only equilibrated for 24 hours prior to the start of the test. The tracer and flush solutions were prepared on the same day as the experiment.

To begin the tracer test, the inlet chamber was flushed with tracer solution using the gear pump. After this was completed the syringe pump was used to inject tracer solution at a specific flow rate for approximately 10 pore volumes (PV). When the tracer solution injection was finished, the inlet chamber was flushed with flush solution using the gear pump. After the flush was finished the syringe pump was used to pump flush solution into the fracture for $11 \mathrm{PV}$. The process of flushing with the gear pump and injecting with the syringe pump was completed one more time with a low ionic strength solution. The low ionic strength solution was injected for $5 \mathrm{PV}$ at a flow rate three times larger than the test flow rate.

Tracer tests were run with the objective of being able to compare the results of favorable and unfavorable attachment. To do this effectively the favorable and unfavorable tests were run under 
identical specific discharge and ionic strength conditions to allow for direct comparison. All the unfavorable attachment tests were completed prior to running the favorable attachment tests to prevent any interference the attached positively charged microspheres might have on the unfavorable results.

\subsubsection{Solution Analysis}

The background and tracer solutions were analyzed for $\mathrm{pH}$, electrical conductivity, and temperature on the day of the tracer test. The zeta potential of the $200 \mathrm{~nm}$ AML microspheres was also measured prior to running the tracer test to ensure the microspheres were positive and stable before injection. The zeta potential was not measured for the other particles because the concentration of the larger $1000 \mathrm{~nm}$ microspheres in the tracer solution was not high enough to obtain an accurate zeta potential reading, and the CML microspheres were consistently negatively charged making the measurement unnecessary. The $\mathrm{pH}$ of the solutions was measured using a bench pH meter (Radiometer PHM 92 Lab pH Meter, Omega Engineering Inc). The pH meter was calibrated periodically by using $\mathrm{pH} 4,7$, and 10 buffer standards to ensure accuracy. The electrical conductivity and temperature of the solutions was measured by Orion Conductivity Meter (Model 150, Thermo Electron Corporation).

\subsubsection{Bromide Analysis}

The samples that were collected after exiting the fracture by the fraction collector were analyzed using ion chromatography. The equipment that was used for the analysis was the Dionex 500 Ion Chromatograph (Dionex, Sunnyvale, CA). The samples were diluted 12 times by adding $0.5 \mathrm{~mL}$ of sample to $5.5 \mathrm{~mL}$ Milli- $\mathrm{Q}^{\circledR}$ water. Prior to the samples being analyzed a bromide calibration curve was determined and the Method Detection Limit (MDL) for the instrument was calculated as 0.34 mg. $\mathrm{L}^{-1}$. The calibration curve data can be found in Appendix A. Several blanks and standards were run throughout the analysis to ensure the calibration remained accurate and the equipment was operating properly.

\subsubsection{Microsphere Analysis}

The concentration of microspheres was determined by using a fluorescent spectrophotometer (fluo-spec) (Perking-Elmer LS-50B) with a $10 \mathrm{~mm}$ x $10 \mathrm{~mm}$ quartz cuvette. The samples were diluted 6 times by adding $0.5 \mathrm{~mL}$ of sample to $2.5 \mathrm{~mL}$ of Milli- $\mathrm{Q}^{\circledR}$ water. A calibration curve and 
MDL was determined for each of the four microspheres used for this experiment. The calibration curves can be found in Appendix A.

The unfavorable attachment tracer tests were performed by mixing the $200 \mathrm{~nm}$ and $1000 \mathrm{~nm}$ CML microspheres together in the tracer solution, which allowed for both particle sizes to be analyzed in one experiment. The process of mixing CML particles for the tracer test was performed previously on similar fracture setups by Rrokaj (2015) [146] and Mondal (2012) [149]. The emission and excitation wavelengths for the $200 \mathrm{~nm}$ and the $1000 \mathrm{~nm}$ CML microspheres were $365 / 415$ and 535/575 respectively. These microspheres were selected by analyzing the fluorescent spectra of the particles to make sure there was no significant overlap. The spectra are shown in Figure 3.3. To eliminate the possibility of interference in the analysis, the fluo-spec was used to run samples containing only one of the two CML microspheres at the emission and excitation wavelengths of the other particle to make sure that no signal was detected. A sample that contained both microspheres at the same concentration was also used to test if the signal from the fluo-spec would be affected by the presence of the other particle. In addition to these interference tests, a tracer test was run with the particles not mixed to make sure the results were the same as the mixed solution tracer tests. All the different tests showed that the microspheres could be mixed without any interference for the unfavorable tracer tests.

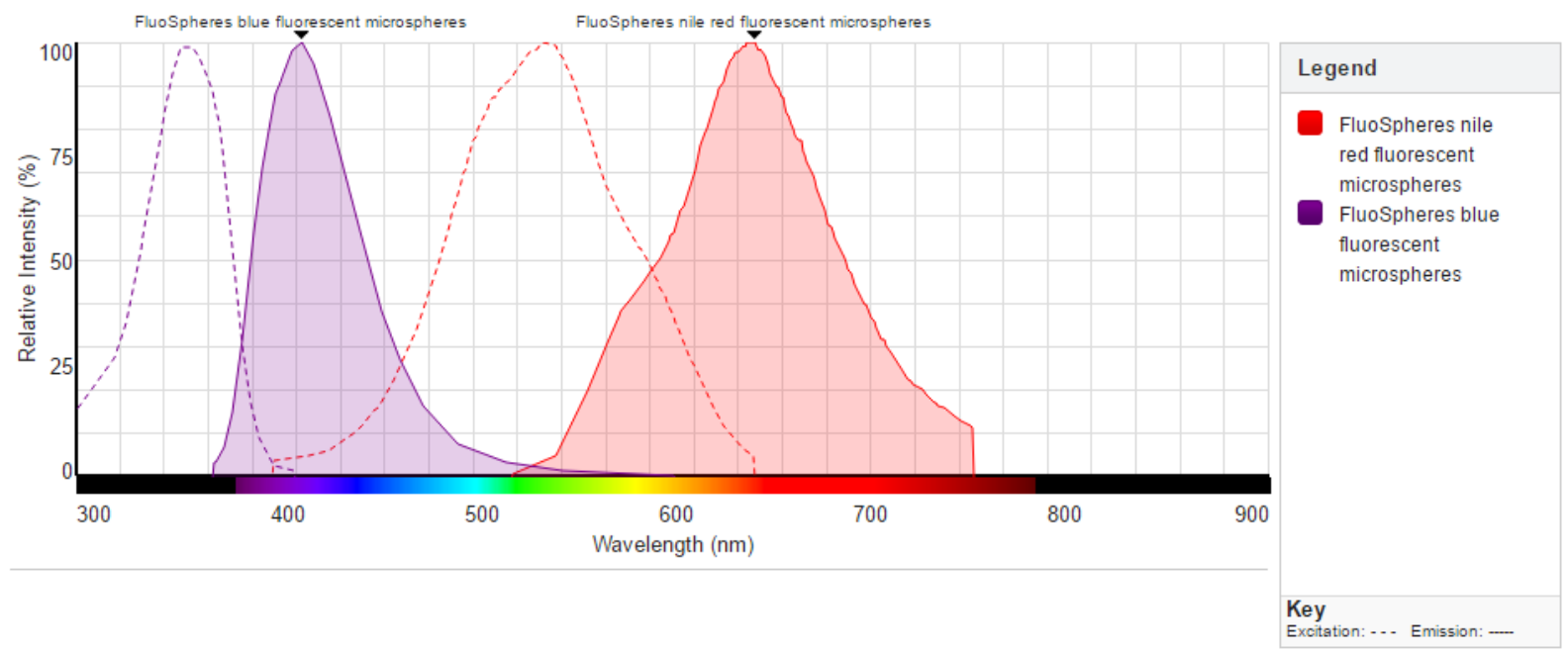

Figure 3.3 Spectra for 200 and $1000 \mathrm{~nm}$ CML microspheres

The emission and excitation wavelengths for the $200 \mathrm{~nm}$ and $1000 \mathrm{~nm}$ AML microspheres were 580/605 and 470/505 respectively. The AML microspheres were not mixed for the tracer test so 
interference when using the fluo-spec was not a concern. The microspheres were not mixed because the AML microspheres were not as stable so the possibility of aggregation so the potential for aggregation was higher.

\subsubsection{Moment Analysis}

A temporal moment analysis was performed using the breakthrough data for bromide and the microspheres. The moment analysis allowed for the calculation of the mean residence time and mass recovery of the tracers. The mean residence time $\left(t_{m}\right)$ was calculated as the difference in time between the centroids of the input pulse and the tracer breakthrough curve. The mass recovery $\left(\mathrm{M}_{\mathrm{r}}\right)$ was determined as the ratio of the mass recovered at the outlet to the total mass of tracer injected. The following equations were used for the moment analysis:

$$
\begin{gathered}
t_{m}=\frac{\int_{0}^{t} C(t) t d t}{\int_{0}^{t} C(t) d t}-\frac{T_{p}}{2} \\
M_{r}=\frac{\int_{0}^{t} Q C(t) d t}{Q C_{o} T_{p}}
\end{gathered}
$$

\subsection{Hydrus-1D Parameter Estimation}

The bromide and microsphere BTCs were fitted using Hydrus-1D [150]. A dual-porosity, physical non-equilibrium model was used to fit the bromide BTC. The dual porosity model assumes the liquid phase can be divided into a mobile and non-mobile region with the solute exchange between the two being modeled as a first-order process. The saturated hydraulic conductivity, dispersivity, fraction of immobile water content, and a mass transfer coefficient were estimated by fitting the bromide BTCs.

The microspheres were modeled using a two-site kinetic, chemical non-equilibrium model. The fitted values of immobile water content and saturated hydraulic conductivity from the bromide BTCs fitting were used to fit the microsphere BTCs. The dispersivity, two attachment coefficients, and two detachment coefficients were estimated by fitting the microsphere BTCs. The attachment and detachment coefficients were set so that one site would have irreversible attachment and one site would have reversible attachment. 


\subsection{Modeling with Compsim}

The water flow, solute transport, and colloid transport in the fracture was modeled using Compsim, which was developed by Sleep and Sykes (1993) [151]. The method used to model this fracture system was adapted from a method used by Dr. Pulin Mondal who is a Research Associate at the University of Toronto. The fracture was modeled as a set of 2D layers which made up the overall 3D system. The model consisted of 7 layers; three equal size layers in the fracture void space and 2 equal size layers in the matrix on each side of the fracture. Figure 3.4 shows a representation of the fracture discretization, with the layers highlighted in blue representing the fracture void space. The thickness $(\Delta z)$ of the fracture void space layers was $0.7 \mathrm{~mm}$ and the thickness of the matrix layers was $0.3 \mathrm{~mm}$. The 2D layers were discretized along the $\mathrm{x}$ (long side of the fracture) and the $\mathrm{y}$ (short side of the fracture). The grid size ( $\Delta \mathrm{x}$ and $\Delta \mathrm{y}$ ) of the blocks was $5 \mathrm{~mm}$ by $5 \mathrm{~mm}$.

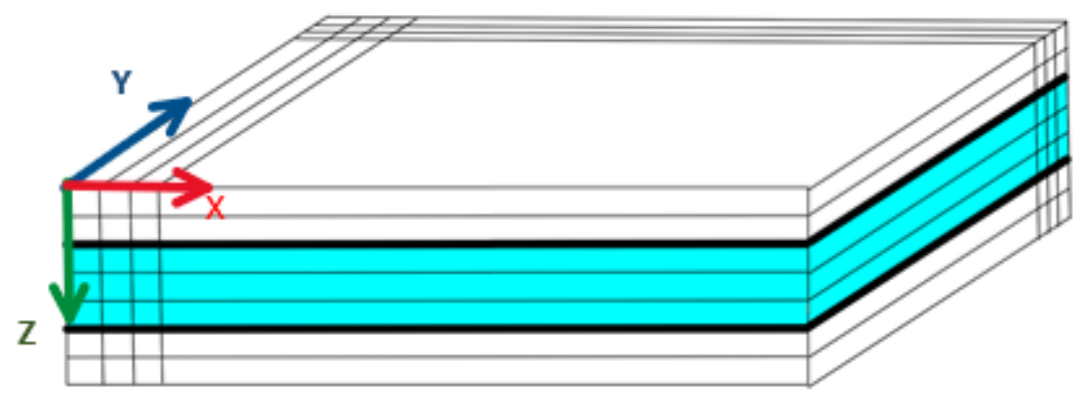

Figure 3.4 Compsim 3D Discretization

Compsim uses Darcy based fluid flow equations to determine the flow field of the system. The aperture of the fracture was considered the separation distance between two parallel plates, and was determined as the average aperture in each grid block from the data obtained by the ATOS II system. The local cubic law (LCL) was applied to convert the aperture field $(b(x, y))$ into a permeability field $\left(k_{f}(x, y)\right)$ with the following formula:

$$
k_{f}(x, y)=\frac{b(x, y)^{2}}{12}
$$

The inner and outer layer of the sandstone matrix were given different values of porosity. The outer layer farther from the fracture void space was considered to have a porosity in the range of 
the core rock block. The inner layer close to the fracture was considered a stylolite zone formed due to the fracturing process, and thus was given a higher porosity. The porosity value of the matrix was selected based on SEM-BSE analysis performed on the sandstone. The matrix porosity was a very important parameter for the model (particularly for solute transport) so it was varied to find the best fit. The permeability of the rock matrix was set to a low value of $10^{-15} \mathrm{~m}^{2}$ for the inner layer and $10^{-16} \mathrm{~m}^{2}$ for the outer layer. The porosity of the grid blocks in the fracture void space was calculated as a scaled value using the following equation:

$$
n(x, y)=\frac{b(x, y)}{3 * \Delta z}
$$

Another important factor that needed to be considered was the velocity profile for the fluid flow through the fracture. The flowrates used in the experiments and model were all in the laminar flow regime $\left(R_{e}<1\right)$, therefore a parabolic velocity profile would develop. To account for this the permeability of the outer layers in the fracture were multiplied by 0.26 and the middle layer was multiplied by 0.48 .

The boundary conditions that were set for the model were a constant head boundary condition for the 5 outlets, and a constant flow boundary condition for the inlet. The first step was to calibrate the model so that the hydraulic aperture would match what was determined from the hydraulic tests. An aperture correction factor was used to adjust the average aperture in each cell and match the experimental and model head loss at a specific flow rate. The primary variables that were fit during the solute transport modeling were the dispersivity, and the matrix porosity. For the colloid transport modeling, the parameters that were fit for the bromide transport were kept the same and other parameters related to colloid transport were fitted. The fitted parameters for colloid transport include attachment and detachment coefficients (2 sets in rock matrix and 2 sets in fracture), collector diameter, attachment efficiency, and maximum solids concentration. 


\section{Chapter 4 \\ Results}

\section{Results}

\subsection{Sandstone Fracture}

The analysis of the sandstone fracture properties was performed prior to this study during the initial setup of the bench-top fracture system; results for the aperture distribution and properties of the sandstone were taken from Rrokaj (2015) [146]. More detailed results on the properties of the sandstone fracture from [146] can be found in Appendix A.

The geometric and arithmetic mean aperture of the fracture was calculated as 210 and $218 \mu \mathrm{m}$ respectively from the aperture field data. Figure 4.1 (a) shows a 3D grayscale image of the bottom plate of the sandstone fracture, and Figure 4.1 (b) shows the aperture distribution of the fracture.
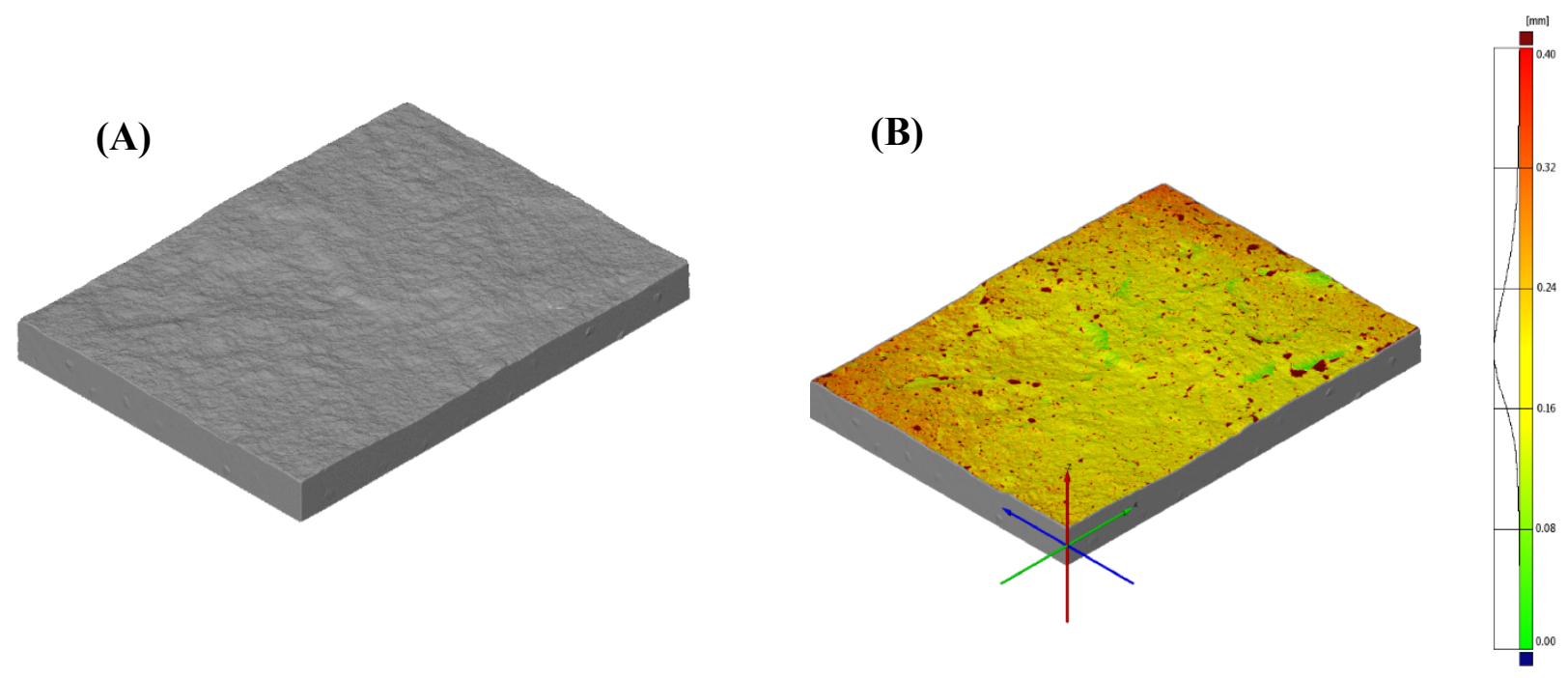

Figure 4.1 (A) 3D grayscale representation of bottom fracture surface (B) aperture distribution. Both figures from Rrokaj (2015) [146].

The red areas on the aperture distribution represent high aperture zones. The isolated red patches on the distribution may represent immobile water zones in the fracture especially if they are surrounded by lower aperture zones. The more orange and red area on the far, long side of the aperture distribution show that this area is most likely a more conductive pathway than the near, long side. The hydraulic tests also confirmed this more conductive pathway because the outlet 
piezometer on the far side had a higher head loss from the inlet than the near side piezometers. A quantification of the surface roughness of the fracture can be found in Appendix A. Using the aperture field generated by the ATOS II scanner, a permeability distribution was determined using the local cubic law (LCL). The permeability distribution is shown in Figure 4.2.

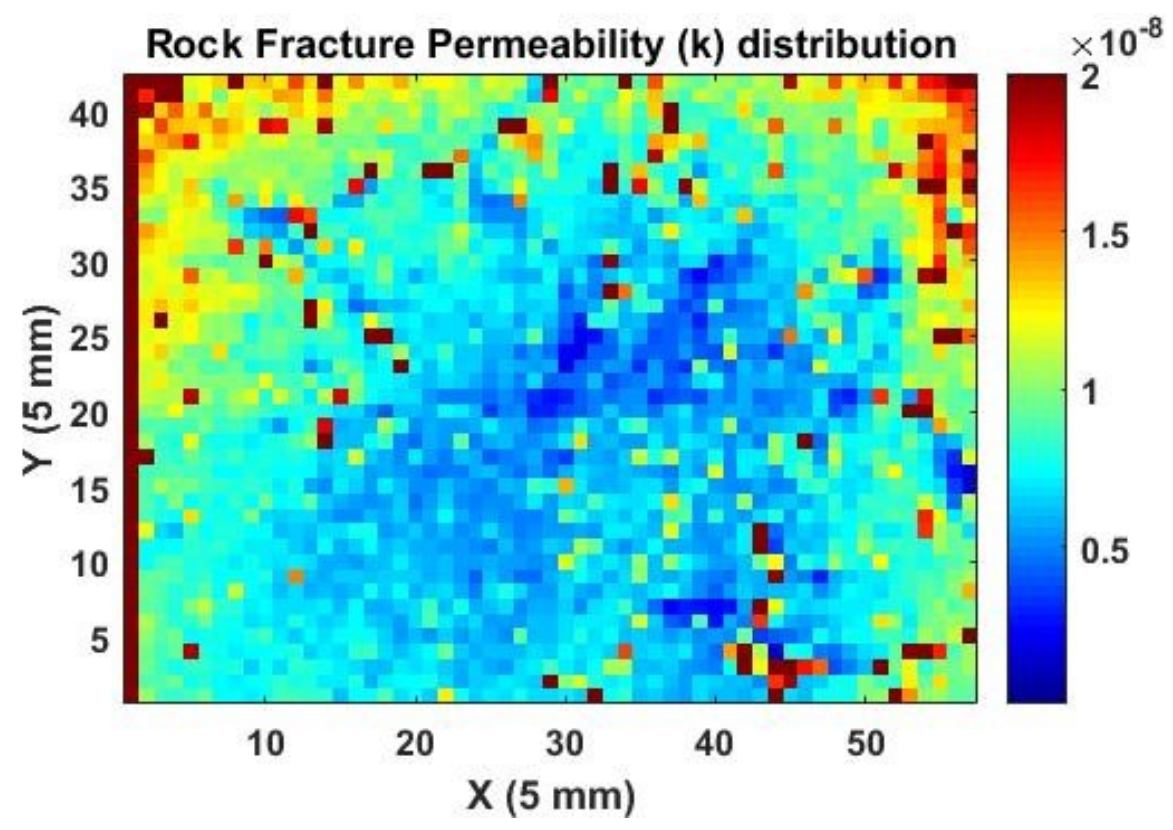

Figure 4.2 Permeability distribution from $\mathrm{LCL}$

The porosity of the sandstone determined from SEM-BSE images was $10.8 \pm 2.5 \%$. The porosity is likely higher than this average value near the fracture surface due to micro-fissures formed during the fracturing process. The XRD analysis determined that there were five mineral phases in the sandstone: quartz, albite, anorthoclase, magnesium calcite, and kaolinite. Figure 4.3 shows the percentage of each of these minerals in the sandstone sample. The elemental composition of the sandstone was determined by SEM-EDS analysis. The results showed the elemental composition of the sandstone was the following: $\mathrm{O}(64.7 \%), \mathrm{Si}(22.6 \%) \mathrm{Na}(3.6 \%), \mathrm{Al}(6.1 \%)$, $\mathrm{Na}(3.6 \%), \mathrm{K}(1.9 \%), \mathrm{Ca}(0.7 \%), \mathrm{Mg}(0.38 \%), \mathrm{Fe}(0.17 \%)$, and trace concentrations of titanium. 


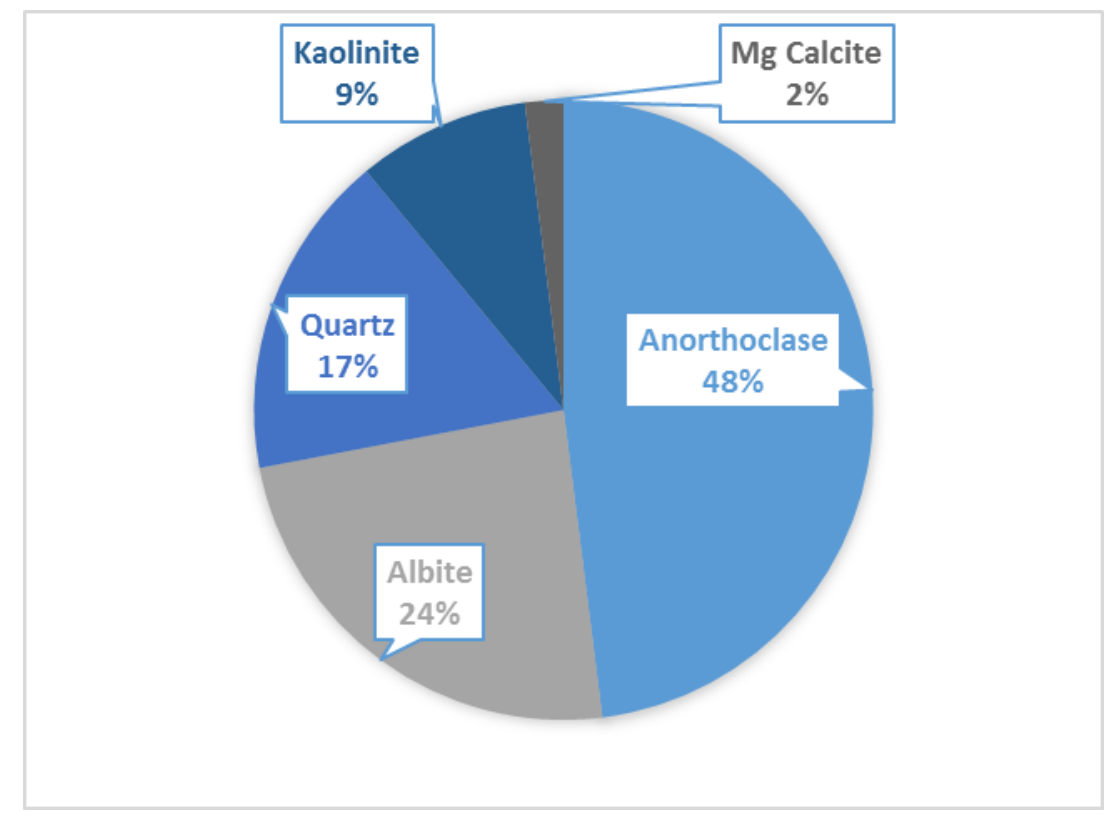

Figure 4.3 Mineral Phases in Sandstone Sample.

Data from Rrokaj (2015) [146]

\subsubsection{Zeta Potential}

The zeta potential of crushed samples of left over sandstone rock was measured using the SurPASS streaming potential instrument by Anton Paar. The results of these tests for all four solution conditions are presented in Table 4.1.

Table 4.1 Streaming potential results for crushed sandstone

\begin{tabular}{c|c|c|c|c} 
Solution & Buffer & Total I.S. $(\mathbf{m M})$ & Zeta Potential (mV) & Correlation \\
\hline 1 & Sodium bicarbonate & 5 & $-17.9 \pm 1.0$ & $0.992 \pm 0.010$ \\
\hline 2 & Sodium bicarbonate & 10 & $-19.0 \pm 0.4$ & $0.998 \pm 0.001$ \\
\hline 3 & Bis-tris & 5 & $-18.4 \pm 1.6$ & $0.949 \pm 0.017$ \\
\hline 4 & Bis-tris & 10 & $-19.1 \pm 0.7$ & $0.964 \pm 0.009$ \\
\hline
\end{tabular}

The results show that the zeta potential for the crushed sandstone does not change significantly between the solution conditions. The correlation is lower and the standard deviation is higher for the bis-tris solutions. The correlation also increases as the ionic strength increases. The expectation is that the zeta potential should decrease as the ionic strength increases and $\mathrm{pH}$ decreases, but this 
is not reflected in the results. The increased correlation for the sodium bicarbonate and higher ionic strength conditions might be an explanation for the unexpected trends in zeta potential. The results suggest that the instrument provides more accurate values when the concentration of the electrolyte $\mathrm{NaCl}$ is higher. The concentration of $\mathrm{NaCl}$ in the bis-tris solutions is $1 \mathrm{mM}$ and $6 \mathrm{mM}$, while the concentration of $\mathrm{NaCl}$ in the sodium bicarbonate solutions is $4 \mathrm{mM}$ and $9 \mathrm{mM}$. The lower concentration of the sodium bicarbonate buffer $(1 \mathrm{mM})$ compared to the bis tris buffer $(5 \mathrm{mM})$ also seems to positively impact the results. Despite the expected zeta potential trends not being reflected in the results, the most important conclusion is that the results confirm that the conditions are favorable when positively charged AML microspheres are used, and the conditions are unfavorable when negatively charged CML microspheres are used.

\subsection{Hydraulic Tests}

Hydraulic tests were performed at multiple flow rates to monitor the equivalent hydraulic aperture according to the process outlined by Tsang (1992) [148]. Table 4.2 below summarizes the results of the hydraulic tests.

Table 4.2 Hydraulic test results

\begin{tabular}{|c|c|c|c|c|}
\hline $\begin{array}{l}\text { Pump Set } \\
\left(\mathrm{mL} \cdot \mathrm{min}^{-1}\right)\end{array}$ & $\begin{array}{l}\text { Measured Flow } \\
\text { Rate }\left(\mathrm{mL}^{\mathrm{min}}{ }^{-1}\right)\end{array}$ & Head Loss $(\mathrm{mm})$ & Aperture $(\mu \mathrm{m})$ & $\begin{array}{c}\text { Reynold's } \\
\text { Number }\end{array}$ \\
\hline 4 & $4.00 \pm 0.04$ & $3.78 \pm 0.68$ & $305 \pm 20$ & 0.33 \\
\hline 6 & $5.80 \pm 0.05$ & $4.81 \pm 0.62$ & $317 \pm 12.80$ & 0.48 \\
\hline 8 & $7.78 \pm 0.15$ & $6.95 \pm 0.98$ & $309 \pm 12$ & 0.65 \\
\hline
\end{tabular}




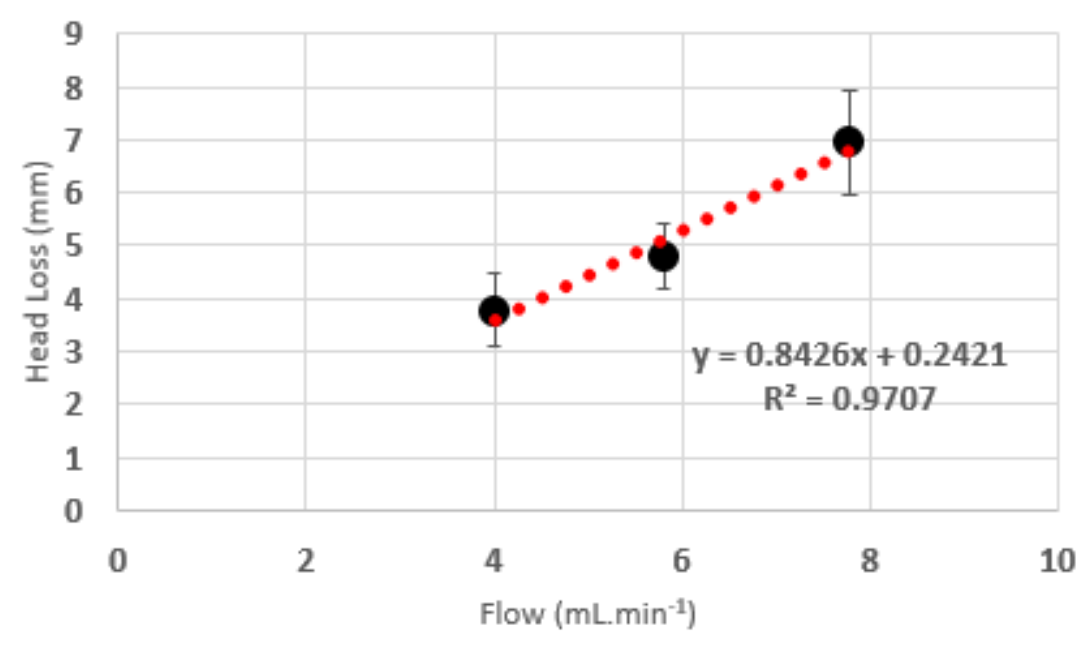

Figure 4.4 Correlation between flow rate and head loss for hydraulic tests

Hydraulic tests were run at three flow rates of 4,6 , and $8 \mathrm{~mL} \cdot \mathrm{min}^{-1}$. The flow rates were selected to provide a large enough head loss to be accurately measured, while keeping the Reynolds number well below 1 to ensure laminar flow and make the cubic law valid. Figure 4.4 shows that the relationship between head loss and flow rate is close to linear $\left(\mathrm{R}^{2}=0.971\right)$, which is expected if the cubic law is valid. The final equivalent hydraulic aperture was found to be $311 \pm 17 \mu \mathrm{m}$. With this aperture at the experimental flow rates of 1.5 and $3.0 \mathrm{~mL} \cdot \mathrm{min}^{-1}$ the specific discharge was calculated to be 0.38 and $0.77 \mathrm{~mm} . \mathrm{s}^{-1}$ respectively. The experimental flow rates of 1.5 and 3.0 $\mathrm{mL} \cdot \mathrm{min}^{-1}$ were not included in the hydraulic tests because they did not provide a significant enough head loss to be measured confidently.

\subsection{Colloid Characterization}

\subsubsection{Buffer Selection}

To make the microsphere suspensions stable the proper buffer needed to be selected for the CML and AML microspheres. The buffer used for the CML microspheres was $\mathrm{NaHCO}_{3}$ which has been used successfully in similar projects [146], [149]. A comparison of the zeta potential for the 200 $\mathrm{nm}$ AML microspheres using two buffers in the $\mathrm{pH}$ range of 5-7 is shown in Table 4.3. Bis-tris was selected as the buffer over citrate because AML microspheres are more stable in cationic buffers [152], which is confirmed by the zeta potential results in Table 4.3. Tests showed that with a bis-tris buffer concentration of $2 \mathrm{mM}$ the $\mathrm{pH}$ would rise by 1.7 (5.4 to 7.1) after $\approx 48$ hours of 
flushing through the fracture. The $5 \mathrm{mM}$ buffer showed a much less significant $\mathrm{pH}$ change of 0.2 (5.9 to 6.1 ) after 48 hours of flushing, so a final buffer selection of $5 \mathrm{mM}$ bis-tris at $\mathrm{pH} 6$ was made.

Table 4.3 Buffer comparison between citrate and bis-tris for AML microspheres

\begin{tabular}{|c|c|c|c|}
\hline Buffer & Concentration & pH & Zeta Potential (mV) \\
\hline Bis-tris & $5 \mathrm{mM}$ & 6.0 & 37.5 \\
\hline Bis-tris & $1 \mathrm{mM}$ & 5.4 & 45.3 \\
\hline Citrate & $1 \mathrm{mM}$ & 5.1 & -8.5 \\
\hline Citrate & $1 \mathrm{mM}$ & 4.3 & 21.6 \\
\hline
\end{tabular}

The results in Table 4.3 show that bis-tris is a more effective buffer than citrate because the particles are more stable (more positive zeta potential). The $\mathrm{pH}$ needed to be below 5 with the citrate buffer to even maintain a positive zeta potential.

\subsubsection{Zeta Potential}

Figure 4.5 shows the zeta potential of the CML and AML microspheres for both solution conditions and with the buffer for the oppositely charged microspheres ( $5 \mathrm{mM}$ bis-tris with CML and $1 \mathrm{mM} \mathrm{NaHCO}$ with $\mathrm{AML}$ ).
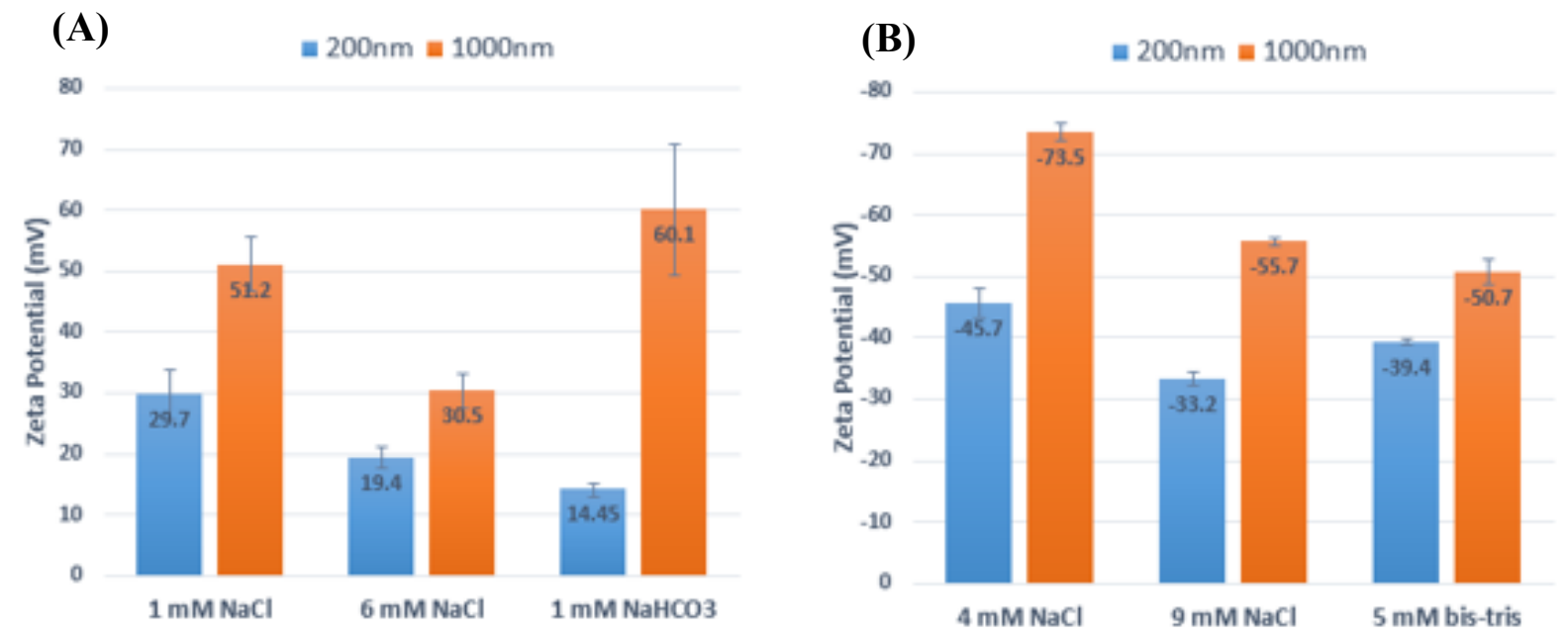

Figure 4.5 (A) zeta potential AML microspheres; NaCl solutions also contain 5 mM bis-tris buffer. (B) zeta potential CML microspheres; $\mathrm{NaCl}$ solutions also contain $1 \mathrm{mM} \mathrm{NaHCO}$ buffer 
The magnitude of the zeta potential was decreased as the ionic strength was increased for all microspheres. For both the CML and AML microspheres, the larger $1000 \mathrm{~nm}$ microspheres had a higher magnitude zeta potential than the $200 \mathrm{~nm}$ microspheres. The AML microspheres maintained their positive charge in the $\mathrm{NaHCO}_{3}$ buffer, and the CML microspheres maintained their negative charge in the bis-tris buffer.

\subsubsection{Size}

The size of the microspheres was analyzed for all solution conditions. The z-average diameter of the $200 \mathrm{~nm}$ CML microspheres was $192.8 \pm 2.8 \mathrm{~nm}$ for all solution conditions. The mean diameter (z-average provided unreasonable results) of the $200 \mathrm{~nm}$ AML microspheres was $306.8 \pm 12.6 \mathrm{~nm}$ for all solution conditions. The results for both $1000 \mathrm{~nm}$ CML and AML microspheres showed the size of the microspheres was much smaller (between 400 and $500 \mathrm{~nm}$ diameter) than what was reported by the manufacturer. The inconsistent and unexpected results obtained from the NanoParticle Analyzer made it necessary to also confirm the particle size with a scanning electron microscope (SEM). Images of the microspheres under the SEM are shown in Figure 2 (A)-(D) for further confirmation of the manufacturer's stated size. 

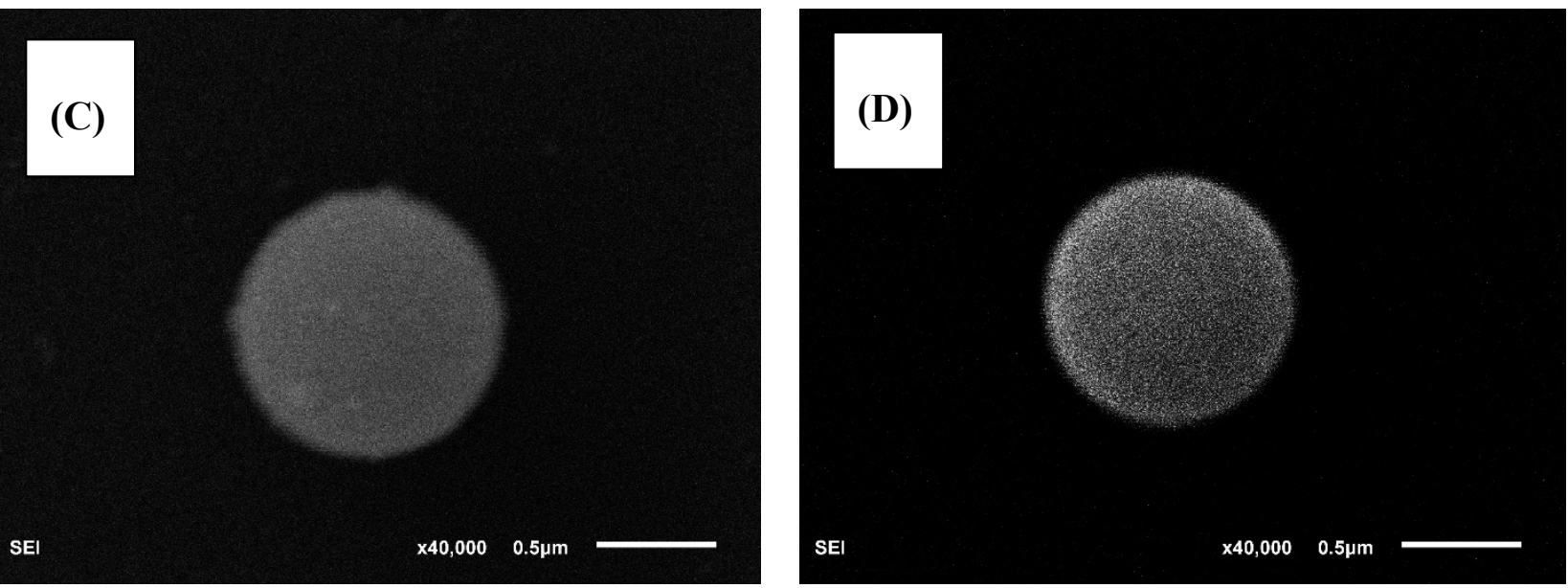

Figure 4.6 SEM images of microspheres (A) $200 \mathrm{~nm}$ AML microsphere (B) $200 \mathrm{~nm}$ CML microsphere (C) $1000 \mathrm{~nm}$ AML microsphere (D) $1000 \mathrm{~nm}$ CML microsphere

The SEM images showed that the sizes of the microspheres were close to what was reported by the manufacturer. With the listed size shown to be accurate, it was reasonable to compare favorable and unfavorable attachment tracer test results of similarly sized microspheres. 


\subsection{Solution Conditions}

The solution $\mathrm{pH}$, conductivity, and temperature were tested before each tracer test. The results for all three solutions (tracer, flush 1, and flush 2) are shown below in Table 4.4 and 4.5.

Table 4.4 Average Solution Conditions for Unfavorable Attachment Tests

\begin{tabular}{l|c|c|c|c|c|c} 
& \multicolumn{2}{c}{ Tracer } & \multicolumn{2}{c}{ Flush 1 } & \multicolumn{2}{c}{ Flush 2 } \\
\hline IS Condition & $5 \mathrm{mM}$ & $10 \mathrm{mM}$ & $5 \mathrm{mM}$ & $10 \mathrm{mM}$ & $5 \mathrm{mM}$ & $10 \mathrm{mM}$ \\
\hline $\mathbf{p H}$ & $8.1 \pm 0.2$ & $7.7 \pm 0.1$ & $8.2 \pm 0.2$ & $7.7 \pm 0.1$ & $8.7 \pm 0.4$ & $8.3 \pm 0.1$ \\
\hline Conductivity $\left(\boldsymbol{\mu S} . \mathrm{cm}^{-1}\right)$ & $550 \pm 15$ & $1122 \pm 15$ & $539 \pm 12$ & $1121 \pm 9$ & $97 \pm 9$ & $95 \pm 11$ \\
\hline Temp. $\left({ }^{\circ} \mathbf{C}\right)$ & $21.5 \pm 0.6$ & $21.0 \pm 0.3$ & $21.5 \pm 0.6$ & $21.0 \pm 0.3$ & $21.7 \pm 0.5$ & $20.9 \pm 0.3$ \\
\hline
\end{tabular}

Table 4.5 Average Solution Conditions for Favorable Attachment Tests

\begin{tabular}{l|c|c|c|c|c|c} 
& \multicolumn{2}{c}{ Tracer } & \multicolumn{2}{c}{ Flush 1 } & \multicolumn{2}{c}{ Flush 2 } \\
\hline IS Condition & $5 \mathrm{mM}$ & $10 \mathrm{mM}$ & $5 \mathrm{mM}$ & $10 \mathrm{mM}$ & $5 \mathrm{mM}$ & $10 \mathrm{mM}$ \\
\hline pH & $5.9 \pm 0.1$ & $5.9 \pm 0.0$ & $5.9 \pm 0.1$ & $5.9 \pm 0.1$ & $8.3 \pm 0.3$ & $8.4 \pm 0.0$ \\
\hline Conductivity $\left(\boldsymbol{\mu S} . \mathrm{cm}^{-1}\right)$ & $477 \pm 25$ & $1051 \pm 15$ & $477 \pm 14$ & $1034 \pm 33$ & $89 \pm 7$ & $91 \pm 2$ \\
\hline Temp. $\left({ }^{\circ} \mathrm{C}\right)$ & $22.3 \pm 1.0$ & $22.8 \pm 1.2$ & $22.2 \pm 0.9$ & $22.7 \pm 1.2$ & $22.2 \pm 1.2$ & $22.8 \pm 1.2$ \\
\hline
\end{tabular}

The results show that the increase in ionic strength caused the $\mathrm{pH}$ for the unfavorable tests to become closer to neutral ( $\mathrm{pH}$ 7). The increase in ionic strength did not have any impact on the $\mathrm{pH}$ results for the favorable attachment test solutions. The $\mathrm{pH}$ of the bis-tris buffered solutions was very consistent at 5.9 , which is likely due to the higher concentration of the buffer (5 $\mathrm{mM})$ compared to the sodium bicarbonate buffer used for the unfavorable attachment tests $(1 \mathrm{mM})$. The conductivity of the favorable and unfavorable solutions is comparable, but the favorable solutions always have a slightly lower conductivity. The likely reason for this is that when the $\mathrm{pH}$ of the bistris base is adjusted to 6 using $\mathrm{HCl}$, the ionic strength of the buffer is lower than the $5 \mathrm{mM}$ concentration. 


\subsection{Bromide Transport}

Bromide was used as a conservative tracer during all tracer tests. The bromide was analyzed and a BTC was generated for three tests at each specific discharge $\left(0.35\right.$ and $\left.0.70 \mathrm{~mm} . \mathrm{s}^{-1}\right)$, with one test from each specific discharge being at the higher ionic strength condition (10 mM). A moment analysis was performed to determine the mass recovery (MR), peak $\mathrm{C} / \mathrm{C}_{0}$, and mean residence time (RT). The actual specific discharges were calculated as 0.38 and $0.77 \mathrm{~mm} . \mathrm{s}^{-1}$.

\section{Specific Discharge: $0.35 \mathrm{~mm} . \mathrm{s}^{-1}$}
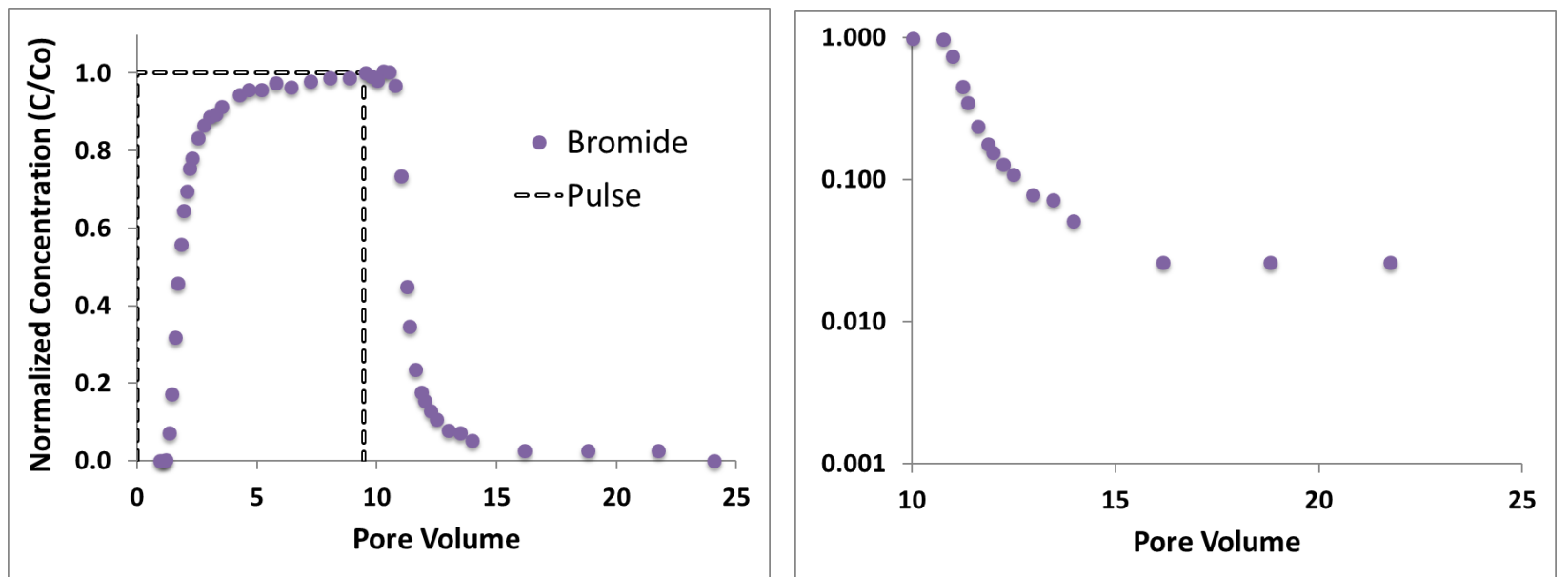

Figure 4.7 Bromide BTC and semi-log plot of tailing at $0.35 \mathrm{~mm} . \mathrm{s}^{-1}$ S.D.

\section{Specific Discharge: $0.70 \mathrm{~mm} . \mathrm{s}^{-1}$}
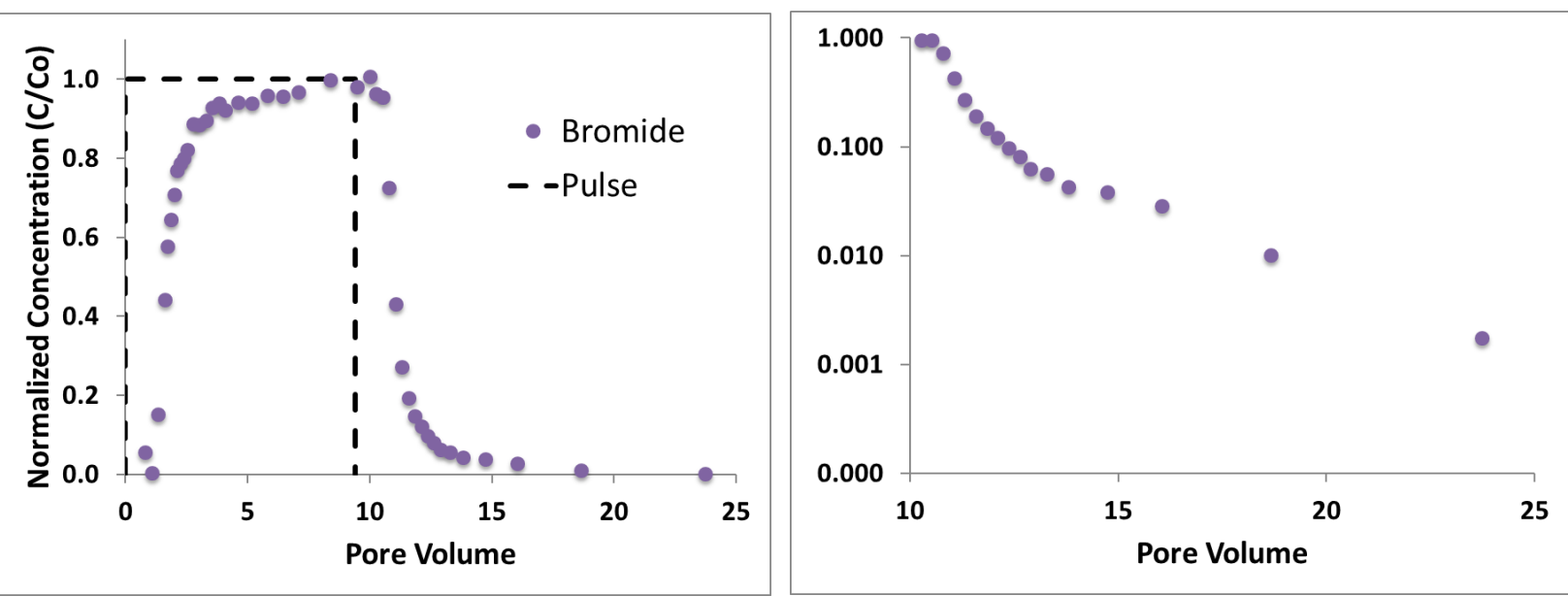

Figure 4.8 Bromide BTC and semi-log plot of tailing at $0.70 \mathrm{~mm} . \mathrm{s}^{-1}$ S.D. 
The results showed that all the tracer tests for both specific discharges had a MR between $93 \%$ and $97 \%$. The average MR (\%), peak $\mathrm{C} / \mathrm{C}_{\mathrm{o}}$, and RT for the $0.35 \mathrm{~mm} . \mathrm{s}^{-1}$ tracer tests was $95.2 \pm 1.7 \%$, $0.99 \pm 0.02$, and $23.8 \pm 0.5$ minutes respectively. The average MR (\%), peak $\mathrm{C} / \mathrm{C}_{\mathrm{o}}$, and $\mathrm{RT}$ for the $0.70 \mathrm{~mm} . \mathrm{s}^{-1}$ tracer tests was $95.5 \pm 1.6 \%, 0.98 \pm 0.02$, and $11.4 \pm 0.2$ minutes respectively. The moment analysis results show that the increase in specific discharge had almost no effect on the recovery of bromide. The only significant change was the approximately $50 \%$ decrease in RT, which was expected when the specific discharge was doubled. Ionic strength also did not have any impact on the bromide transport and recovery. Figure 4.7 and 4.8 present a sample experimental BTC for each specific discharge. The shape and tailing of the BTCs in Figure 4.7 and 4.8 is very similar, which is consistent with the results from the moment analysis.

\subsection{Unfavorable Attachment Tracer Tests}

Tracer tests were run under unfavorable attachment conditions using $200 \mathrm{~nm}$ and $1000 \mathrm{~nm} \mathrm{CML}$ microspheres. The concentrations were measured using a fluorescence spectrophotometer and BTCs were generated. A moment analysis was performed to determine values such as the mass recovery, peak $\mathrm{C} / \mathrm{C}_{\mathrm{o}}$, and residence time. Tests were run under total ionic strengths of $5 \mathrm{mM}$ and $10 \mathrm{mM}$, and two specific discharges of $0.35 \mathrm{~mm} \cdot \mathrm{s}^{-1}$ and $0.70 \mathrm{~mm} \cdot \mathrm{s}^{-1}$. The average $\mathrm{pH}$, temperature, and conductivity for the $5 \mathrm{mM}$ ionic strength tracer solution was $8.1 \pm 0.2,21.5 \pm 0.6^{\circ} \mathrm{C}$, and 550 $\pm 15 \mu \mathrm{S} . \mathrm{cm}^{-1}$ respectively. The average $\mathrm{pH}$, temperature, and conductivity for the $10 \mathrm{mM}$ ionic strength tracer solution was $7.7 \pm 0.1,21.0 \pm 0.3^{\circ} \mathrm{C}$, and $1121 \pm 15 \mu{\mathrm{S} . \mathrm{cm}^{-1}}^{-1}$ respectively. The average zeta potential of the $200 \mathrm{~nm}$ CML microspheres under the $5 \mathrm{mM}$ and $10 \mathrm{mM}$ solution conditions was $-45.7 \mathrm{mV}$ and $-33.2 \mathrm{mV}$ respectively. The average zeta potential of the $1000 \mathrm{~nm}$ CML microspheres under the $5 \mathrm{mM}$ and $10 \mathrm{mM}$ solution conditions was $-73.5 \mathrm{mV}$ and $-55.7 \mathrm{mV}$ respectively. The actual calculated specific discharges were 0.38 and $0.77 \mathrm{~mm} . \mathrm{s}^{-1}$. The BTCs for each condition are presented in sections 4.6.1 and 4.6.2. 


\subsubsection{Specific Discharge $0.35 \mathrm{~mm} . \mathrm{s}^{-1}$}

Figures 4.9 and 4.10 show the BTCs and semi-log BTCs of the $200 \mathrm{~nm}$ and $1000 \mathrm{~nm} \mathrm{CML}$ microspheres at $5 \mathrm{mM}$ and $10 \mathrm{mM}$ ionic strength respectively. The semi-log plot shows the tailing portion of the BTC.

\section{Ionic Strength: $5 \mathrm{mM}$}
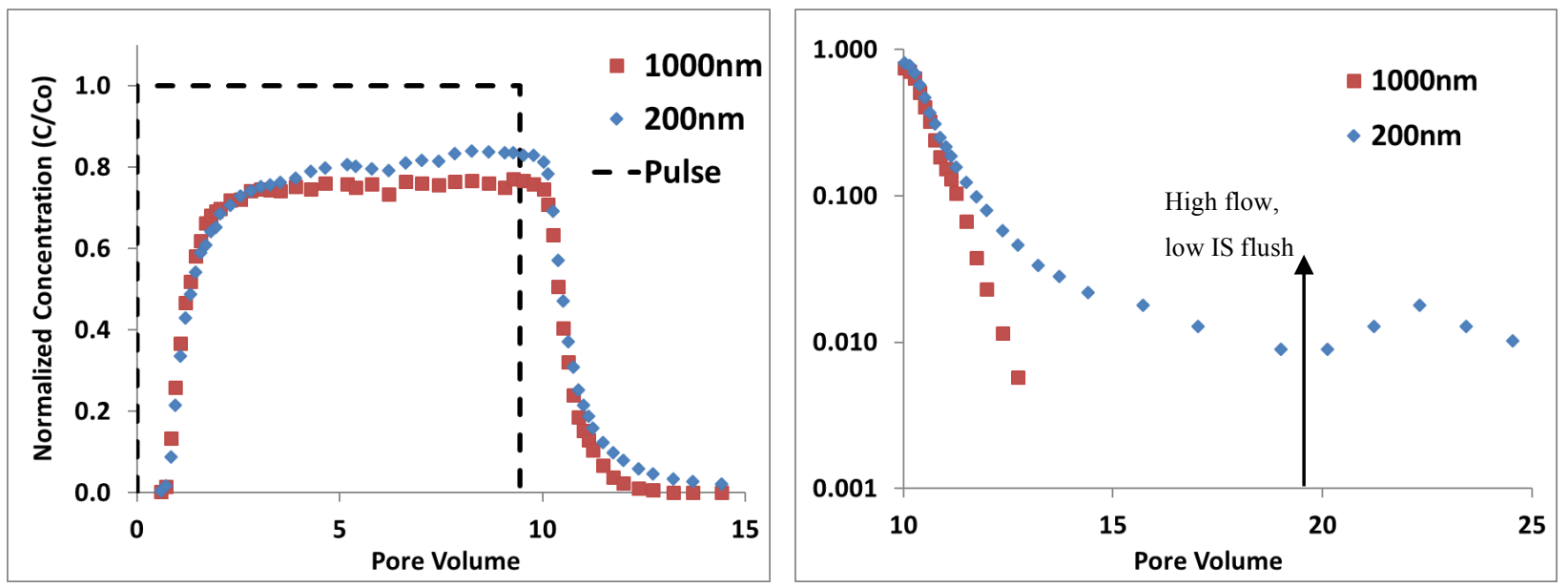

Figure 4.9 Unfavorable attachment BTC and semi-log plot of tailing at $5 \mathrm{mM}$ I.S.

\section{Ionic Strength: $10 \mathrm{mM}$}
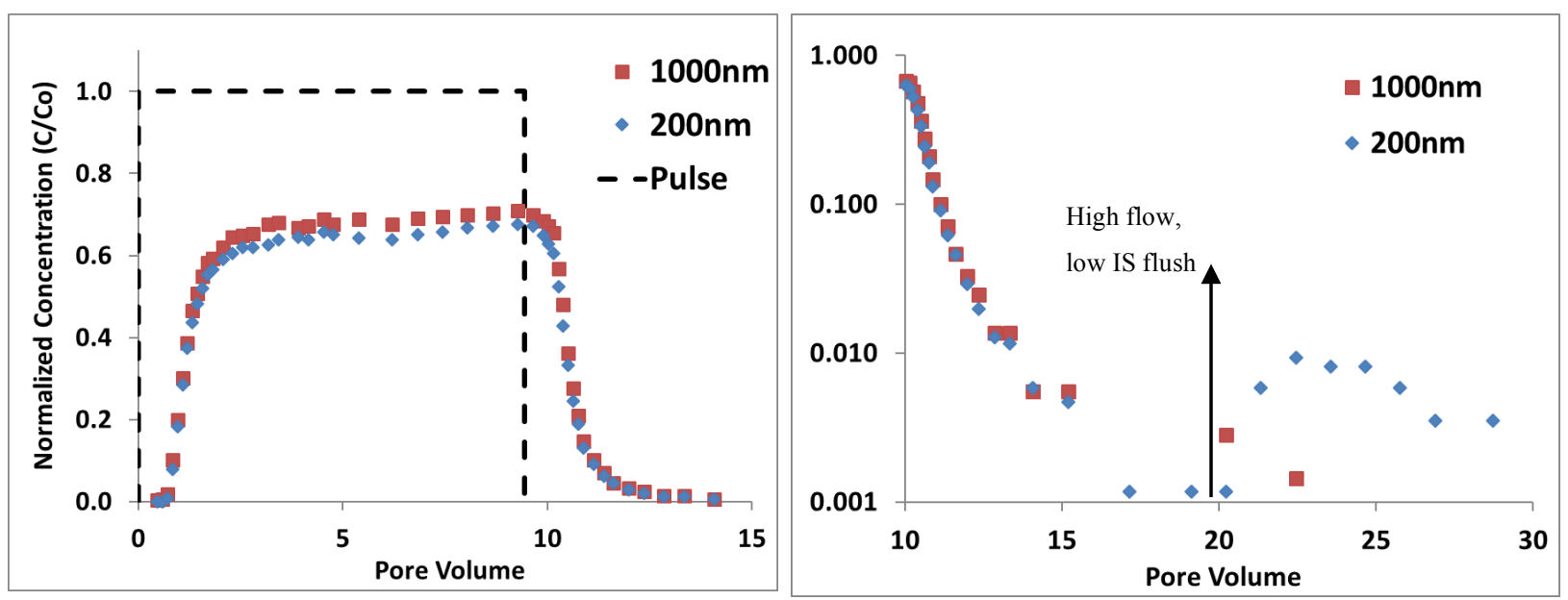

Figure 4.10 Unfavorable attachment BTC and semi-log plot of tailing at 5 mM I.S. 
The smaller $200 \mathrm{~nm}$ CML microspheres had a higher MR (83\%) than the $1000 \mathrm{~nm}$ microspheres (77\%) in the lower ionic strength test. The result was reversed when the ionic strength was increased to $10 \mathrm{mM}$, with the MR of the smaller microspheres decreasing to $65 \%$ while the MR of the larger microspheres only decreased to $69 \%$. The smaller microspheres were more impacted by the increase in ionic than the larger ones. The $200 \mathrm{~nm}$ microspheres had more tailing than the larger $1000 \mathrm{~nm}$ microspheres, which was particularly noticeable for the $5 \mathrm{mM}$ ionic strength case. There was less tailing of the $200 \mathrm{~nm}$ microspheres when the ionic strength was raised to $10 \mathrm{mM}$, whereas the $1000 \mathrm{~nm}$ tailing was not significantly impacted. The RT of the $200 \mathrm{~nm}$ microspheres decreased from 20 minutes to 16.7 minutes with the increase in ionic strength, which shows that the decreased tailing led to a lower RT. The RT of the $1000 \mathrm{~nm}$ microspheres did not change with ionic strength (16.1 to 16.2 minutes) because the increase in ionic strength did not have a major impact on the tailing or shape of the BTC. A small spike in concentration can be seen in the semi-log BTC of the $200 \mathrm{~nm}$ microspheres at both 5 and $10 \mathrm{mM}$ ionic strength. The spike happens after $20 \mathrm{PV}$ and is due to the low ionic strength, high velocity flush solution.

\subsubsection{Specific Discharge $0.70 \mathrm{~mm} . \mathrm{s}^{-1}$}

Figures 4.11 and 4.12 show the BTCs and semi-log BTCs of the 200 and $1000 \mathrm{~nm} \mathrm{CML}$ microspheres at 5 and $10 \mathrm{mM}$ ionic strength respectively. The semi-log plot shows the tailing portion of the BTC.

\section{Ionic Strength: $5 \mathrm{mM}$}
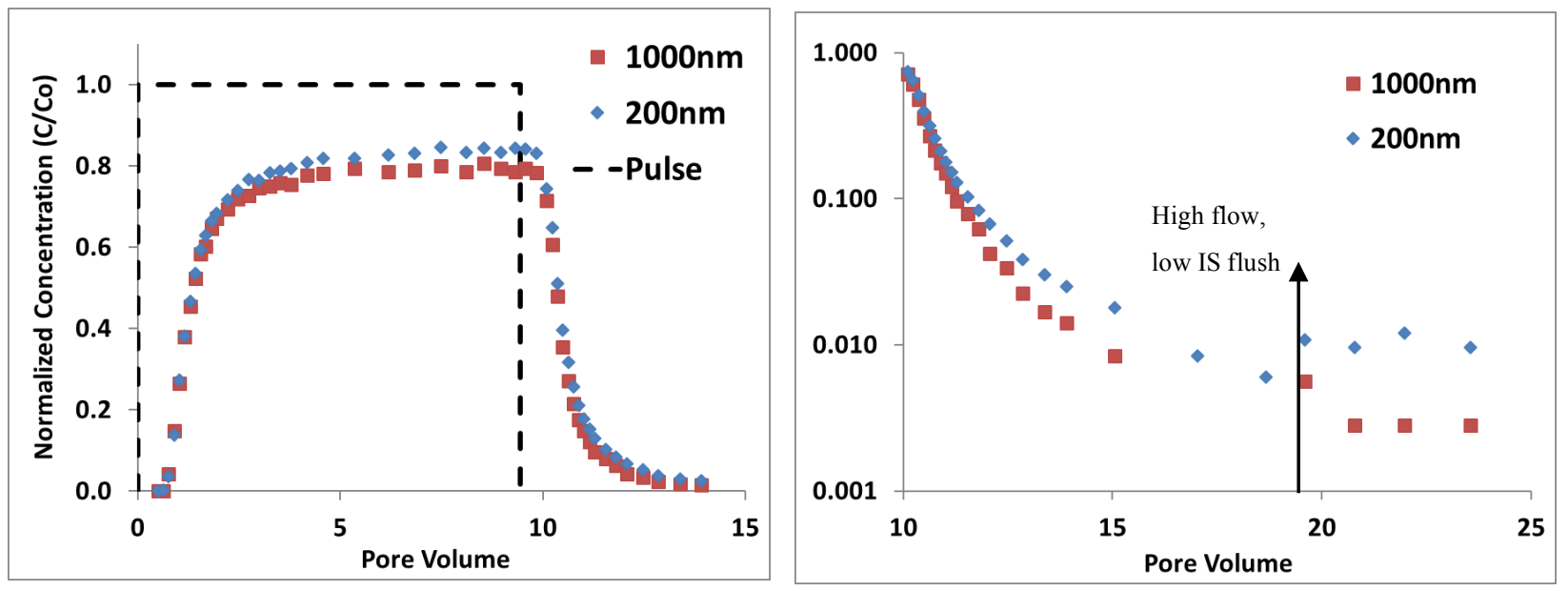

Figure 4.11 Unfavorable attachment BTC and semi-log plot of tailing at $5 \mathrm{mM}$ I.S. 


\section{Ionic Strength: $10 \mathrm{mM}$}
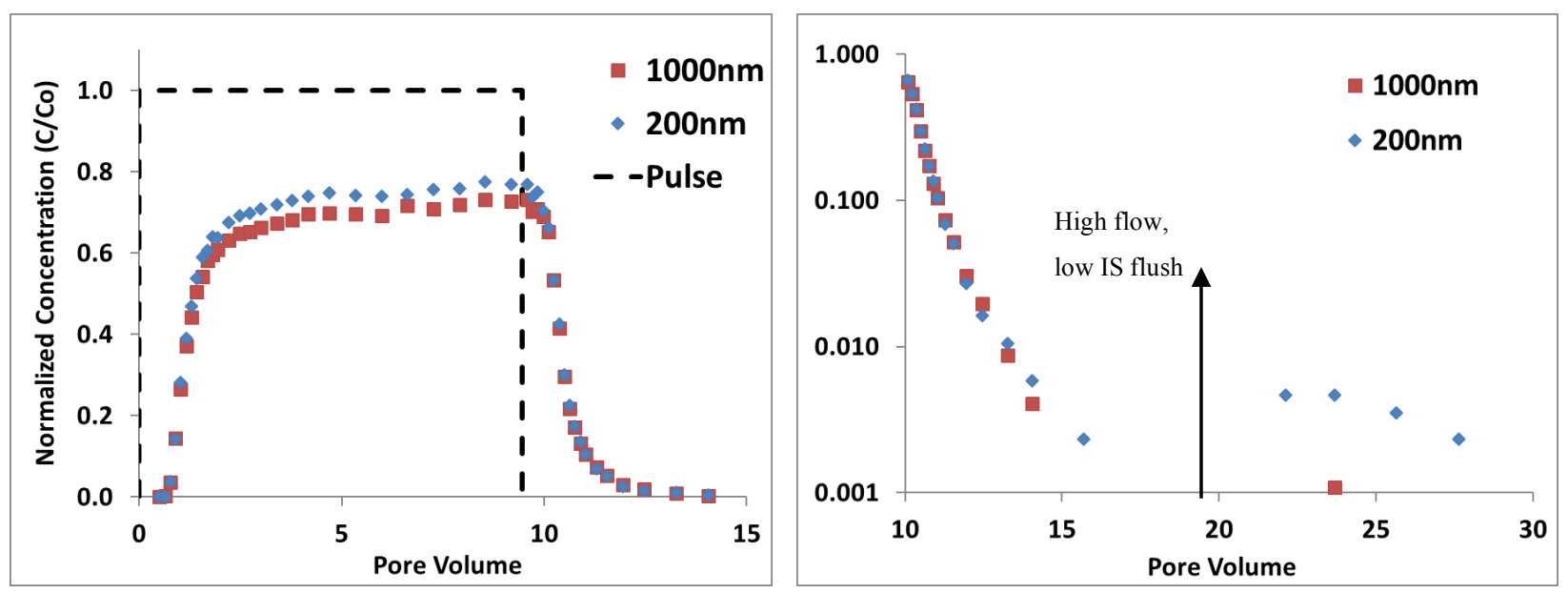

Figure 4.12 Unfavorable attachment BTC and semi-log plot of tailing at $10 \mathrm{mM}$ I.S.

The BTCs of the 200 and $1000 \mathrm{~nm}$ microspheres at $5 \mathrm{mM}$ ionic strength are almost identical to the $5 \mathrm{mM}$ ionic strength case at the lower $0.35 \mathrm{~mm} . \mathrm{s}^{-1} \mathrm{SD}$. The MR of the $200 \mathrm{~nm}$ and $1000 \mathrm{~nm}$ microspheres was $83 \%$ and $76 \%$, which is almost the same as the lower SD case. To fully investigate the impact of specific discharge a test was also run with both high ionic strength (10 $\mathrm{mM})$ and high specific discharge $\left(0.70 \mathrm{~mm} \cdot \mathrm{s}^{-1}\right)$; the $\mathrm{MR}$ results of the 200 and $1000 \mathrm{~nm}$ microspheres was $74 \%$ and $70 \%$ respectively. The results showed that the increased SD led to an increase in MR for the $200 \mathrm{~nm}$ microspheres at $10 \mathrm{mM}$ ionic strength, but the $1000 \mathrm{~nm}$ microspheres were not noticeably impacted by SD at either ionic strength condition. The higher SD also led to a RT that was about half as long as the lower SD case under the same ionic strength conditions. Table 4.6 presents a summary of the results from the unfavorable attachment tracer tests. 
Table 4.6 Summary of Unfavorable Attachment Tracer Tests

\begin{tabular}{|c|c|c|c|c|c|}
\hline $\begin{array}{l}\text { Particle Size } \\
\quad(\mathrm{nm})\end{array}$ & $\begin{array}{c}\text { Specific } \\
\text { Discharge } \\
\left(\mathrm{mm} . \mathrm{s}^{-1}\right)\end{array}$ & $\begin{array}{c}\text { lonic } \\
\text { Strength } \\
(\mathrm{mM})\end{array}$ & $\begin{array}{c}\text { Mass } \\
\text { Recovery (\%) }\end{array}$ & Peak $\mathrm{C} / \mathrm{C}_{\mathrm{o}}$ & $\begin{array}{c}\text { Mean } \\
\text { Residence } \\
\text { Time (min) }\end{array}$ \\
\hline \multirow{4}{*}{$200 \mathrm{~nm}$} & \multirow[b]{2}{*}{0.35} & 5 & 83.3 & 0.86 & 20.0 \\
\hline & & 10 & 64.6 & 0.68 & 16.7 \\
\hline & \multirow[b]{2}{*}{0.70} & 5 & 82.9 & 0.85 & 9.5 \\
\hline & & 10 & 74.0 & 0.78 & 8.1 \\
\hline \multirow{4}{*}{$1000 \mathrm{~nm}$} & \multirow{2}{*}{0.35} & 5 & 76.6 & 0.78 & 16.1 \\
\hline & & 10 & 69.4 & 0.72 & 16.2 \\
\hline & \multirow{2}{*}{0.70} & 5 & 76.6 & 0.80 & 8.6 \\
\hline & & 10 & 70.0 & 0.73 & 8.2 \\
\hline
\end{tabular}

\subsection{Favorable Attachment Tracer Tests}

Tracer tests were run under favorable attachment conditions using $200 \mathrm{~nm}$ and $1000 \mathrm{~nm}$ AML microspheres. The concentrations were measured using a fluorescence spectrophotometer and BTCs were generated. A moment analysis was performed to determine values such as the mass recovery, peak $\mathrm{C} / \mathrm{C}_{0}$, and residence time. Tests were run under total ionic strengths of $5 \mathrm{mM}$ and $10 \mathrm{mM}$, and two specific discharges of $0.35 \mathrm{~mm} . \mathrm{s}^{-1}$ and $0.70 \mathrm{~mm} \cdot \mathrm{s}^{-1}$. The average $\mathrm{pH}$, temperature, and conductivity for the $5 \mathrm{mM}$ ionic strength tracer solution was $5.9 \pm 0.1,22.3 \pm 1.0^{\circ} \mathrm{C}$, and 477 $\pm 25 \mu \mathrm{S} . \mathrm{cm}^{-1}$ respectively. The average $\mathrm{pH}$, temperature, and conductivity for the $10 \mathrm{mM}$ ionic strength tracer solution was $5.9 \pm 0.0,22.8 \pm 1.2^{\circ} \mathrm{C}$, and $1051 \pm 15 \mu{\mathrm{S} . \mathrm{cm}^{-1}}^{-}$respectively. The average zeta potential of the $200 \mathrm{~nm}$ AML microspheres at the $5 \mathrm{mM}$ and $10 \mathrm{mM}$ ionic strength was $29.7 \mathrm{mV}$ and $19.4 \mathrm{mV}$ respectively. The average zeta potential of the $1000 \mathrm{~nm}$ AML microspheres at the $5 \mathrm{mM}$ and $10 \mathrm{mM}$ ionic strength was $51.2 \mathrm{mV}$ and $30.5 \mathrm{mV}$ respectively. Zeta potential measurements of the effluent were also taken randomly throughout the $200 \mathrm{~nm}$ AML transport tests to confirm that the conditions remained favorable. The actual calculated specific discharges were 0.38 and $0.77 \mathrm{~mm} . \mathrm{s}^{-1}$. Unlike the CML microspheres, the AML microspheres were 
not mixed, which prevented the possibility of interference between the two microsphere sizes. The BTCs presented in sections 4.6.1 and 4.6.2 show both microsphere sizes plotted together although these experiments did not take place at the same time.

\subsubsection{Specific Discharge 0.35 mm. $\mathrm{s}^{-1}$}

Figures 4.13 and 4.14 show the BTCs and semi-log BTCs of the 200 and $1000 \mathrm{~nm}$ AML microspheres at 5 and $10 \mathrm{mM}$ ionic strength respectively. The semi-log plot shows the tailing portion of the BTC. The average effluent zeta potential for the $200 \mathrm{~nm}$ microspheres at $5 \mathrm{mM}$ and $10 \mathrm{mM}$ ionic strengths was $21.5 \mathrm{mV}$ and $17.1 \mathrm{mV}$ respectively.

\section{Ionic Strength: $5 \mathrm{mM}$}
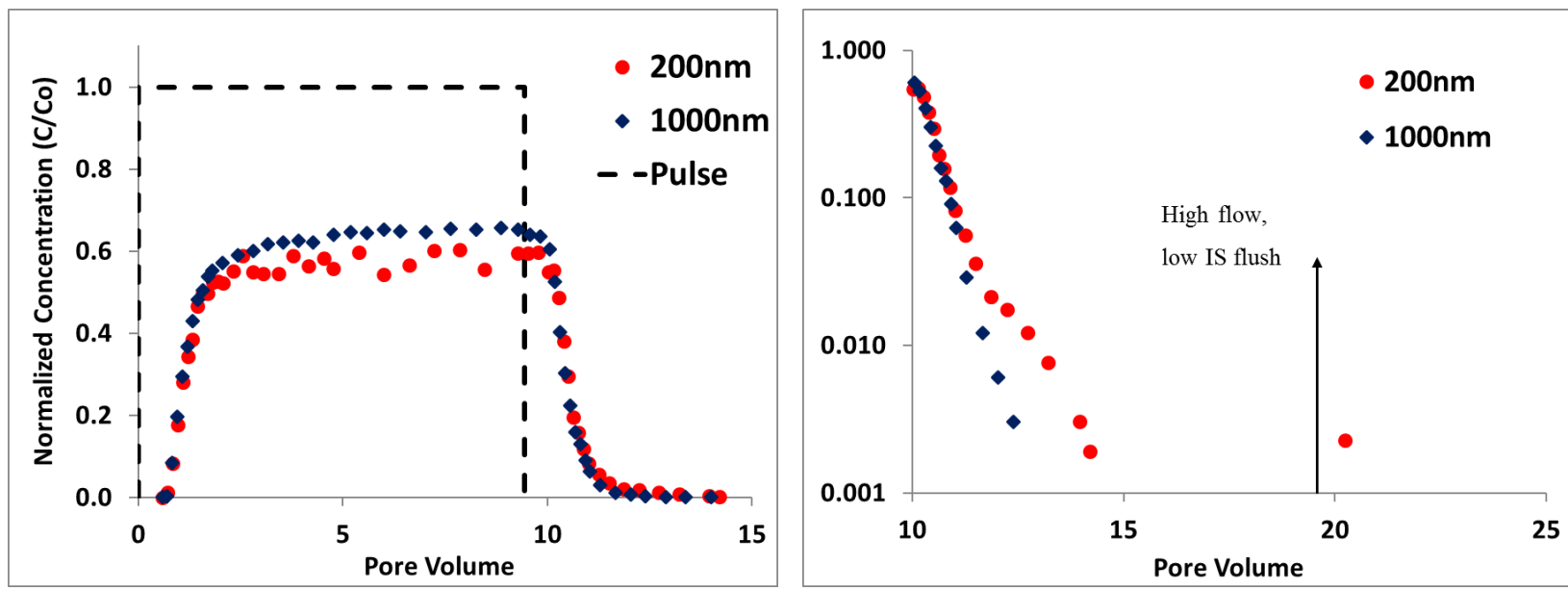

Figure 4.13 Favorable attachment BTC and semi-log plot of tailing at 5 mM I.S. 


\section{Ionic Strength: $10 \mathrm{mM}$}
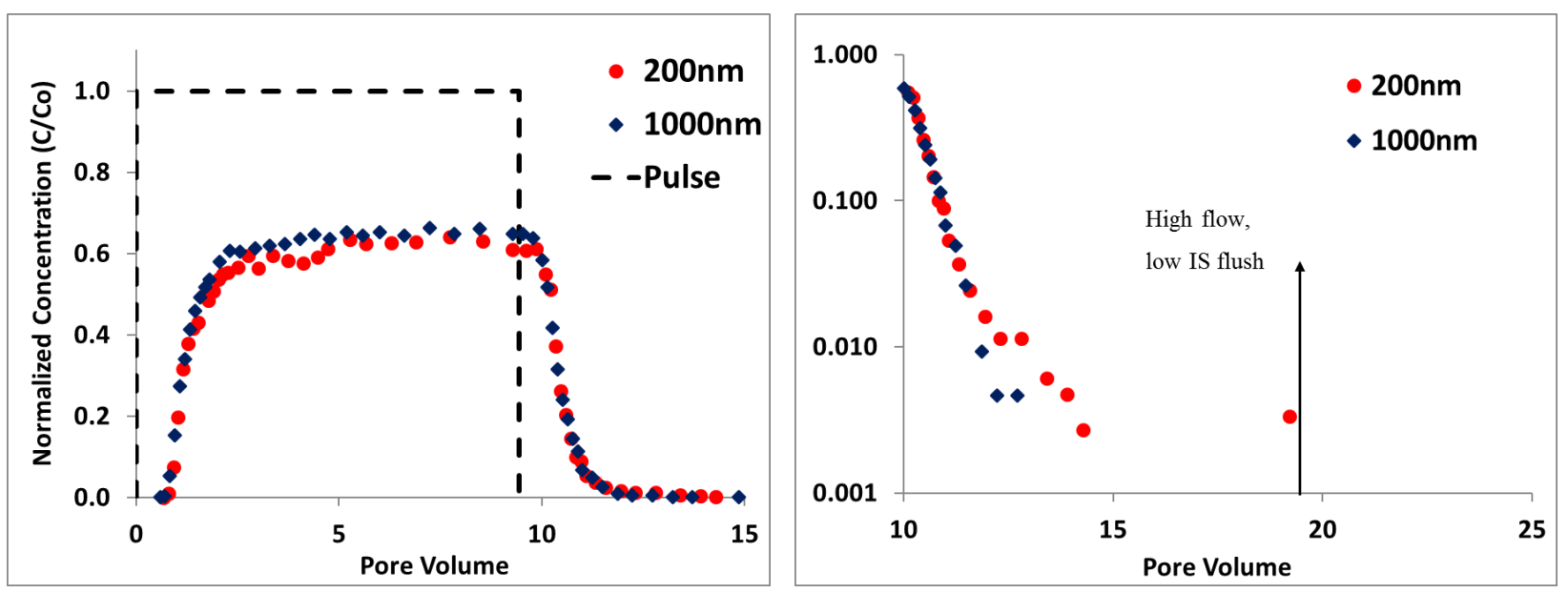

Figure 4.14 Favorable attachment BTC and semi-log plot of tailing at $10 \mathrm{mM}$ I.S.

The MR of the $200 \mathrm{~nm}$ and $1000 \mathrm{~nm}$ AML microspheres was 59\% and 64\% respectively at $5 \mathrm{mM}$ ionic strength. The positively charged microspheres showed a lower $\mathrm{MR}$ and peak $\mathrm{C} / \mathrm{C}_{\mathrm{o}}$ for both particle sizes when compared to their negatively charged counterparts. The larger microspheres had a higher recovery than the smaller microspheres under favorable conditions, which is the opposite of what was observed under unfavorable conditions at $5 \mathrm{mM}$ ionic strength. The $200 \mathrm{~nm}$ AML microspheres had significantly less tailing than the similarly sized $200 \mathrm{~nm}$ CML microspheres. The $1000 \mathrm{~nm}$ AML microspheres showed very little tailing as well, but not much change from the tailing of the $1000 \mathrm{~nm}$ CML microspheres. The RT of the $200 \mathrm{~nm}$ and $1000 \mathrm{~nm}$ cationic microspheres was 15.4 and 15.2 minutes respectively, which in both cases was shorter than their anionic counterparts. The decrease in RT from unfavorable conditions was more significant for the $200 \mathrm{~nm}$ AML microspheres compared to the $1000 \mathrm{~nm}$ AML microspheres due to the larger reduction in tailing effects. The increase in ionic strength to $10 \mathrm{mM}$ did not have any impact on the results for either particle size under favorable conditions.

\subsubsection{Specific Discharge $0.70 \mathrm{~mm} . \mathrm{s}^{-1}$}

Figure 4.15 shows the BTC and semi-log BTC of the $200 \mathrm{~nm}$ and $1000 \mathrm{~nm}$ AML microspheres at $5 \mathrm{mM}$ ionic strength. A test was not run at $10 \mathrm{mM}$ ionic strength for the $0.70 \mathrm{~mm} . \mathrm{s}^{-1}$ specific discharge because previous tests showed that neither ionic strength nor specific discharge variations had a significant impact on the results. The semi-log plot shows the tailing portion of 
the BTC. The average effluent zeta potential of the $200 \mathrm{~nm}$ AML microspheres at the higher SD was $22.9 \mathrm{mV}$.

Ionic Strength: $5 \mathrm{mM}$
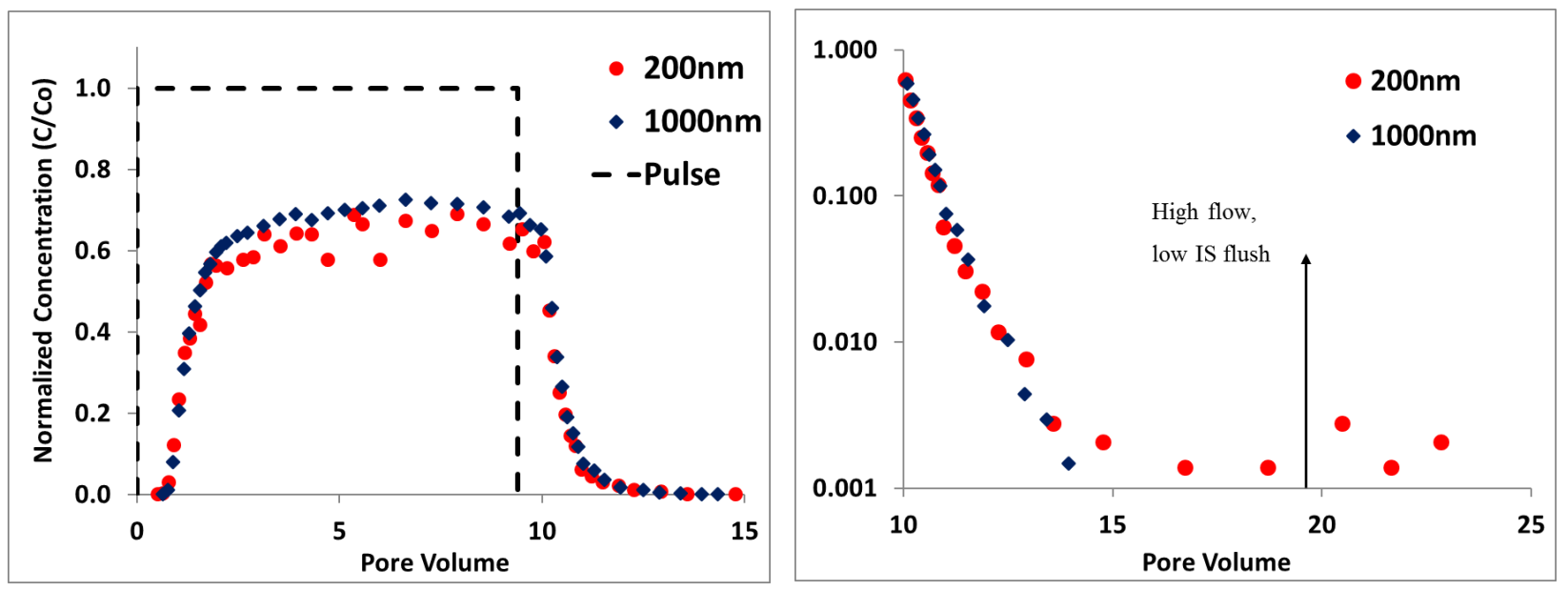

Figure 4.15 Favorable attachment BTC and semi-log plot of tailing at 5 mM I.S.

The increased specific discharge resulted in a small increase in MR for both the $200 \mathrm{~nm}$ and 1000 nm AML microspheres. The MR of the smaller microspheres increased from $59 \%$ to $62 \%$, and the MR of the larger microspheres increased from $64 \%$ to $68 \%$ with the increase in specific discharge. The overall shape of the BTC was not significantly impacted by the higher specific discharge. The RT for both microsphere sizes was about half as long as it was for the slower specific discharge under favorable conditions. Table 4.7 presents a summary of the favorable attachment tracer tests. 
Table 4.7 Favorable Attachment Tracer Test Summary

\begin{tabular}{|c|c|c|c|c|c|}
\hline $\begin{array}{l}\text { Particle Size } \\
\quad(\mathrm{nm})\end{array}$ & $\begin{array}{c}\text { Specific } \\
\text { Discharge } \\
\left(\mathrm{mm} . \mathrm{s}^{-1}\right)\end{array}$ & $\begin{array}{c}\text { lonic } \\
\text { Strength } \\
(\mathrm{mM})\end{array}$ & $\begin{array}{c}\text { Mass } \\
\text { Recovery (\%) }\end{array}$ & Peak $\mathrm{C} / \mathrm{C}_{\mathrm{o}}$ & $\begin{array}{c}\text { Mean } \\
\text { Residence } \\
\text { Time (min) }\end{array}$ \\
\hline \multirow{3}{*}{$200 \mathrm{~nm}$} & \multirow[b]{2}{*}{0.35} & 5 & 58.5 & 0.63 & 15.4 \\
\hline & & 10 & 58.1 & 0.63 & 15.1 \\
\hline & 0.70 & 5 & 61.8 & 0.69 & 7.5 \\
\hline \multirow{3}{*}{$1000 \mathrm{~nm}$} & \multirow{2}{*}{0.35} & 5 & 64.1 & 0.68 & 15.2 \\
\hline & & 10 & 62.5 & 0.66 & 14.8 \\
\hline & 0.70 & 5 & 67.8 & 0.73 & 7.8 \\
\hline
\end{tabular}

\subsection{Comparisons and Hydrus-1D Parameter Estimation}

Hydrus-1D was used to estimate transport parameters for both bromide and microspheres. The bromide and microsphere BTCs with Hydrus-1D model fit are shown to compare the effects of various conditions. Hydrus-1D fits are shown for microsphere transport with varying ionic strength (for CML microspheres), particle size, and attachment conditions. Increased specific discharge did not have a significant impact on the BTCs of AML or CML microspheres and neither did increased ionic strength for AML microspheres so the Hydrus-1D fits are not presented.

\subsubsection{Bromide Transport}

The bromide BTCs were fit using a two-region model with dual-porosity transport processes (physical nonequilibrium model). Three experimental BTCs were fitted at each specific discharge. The fraction of immobile water was the first parameter that was fit because it was kept constant for all subsequent bromide and microsphere transport simulations. The fraction of immobile water that best fit the bromide BTCs was determined to be 0.25 . Three other parameters were fit for the dual porosity model: dispersivity $\left(\mathrm{D}_{\mathrm{L}}\right)$, saturated hydraulic conductivity $\left(\mathrm{K}_{\mathrm{S}}\right)$, and a mobileimmobile water mass transfer coefficient $(\omega)$. The BTCs for both $0.35 \mathrm{~mm} . \mathrm{s}^{-1}$ and $0.70 \mathrm{~mm} . \mathrm{s}^{-1}$ were fitted and are shown below in Figure 4.16 and 4.17 with the fitted parameters presented in Table 4.8. 
Specific Discharge: $0.35 \mathrm{~mm} . \mathrm{s}^{-1}$
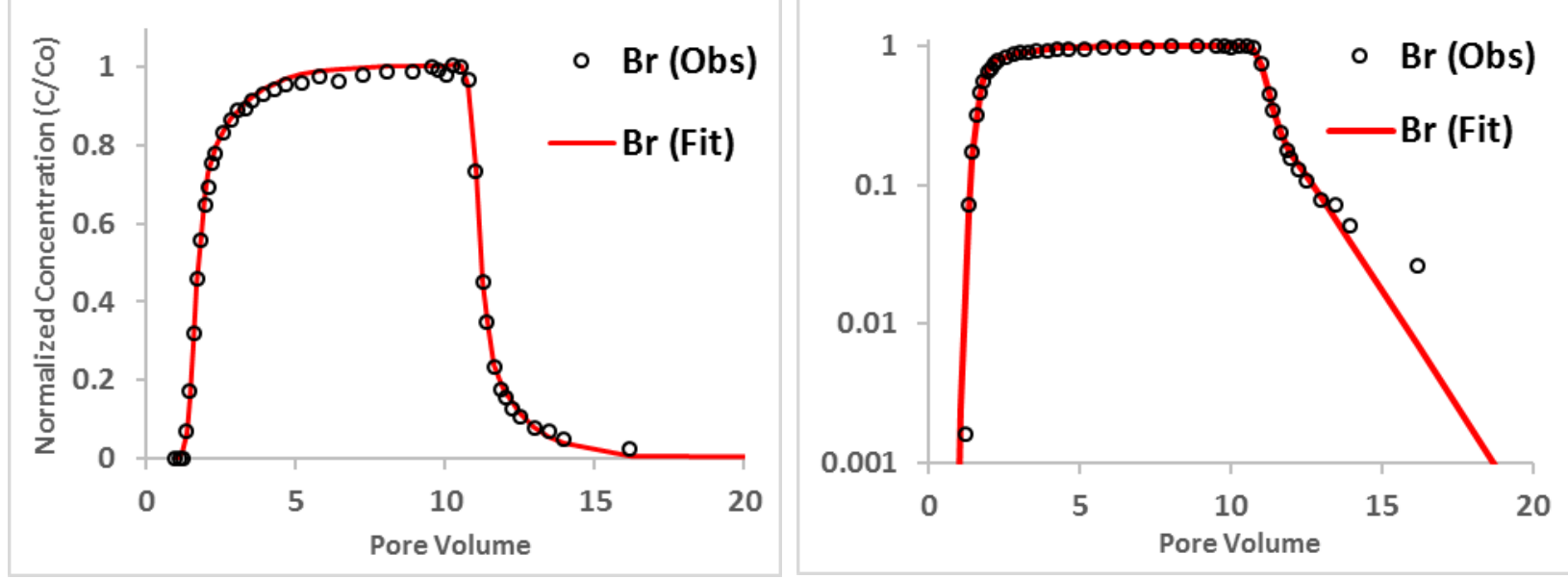

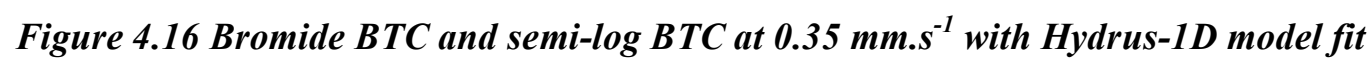

Specific Discharge: $0.70 \mathrm{~mm} . \mathrm{s}^{-1}$
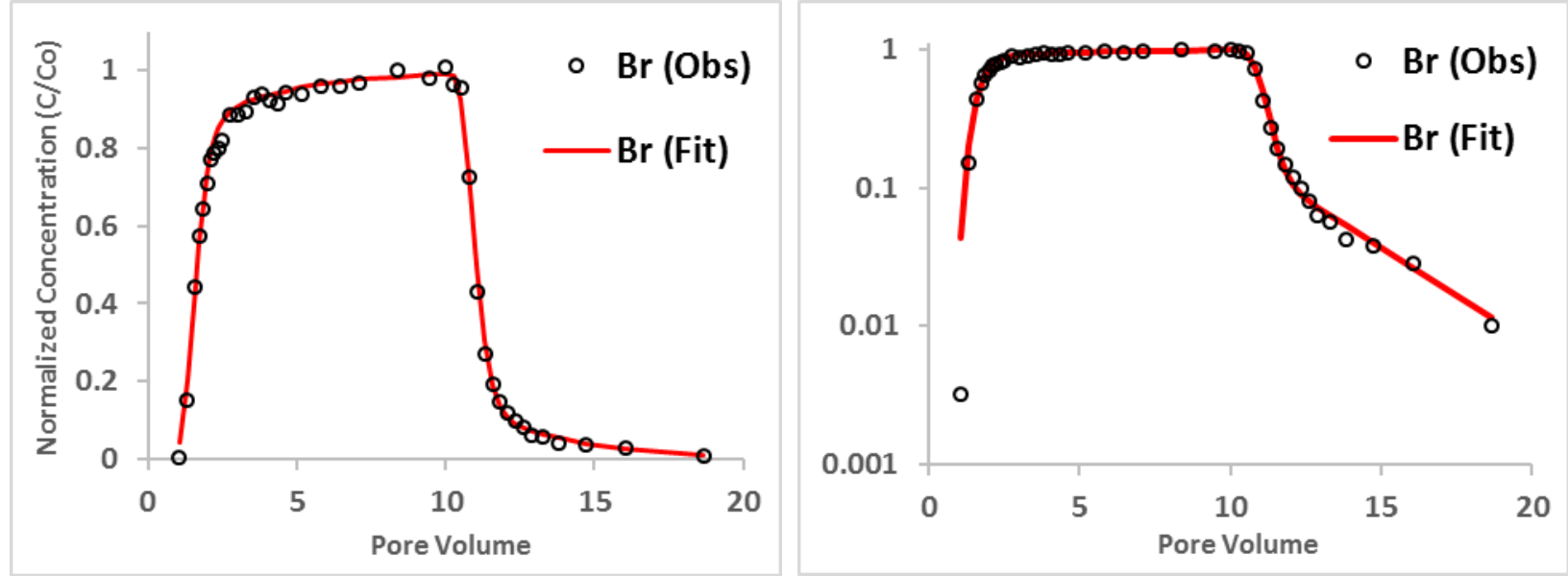

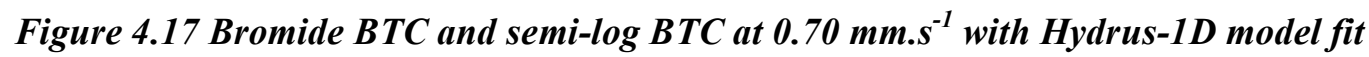




\begin{tabular}{cc|c|} 
Parameter & $\mathbf{0 . 3 5} \mathbf{~ m m . \mathbf { s } ^ { - 1 }}$ & $\mathbf{0 . 7 0 ~} \mathbf{~ m m . \mathbf { s } ^ { - 1 }}$ \\
\hline Saturated Hydraulic Conductivity $\left(\mathrm{K}_{\mathrm{s}}\right)\left(\mathbf{m m} . \mathbf{s}^{-1}\right)$ & $47.46 \pm 1.06$ & $48.16 \pm 0.21$ \\
\hline Longitudinal Dispersivity $\left(\mathbf{D}_{\mathrm{L}}\right)(\mathbf{m m})$ & $4.01 \pm 3.12$ & $9.21 \pm 0.86$ \\
\hline $\begin{array}{c}\text { Water Mass Transfer Coefficient Between } \\
\text { Mobile and Immobile Zones }(\boldsymbol{\omega})\left(\mathbf{s}^{-1} \times \mathbf{1 0}^{4}\right)\end{array}$ & $2.40 \pm 0.43$ & $2.68 \pm 0.57$ \\
\hline R-Squared Regression $\left(\mathbf{R}^{2}\right)(\%)$ & $99.5 \pm 0.5$ & $99.7 \pm 0.1$ \\
\hline
\end{tabular}

A good fit was found for both the 0.35 and $0.70 \mathrm{~mm} \cdot \mathrm{s}^{-1}$ bromide BTCs with average $\mathrm{R}^{2}$ values of $99.5 \%$ or greater. The saturated hydraulic conductivity and mass transfer coefficient are very similar for both cases, but the longitudinal dispersivity more than doubles with the increase in SD.

\subsubsection{Microspheres Ionic Strength Comparisons}

The microspheres were modeled with Hydrus-1D using a two-site kinetic (chemical nonequilibrium) model. The two-site model consisted of two attachment coefficients ( $\mathrm{K}_{\text {att1 }}$ and $\left.\mathrm{K}_{\mathrm{att} 2}\right)$ and two detachment coefficients $\left(\mathrm{K}_{\mathrm{det} 1}\right.$ and $\left.\mathrm{K}_{\mathrm{det} 2}\right)$. In addition to the attachment and detachment coefficients, the longitudinal dispersivity $\left(\mathrm{D}_{\mathrm{L}}\right)$ was also fitted. The values of hydraulic conductivity and immobile water content from the bromide transport fitting were used for the colloid transport model. Blocking was also taken into consideration for BTCs with sloped plateaus by fitting a maximum solids concatenation for each attachment site $\left(\mathrm{S}_{\max 1}\right.$ and $\left.\mathrm{S}_{\max 2}\right)$, but only after the best fit was obtained from fitting other parameters. The BTCs for both $200 \mathrm{~nm}$ and $1000 \mathrm{~nm}$ CML microspheres were fitted and are shown below in Figure 4.18 and 4.19. High and low ionic strength conditions are plotted together to highlight the effect of varying the ionic strength for each particle size. The Hydrus-1D fitted parameters for the CML microsphere BTCs are presented in Table 4.9. 
Particle Size: $200 \mathrm{~nm}$
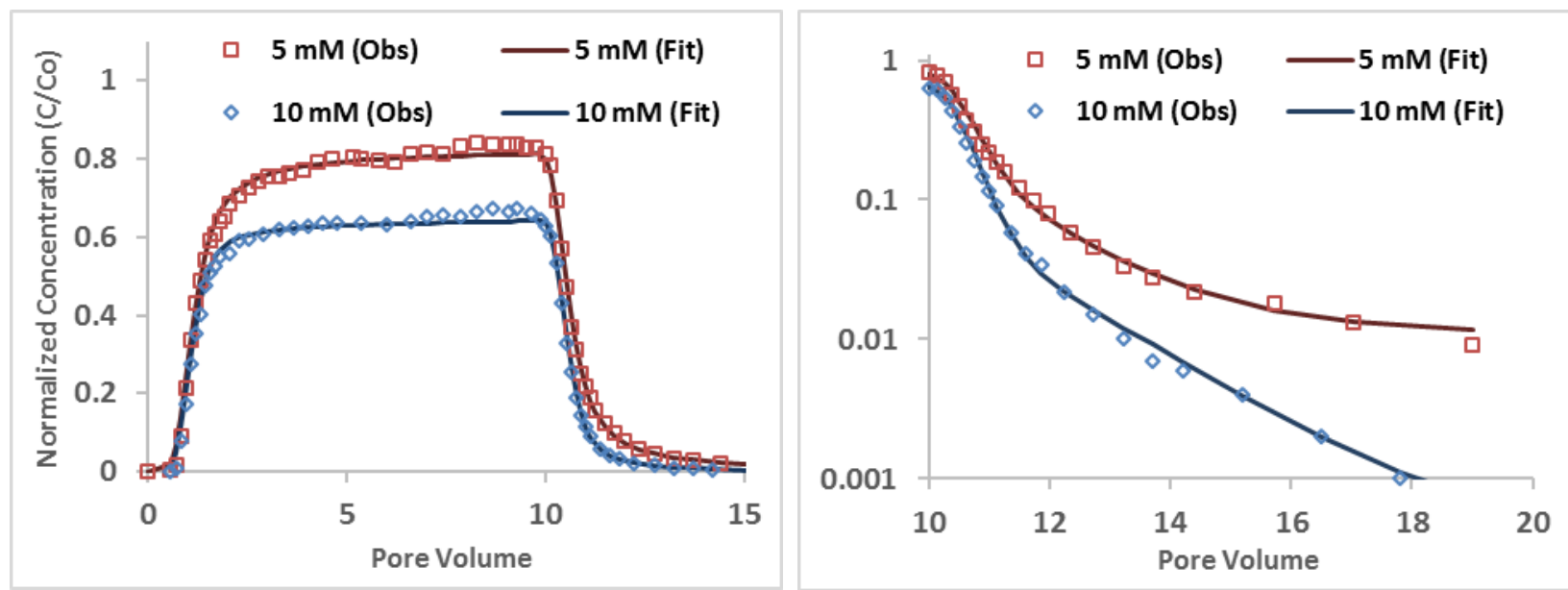

Figure 4.18 Ionic strength effects $200 \mathrm{~nm}$ CML microspheres with Hydrus-1D model fit. BTC and semi-log BTC at $0.35 \mathrm{~mm} . \mathrm{s}^{-1} \mathrm{SD}$

\section{Particle Size: $1000 \mathrm{~nm}$}
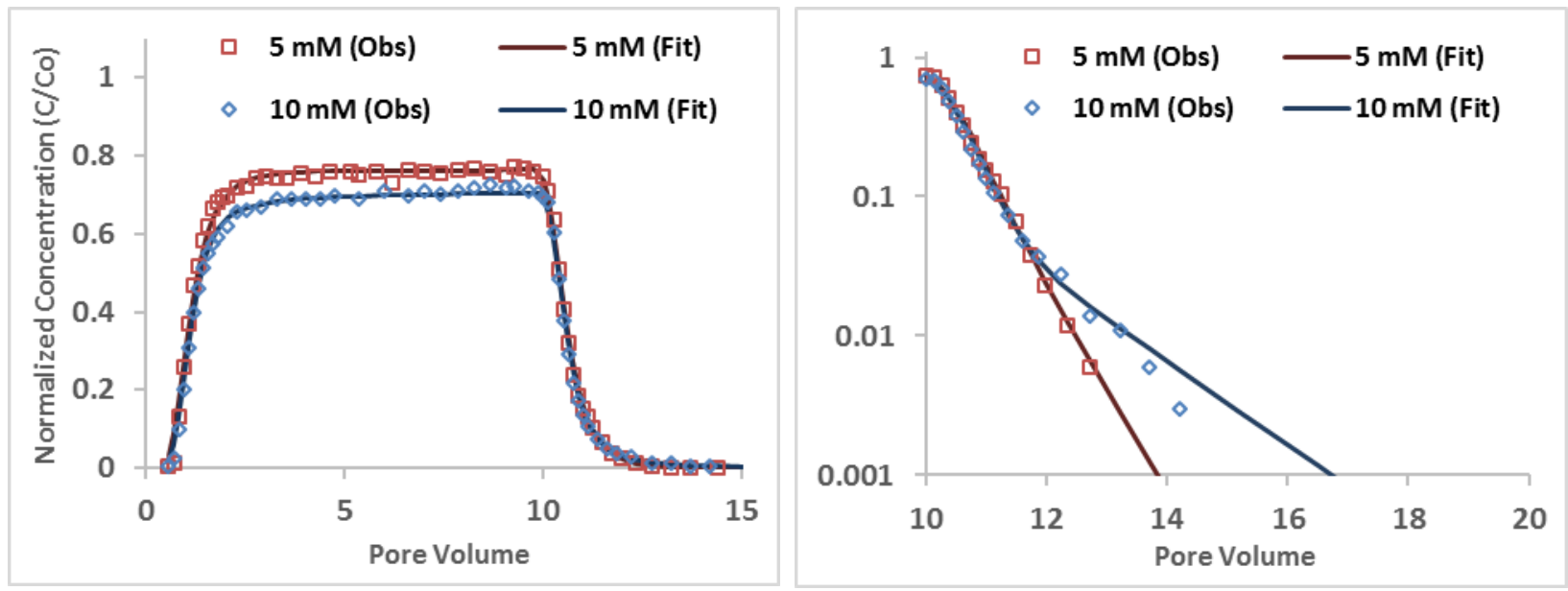

Figure 4.19 Ionic strength effects $1000 \mathrm{~nm}$ CML microspheres with Hydrus-1D model fit. BTC and semi-log BTC at $0.35 \mathrm{~mm} . \mathrm{s}^{-1} \mathrm{SD}$ 
Table 4.9 Hydrus 1D Parameter Estimation Unfavorable Attachment Ionic Strength Comparisons

$200 \mathrm{~nm}$

$1000 \mathrm{~nm}$

\begin{tabular}{|c|c|c|c|c|}
\hline Parameter & $5 \mathrm{mM}$ & $10 \mathrm{mM}$ & $5 \mathrm{mM}$ & $10 \mathrm{mM}$ \\
\hline Longitudinal Dispersivity $\left(D_{L}\right)(\mathrm{mm})$ & 16.5 & 15.1 & 19.9 & 15.6 \\
\hline Attachment Coefficient $1\left(K_{\text {att } 1}\right)\left(s^{-1}\right)$ & $2.59 \times 10^{-4}$ & $5.34 \times 10^{-4}$ & $3.25 \times 10^{-4}$ & $4.20 \times 10^{-4}$ \\
\hline Detachment Coefficient $1\left(K_{\operatorname{det} 1}\right)\left(s^{-1}\right)$ & $9.63 \times 10^{-6}$ & $1.95 \times 10^{-7}$ & $1.00 \times 10^{-10}$ & $1.00 \times 10^{-1 c}$ \\
\hline Attachment Coefficient $2\left(K_{\text {att } 2}\right)\left(\mathrm{s}^{-1}\right)$ & $2.38 \times 10^{-4}$ & $1.00 \times 10^{-4}$ & $2.17 \times 10^{-4}$ & $1.12 \times 10^{-4}$ \\
\hline Detachment Coefficient $2\left(K_{\text {det2 }}\right)\left(s^{-1}\right)$ & $1.00 \times 10^{-3}$ & $8.68 \times 10^{-4}$ & $2.50 \times 10^{-3}$ & $1.00 \times 10^{-3}$ \\
\hline R-Squared Regression $\left(\mathbf{R}^{2}\right)(\%)^{*}$ & $99.8(99.6)$ & $99.7(99.3)$ & $99.7(98.5)$ & $99.8(99.8)$ \\
\hline
\end{tabular}

*Value in parentheses represents $\boldsymbol{R}^{2}$ fit for duplicate experiment using same Hydrus fitting parameters

A good fit was obtained for the CML microspheres under all ionic strength and particle size conditions. The $\mathrm{R}^{2}$ value was above $98 \%$ for all tested cases. A good fit was found by making one attachment site reversible (high $\mathrm{K}_{\mathrm{det}}$ ) and one attachment site irreversible (low $\mathrm{K}_{\text {det }}$ ). The fitted dispersivities were higher for the microspheres than they were for bromide. The dispersivity decreased as ionic strength increased for both CML microsphere sizes. The increase in ionic strength resulted in an increase in $\mathrm{K}_{\mathrm{att} 1}$, a decrease in $\mathrm{K}_{\mathrm{att} 2}$, and a decrease in $\mathrm{K}_{\text {det2 }}$ for all scenarios. The only case where adjusting the value of $\mathrm{S}_{\max }$ noticeably improved the fit of the BTC was for the $200 \mathrm{~nm}$ CML microspheres at $5 \mathrm{mM}$ ionic strength because the plateau of the BTC was the most sloped. Adjusting $S_{\max }$ had no impact on the fit until it was lowered below approximately 20. The fitted values for $S_{\max 1}$ and $S_{\max 2}$ for the $200 \mathrm{~nm} 5 \mathrm{mM}$ ionic strength BTC was 13 and 5 respectively. The value of $\mathrm{S}_{\max }$ was kept above 50 for all other tested cases.

\subsubsection{Particle Size Comparisons}

BTCs were fit with Hydrus-1D for both AML and CML microspheres (favorable and unfavorable attachment conditions). The effect of particle size was examined for both favorable and unfavorable conditions by comparing the BTCs and fitted Hydrus-1D parameters of the $200 \mathrm{~nm}$ and $1000 \mathrm{~nm}$ microspheres. Both particle sizes were plotted together to highlight the differences with changing particle diameter. The fitted BTCs for both favorable and unfavorable conditions 
are shown in Figure 4.20 and 4.21. The Hydrus-1D fitted parameters for the CML and AML microsphere BTCs are presented in Table 4.10.

\section{Unfavorable Attachment}
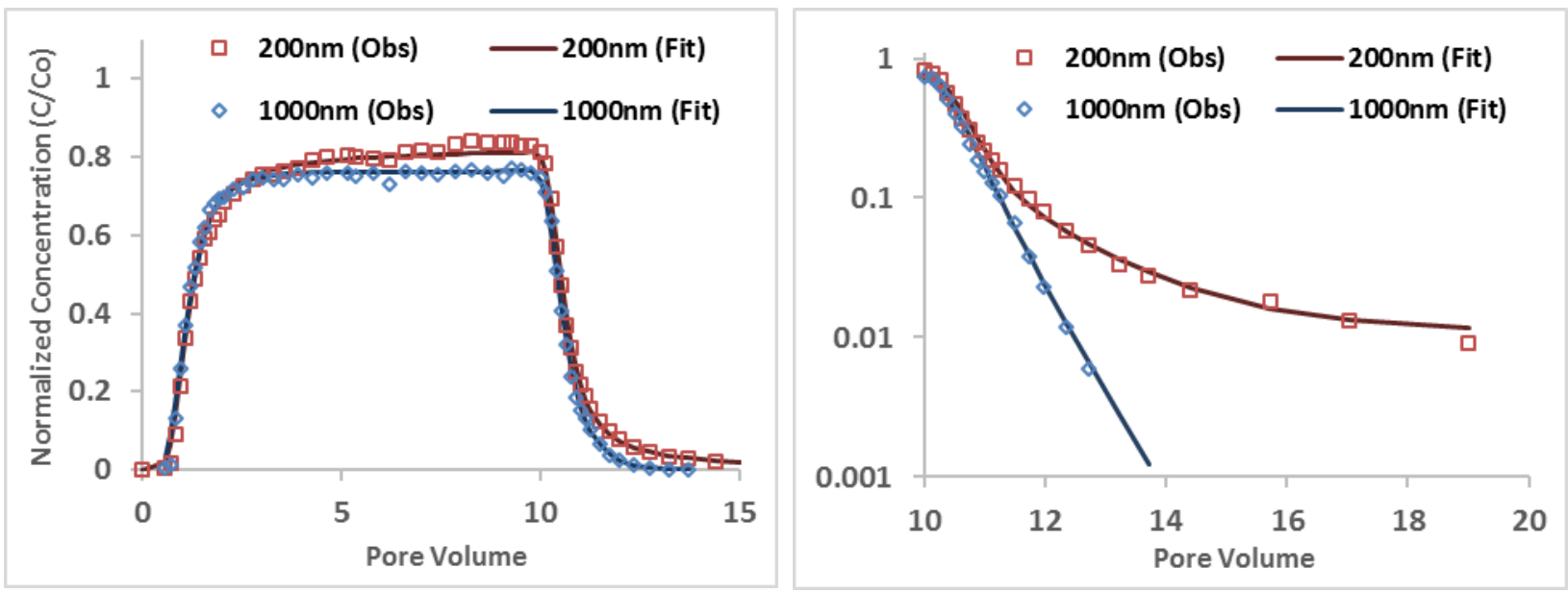

Figure 4.20 Particle size effects under unfavorable attachment conditions with Hydrus-1D model fit. BTC and semi-log BTC at $0.35 \mathrm{~mm} . \mathrm{s}^{-1}$ SD and $5 \mathrm{mM} \mathrm{IS}$

Favorable Attachment
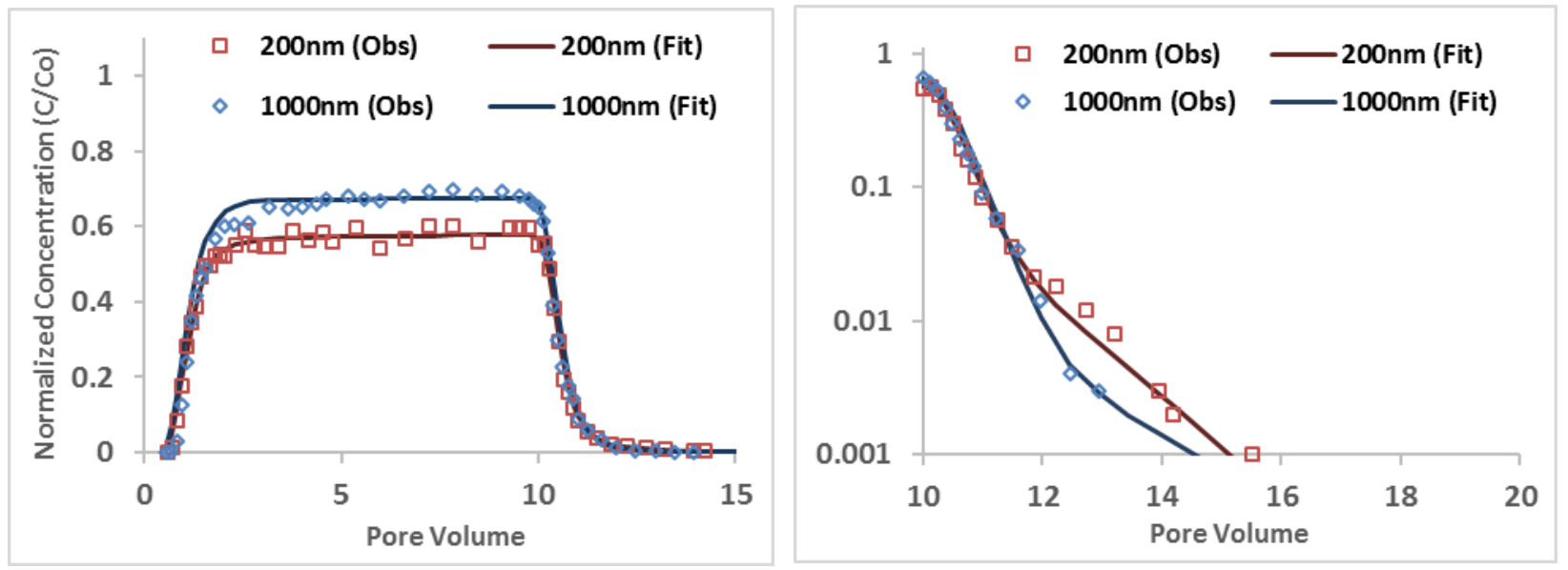

Figure 4.21 Particle size effects under favorable attachment conditions with Hydrus-1D model fit. BTC and semi-log BTC at $0.35 \mathrm{~mm}^{-1}$ SD and $5 \mathrm{mM} \mathrm{IS}$ 
Table 4.10 Hydrus 1D Parameter Estimation Particle Size Comparison for Favorable and Unfavorable Attachment Conditions

\begin{tabular}{|c|c|c|c|c|}
\hline \multirow[b]{2}{*}{ Parameter } & \multicolumn{2}{|c|}{ Unfavorable Attachment } & \multicolumn{2}{|c|}{ Favorable Attachment } \\
\hline & $200 \mathrm{~nm}$ & $1000 \mathrm{~nm}$ & $200 \mathrm{~nm}$ & $1000 \mathrm{~nm}$ \\
\hline Longitudinal Dispersivity $\left(D_{L}\right)(m m)$ & 16.5 & 19.9 & 15.8 & 19.3 \\
\hline Attachment Coefficient $1\left(K_{\text {att } 1}\right)\left(\mathrm{s}^{-1}\right)$ & $2.59 \times 10^{-4}$ & $3.25 \times 10^{-4}$ & $6.46 \times 10^{-4}$ & $4.67 \times 10^{-4}$ \\
\hline Detachment Coefficient $1\left(K_{\text {det1 }}\right)\left(s^{-1}\right)$ & $9.63 \times 10^{-6}$ & $1.00 \times 10^{-10}$ & $1.00 \times 10^{-10}$ & $1.00 \times 10^{-10}$ \\
\hline Attachment Coefficient $2\left(K_{\text {att2 }}\right)\left(\mathrm{s}^{-1}\right)$ & $2.38 \times 10^{-4}$ & $2.17 \times 10^{-4}$ & $1.00 \times 10^{-4}$ & $2.52 \times 10^{-5}$ \\
\hline Detachment Coefficient $2\left(K_{\text {det2 }}\right)\left(s^{-1}\right)$ & $1.00 \times 10^{-3}$ & $2.50 \times 10^{-3}$ & $1.26 \times 10^{-3}$ & $1.00 \times 10^{-3}$ \\
\hline R-Squared Regression $\left(\mathbf{R}^{2}\right)(\%)^{*}$ & $99.8(99.6)$ & $99.7(98.5)$ & $99.5(98.8)$ & $98.4(99.1)$ \\
\hline
\end{tabular}

*Value in parentheses represents $\boldsymbol{R}^{2}$ fit for duplicate experiment using same Hydrus fitting parameters

A good fit was found for both particle sizes under favorable and unfavorable attachment conditions, with all $\mathrm{R}^{2}$ values being greater than $98 \%$. The results show that for both favorable and unfavorable attachment conditions the dispersivity is higher for the larger $1000 \mathrm{~nm}$ microspheres. For unfavorable attachment conditions, the attachment coefficients are not significantly impacted by the change in particle size. There is a decrease in $\mathrm{K}_{\text {det1 }}$, and an increase in $\mathrm{K}_{\text {det2 }}$ as the diameter of the CML microspheres increases. For favorable attachment conditions, the detachment coefficients are not significantly impacted by the change in microsphere size. The attachment coefficients of the AML microspheres both decrease as the particle diameter increases.

\subsubsection{Favorable vs Unfavorable Attachment}

The differences between favorable and unfavorable attachment conditions were compared by examining the BTCs and Hydrus-1D fitting parameters for AML and CML microspheres. The AML and CML microsphere BTCs under the same conditions (size, SD, IS) were plotted together to highlight differences in transport with changing microsphere charge. The fitted BTCs for both particle sizes are shown in Figure 4.22 and 4.23. The Hydrus-1D fitted transport parameters are presented in the previous section in Table 4.10. 
Particle Size: $200 \mathrm{~nm}$
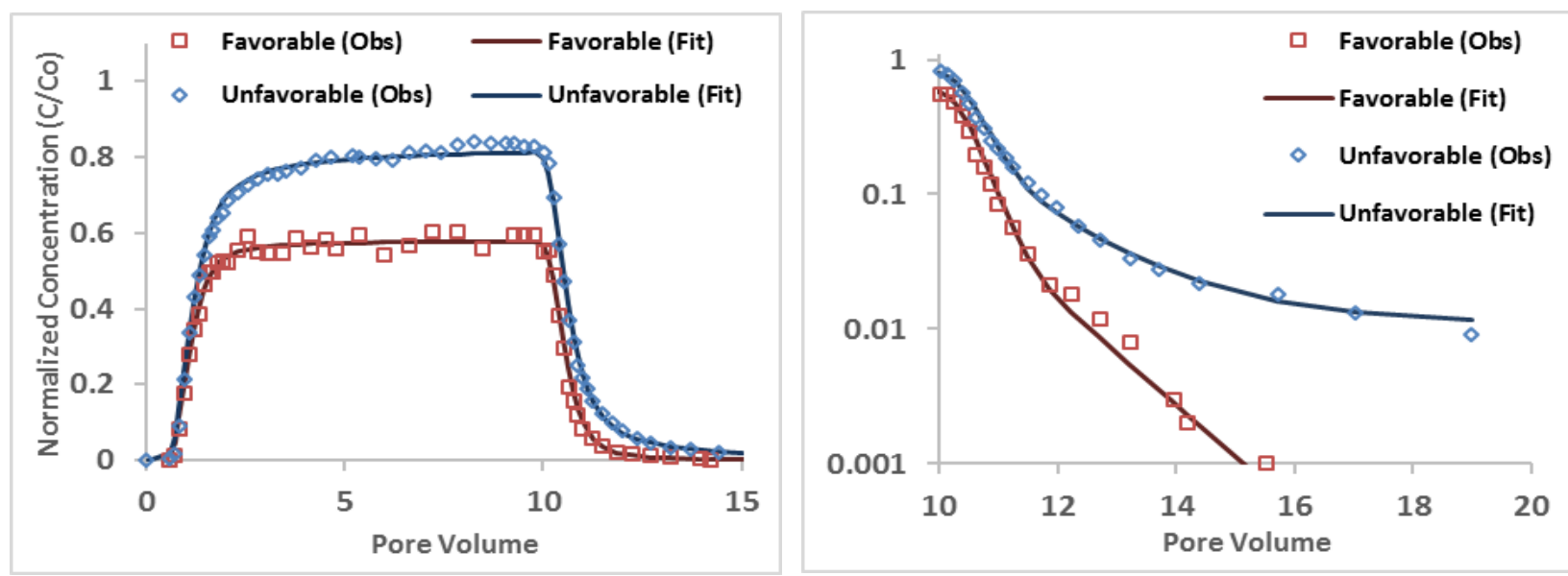

Figure 4.22 Favorable vs Unfavorable attachment conditions for $200 \mathrm{~nm}$ microspheres with Hydrus-

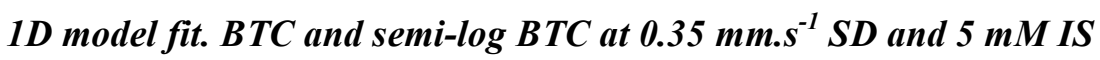

\section{Particle Size: $1000 \mathrm{~nm}$}
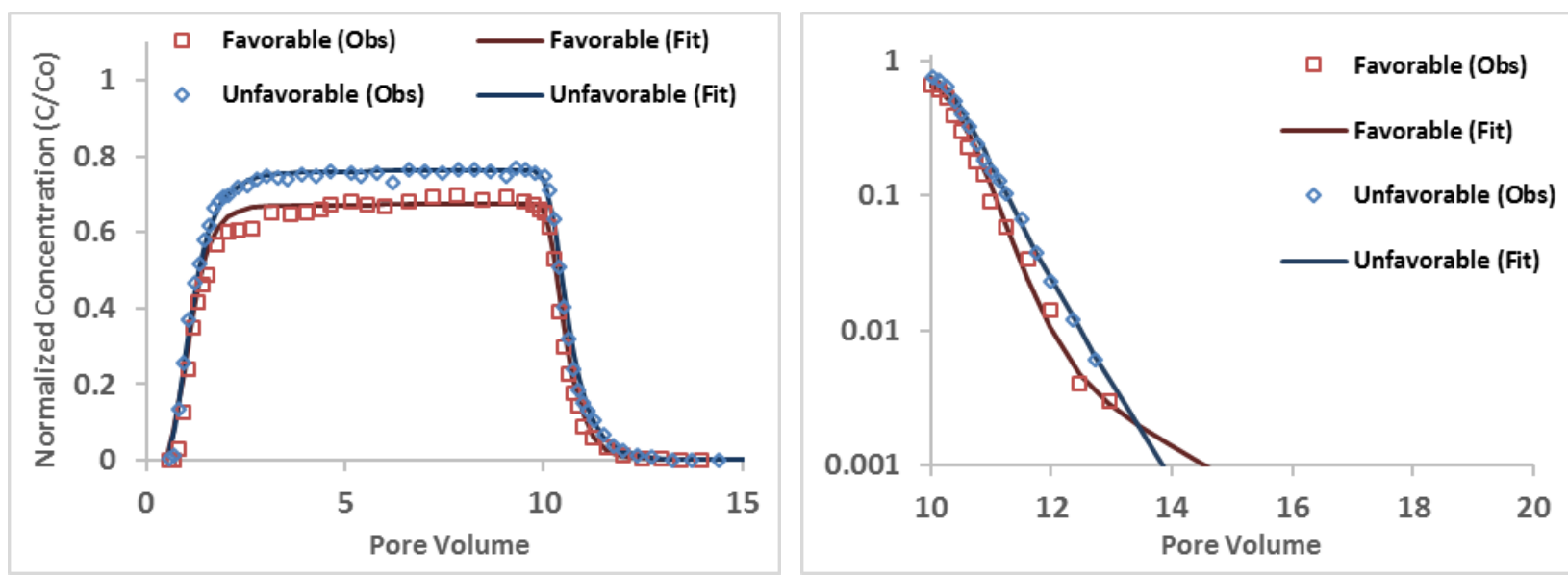

Figure 4.23 Favorable vs Unfavorable attachment conditions for $1000 \mathrm{~nm}$ microspheres with Hydrus-

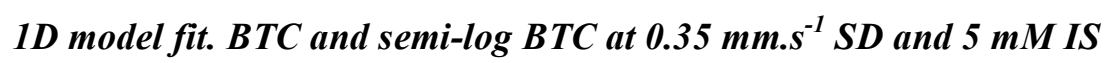

There is not a significant change in dispersivity for similarly sized microspheres between favorable and unfavorable attachment conditions. The AML microspheres have a slightly smaller dispersivity than the CML microspheres for both particle diameters. The value of $\mathrm{K}_{\text {attl }}$ is higher for AML microspheres than CML microspheres, with the difference being more pronounced for 
the smaller particle size. The value of $K_{\text {att2 }}$ is higher for CML microspheres than AML microspheres, with the difference being more pronounced for the larger particle size. The value of $\mathrm{K}_{\text {det1 }}$ is very low for all cases $\left(1.00 \times 10^{-10} \mathrm{~s}^{-1}\right)$ except for the $200 \mathrm{~nm}$ CML microspheres, which is the BTC that has the most tailing.

\subsection{Compsim 3D Modeling}

The 3D modeling software Compsim was used to model bromide transport and the $200 \mathrm{~nm}$ microsphere transport under favorable and unfavorable attachment conditions. An aperture correction factor of 1.45 was applied to scale the aperture and match the model and experimental head loss. Fitted parameters such as the matrix porosity, the dispersivity, and a porosity correction factor were taken from the bromide transport model and used in the colloid transport model.

\subsubsection{Bromide Transport}

The bromide transport tests were modeled at both 0.35 and $0.70 \mathrm{~mm} . \mathrm{s}^{-1}$ specific discharge. The parameters that were fitted were matrix porosity (inner and outer rock layer), dispersivity, and a porosity scaling factor. The function of the porosity scaling factor was to assign a porosity to the areas in the fracture space. The porosity was calculated by dividing the aperture by the porosity scaling factor to get a value from 0 to 1 . The porosity scaling factor was fit first because it had a significant impact on flow velocity and changes would cause a left or right shift of the fitted BTC. After the porosity scaling factor was set, the dispersivity and matrix porosity were adjusted to fit the shape and tailing of the observed BTC. Figure 4.24 and 4.25 show the final BTC fit for 0.35

and $0.70 \mathrm{~mm} . \mathrm{s}^{-1}$ specific discharge respectively. The final fitted parameters are shown in Table 4.11. 

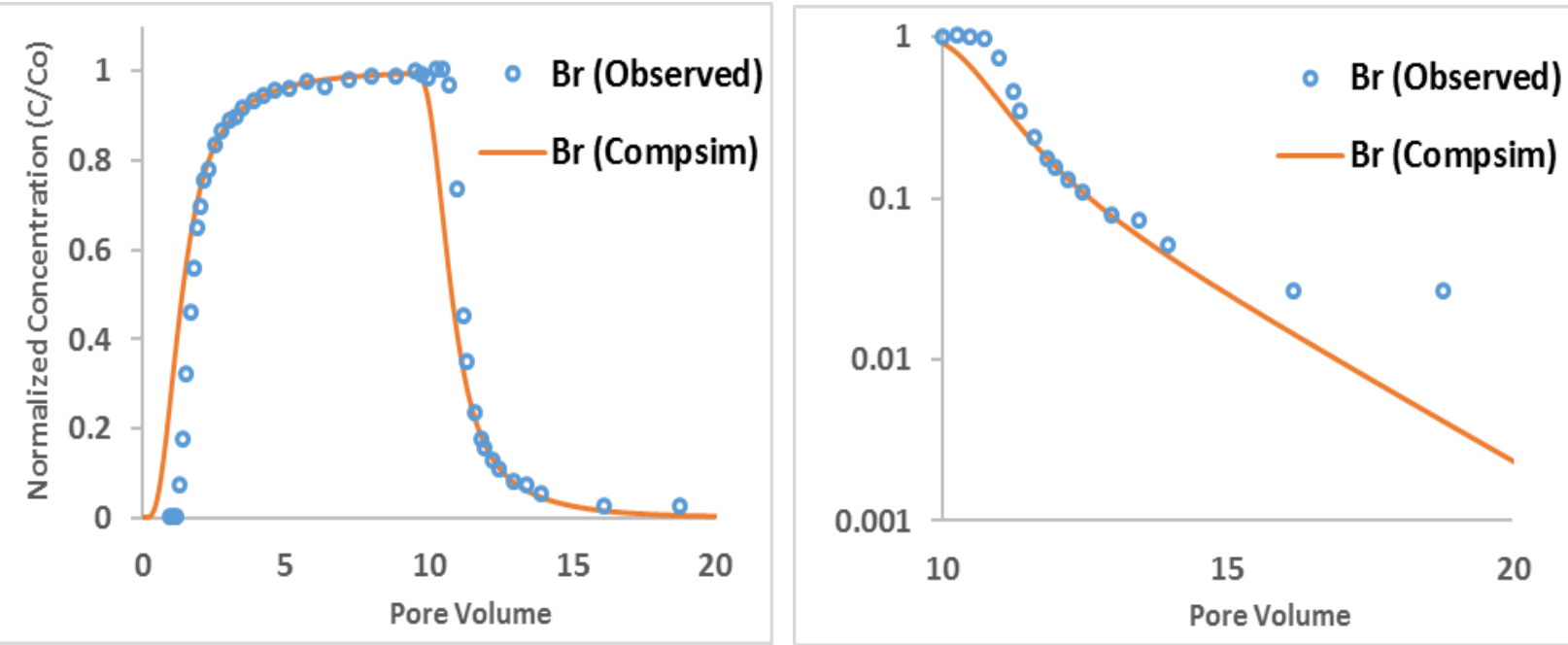

Figure 4.24 Bromide experimental and semi-log BTC with Compsim model fit at $0.35 \mathrm{~mm} . \mathrm{s}^{-1} \mathrm{SD}$
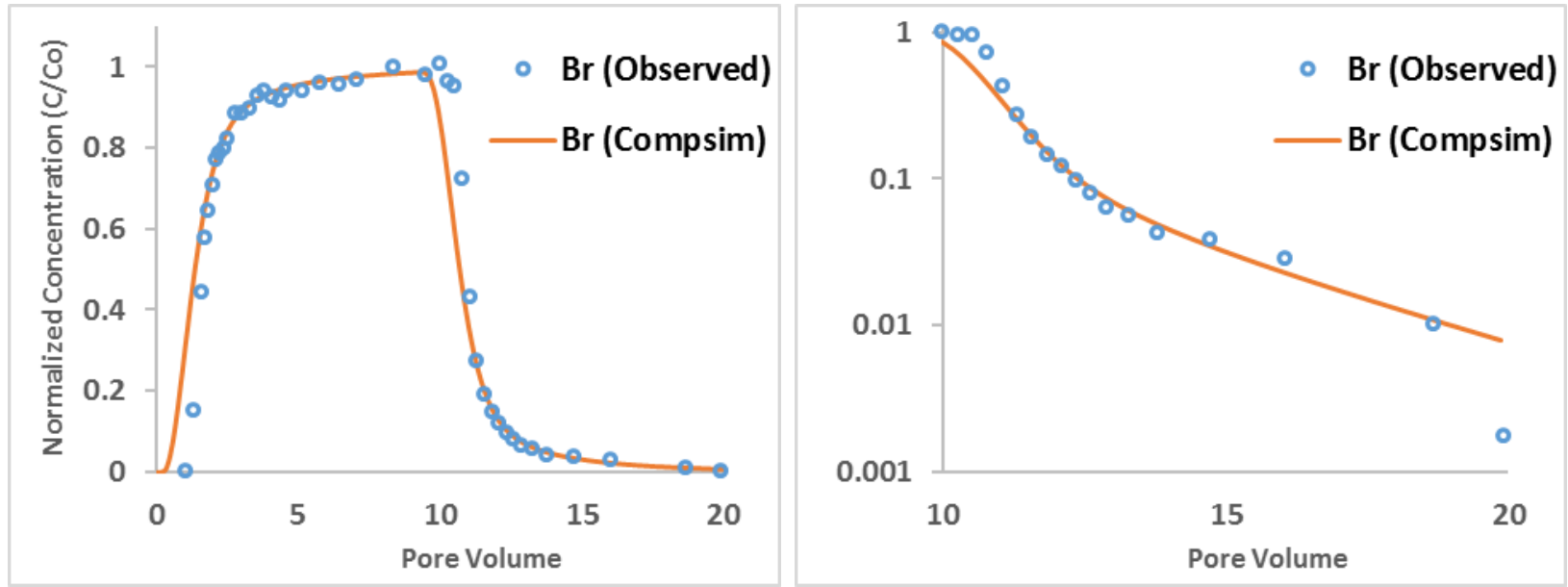

Figure 4.25 Bromide experimental and semi-log BTC with Compsim model fit at $0.70 \mathrm{~mm} . \mathrm{s}^{-1} \mathrm{SD}$

Table 4.11 Compsim Fitting Parameters for 0.35 and $0.70 \mathrm{~mm} . \mathrm{s}^{-1} \mathrm{Br}$ Transport

Parameter

\begin{tabular}{|c|c|} 
Parameter & Fitted Value \\
\hline Porosity Scaling Factor $(\mathbf{m m})$ & 2.1 \\
\hline Longitudinal Dispersivity $\left(\mathbf{D}_{\mathrm{L}}\right)(\mathbf{m m})$ & 20 \\
\hline Inner Matrix Porosity $(\%)$ & 25 \\
\hline Outer Matrix Porosity $(\%)$ & 10 \\
\hline
\end{tabular}


The fitted parameters were kept the same for both 0.35 and $0.70 \mathrm{~mm} . \mathrm{s}^{-1}$ specific discharge because the observed BTCs were very similar. A good fit was obtained for the peak and tailing portions of the BTC, although the model predicted earlier arrival of bromide and an earlier decrease in concentration from the peak. A higher inner matrix porosity was used to account for the microfractures and channels that were created during the fracturing process. The fitted outer matrix porosity matches up well with the $10.8 \%$ matrix porosity that was determined in an earlier analysis of a sample of the sandstone (Section 4.1).

\subsubsection{Colloid Transport}

An equivalent collector diameter, attachment and detachment coefficients, and a sticking efficiency were fitted for the colloid transport model in Compsim. The collector diameter had to be set prior to adjusting the other fitting parameters because it has a large impact on the peak of the BTC. The collector diameter was kept the same for both favorable and unfavorable model runs so that the other fitting parameters under both conditions could be compared. Figure 4.28 shows the effect that changing the collector diameter while keeping all other fitting parameters the same has on the BTC for favorable and unfavorable conditions. Increasing the collector diameter increases the height of the BTC peak without much effect on the BTC shape. A collector diameter of $200 \mu \mathrm{m}$ was selected. After the selection of the collector diameter, the sticking efficiency was fitted because it also had a major impact on the peak of the BTC. After the correct BTC height was found the attachment and detachment coefficients were fitted. The attachment and detachment coefficients were important for matching the shape and tailing of the BTC. There were four capture zones in the seven-layer fracture that each had their own attachment and detachment coefficients: outer rock matrix (layer 1 and 7), inner rock matrix (layer 2 and 6), upper fracture (layer 3), and lower fracture (layer 5). Layer 4 does not have attachment and detachment coefficients because it is the center layer of the fracture and there would be no attachment or detachment. The primary fitting was done using the two sets of attachment and detachment coefficients in the fracture zone to keep the fitting from getting too complicated. In addition, there would be little to no flow of microspheres through the rock matrix so changing the attachment and detachment coefficients in these zones had very little effect on the fit (especially in the outer matrix). The final fits for both favorable and unfavorable attachment conditions of the $200 \mathrm{~nm}$ microspheres is shown in Figure 4.26 and 4.27. The fitted Compsim parameters are presented in Table 4.9. 

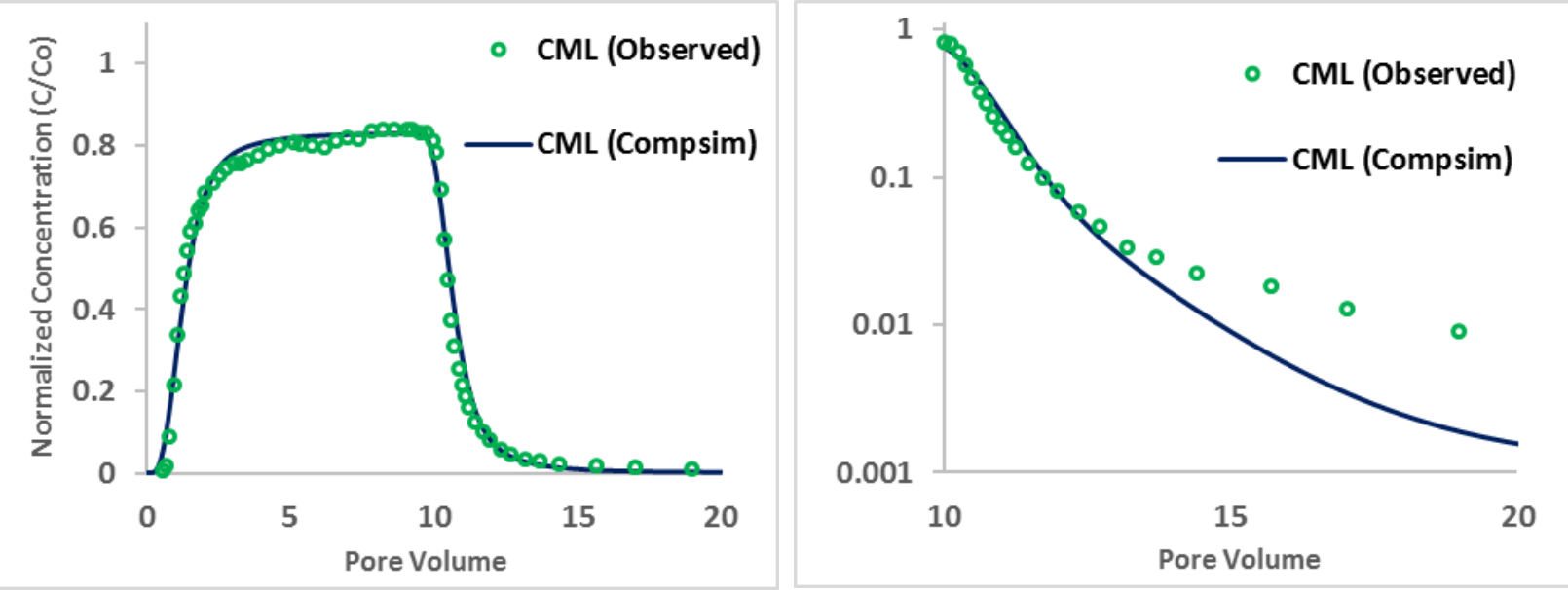

Figure 4.26 CML microsphere (unfavorable attachment) experimental BTC and semi-log BTC with Compsim model fit at $0.35 \mathrm{~mm} . \mathrm{s}^{-1}$ SD and $5 \mathrm{mM} I S$
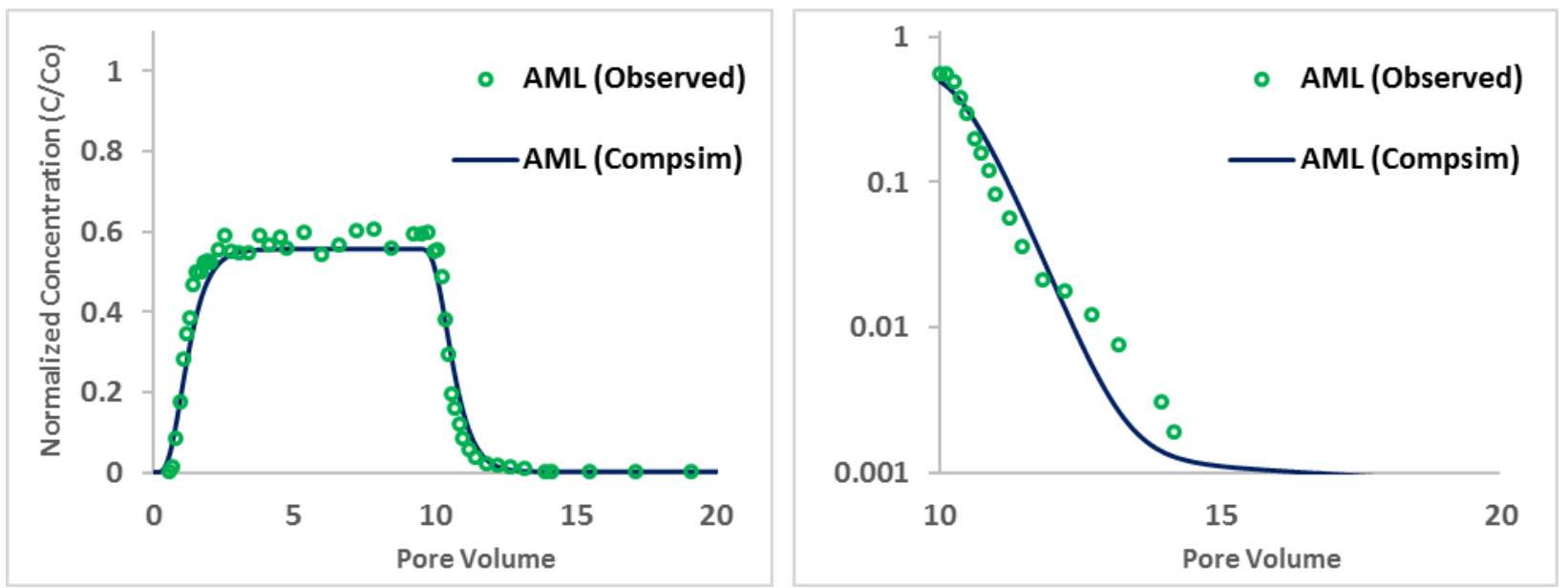

Figure 4.27 AML microspheres (favorable attachment) experimental BTC and semi-log BTC with Compsim model fit at $0.35 \mathrm{~mm}^{-1} \mathrm{SD}$ and $5 \mathrm{mM} \mathrm{IS}$

The fit was good for both favorable and unfavorable attachment. The tailing portion of the unfavorable condition is shown to be slightly underestimated by the model when looking at the semi-log BTC. The tailing of the favorable condition is a better fit, with both the model and the observed values following a log-linear trend after $10 \mathrm{PV}$. 

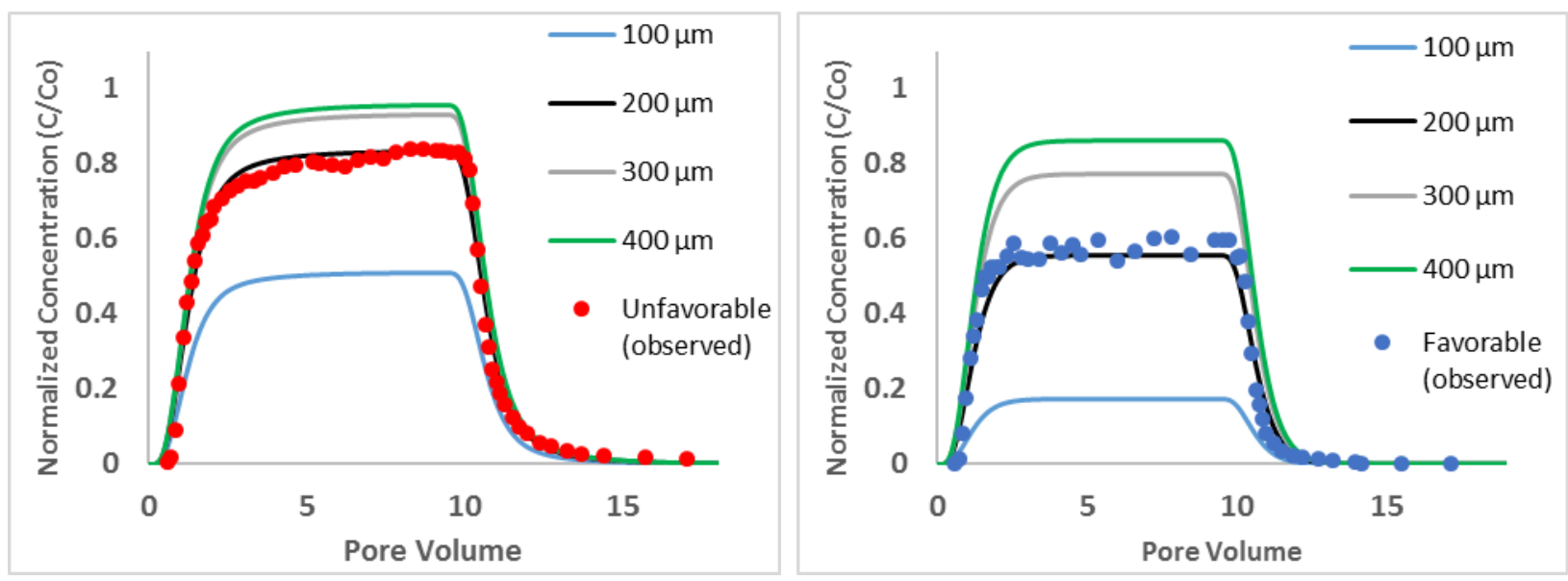

Figure 4.28 Effect of collector diameter on Compsim model fit

Table 4.12 Compsim Fitting Parameters for Microsphere Transport

\begin{tabular}{c|c|c|} 
Parameter & Unfavorable Attachment & Favorable Attachment \\
\hline Attachment water 1 $\left(\mathbf{K}_{\mathrm{aw} 1}\right)\left(\mathbf{s}^{-1}\right)$ & $5.00 \times 10^{-4}$ & $5.00 \times 10^{-5}$ \\
\hline Attachment water 2 $\left(\mathbf{K}_{\mathrm{aw} 2}\right)\left(\mathbf{s}^{-1}\right)$ & $5.00 \times 10^{-5}$ & $9.00 \times 10^{-4}$ \\
\hline Detachment water 1 $\left(\mathbf{K}_{\mathrm{dw} 1}\right)\left(\mathbf{s}^{-1}\right)$ & $1.00 \times 10^{-3}$ & $1.00 \times 10^{-8}$ \\
\hline Detachment water 2 $\left(\mathbf{K}_{\mathrm{dw} \mathbf{2}}\right)\left(\mathbf{s}^{-1}\right)$ & $1.00 \times 10^{-8}$ & $1.00 \times 10^{-8}$ \\
\hline Sticking Efficiency $(\boldsymbol{\alpha})$ & $1.20 \times 10^{-4}$ & $2.70 \times 10^{-4}$ \\
\hline
\end{tabular}

The results show that the sticking efficiency for favorable attachment is more than 2 times greater than it is for unfavorable attachment. The unfavorable attachment conditions required the attachment and detachment coefficients be set so that one zone represented reversible attachment $\left(\mathrm{K}_{\mathrm{dw} 1}\right.$ larger than $\left.\mathrm{K}_{\mathrm{aw} 1}\right)$ and one zone represented irreversible attachment $\left(\mathrm{K}_{\mathrm{dw} 2}\right.$ much smaller than $\mathrm{K}_{\mathrm{aw} 2}$ ). The favorable attachment conditions were fit by making both capture zones irreversible, and increasing the magnitude of one of the attachment coefficients $\left(\mathrm{K}_{\mathrm{aw} 2}\right)$. The concentration distribution of $200 \mathrm{~nm}$ microspheres under both unfavorable and favorable conditions in the middle layer of the fracture (layer 4) is shown in Figure 4.29. An attached microsphere distribution is presented in Figure 4.30 to illustrate the differences caused by changing the attachment and 
detachment coefficients. The top fracture layer (layer 3) is shown for unfavorable attachment because it represents the reversible attachment zone, whereas the bottom fracture layer (layer 5) is shown for favorable attachment because it represents the high attachment irreversible zone.

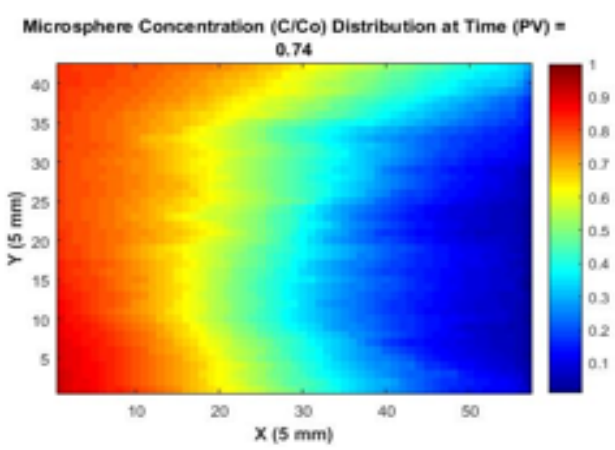

Microsphere Concentration (C/Co) Distribution at Time (PV) =

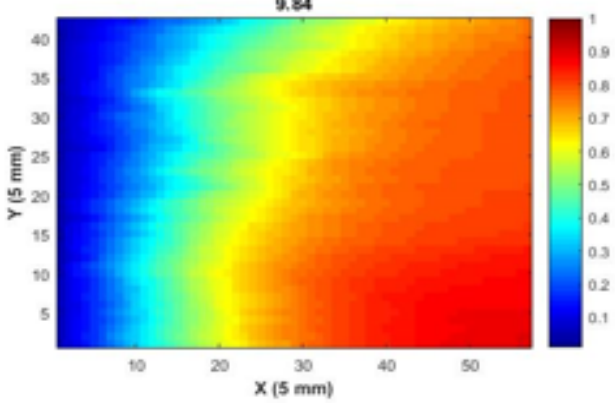

Microsphere Concentration (C/Co) Distribution at Time (PV) =

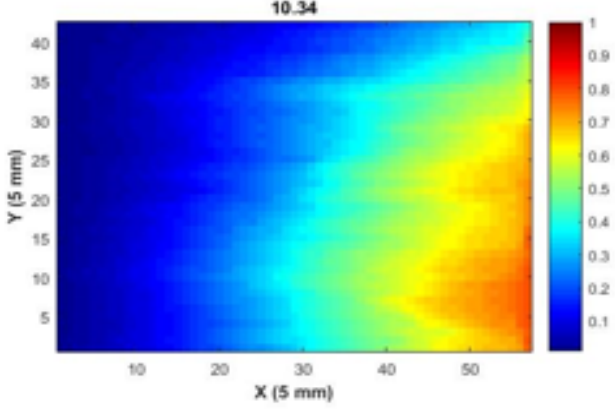

Microsphere Concentration (C/Co) Distribution at Time (PV) =

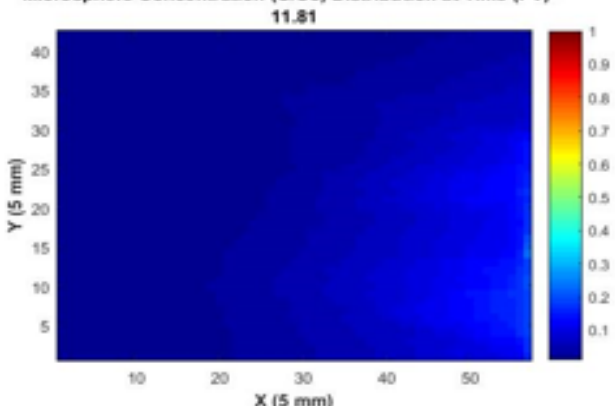

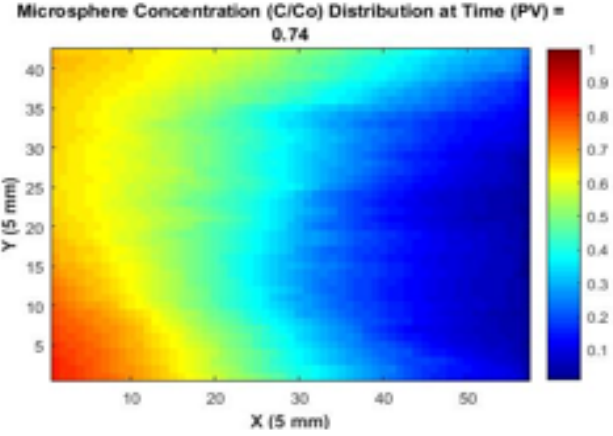

Microsphere Concentration (CiCo) Distribution at Time (PV) =

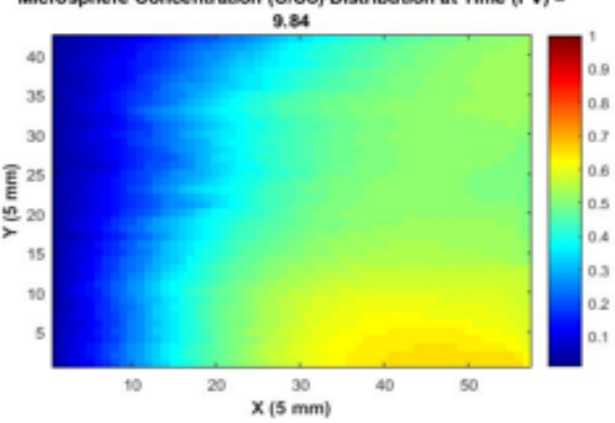

Microsphere Concentration (C/Co) Distribution at Time (PV) =

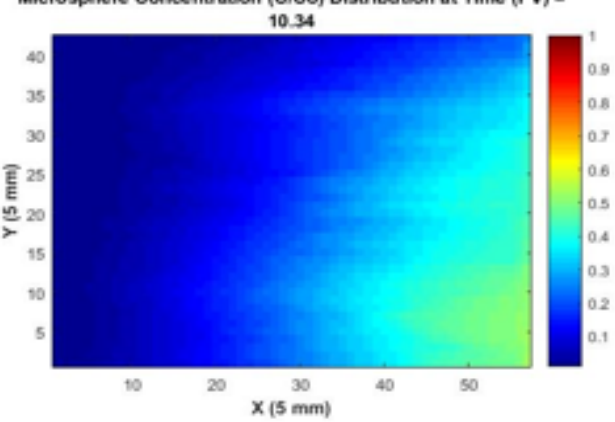

Microsphere Concentration (C/Co) Distribution at Time (PV) =

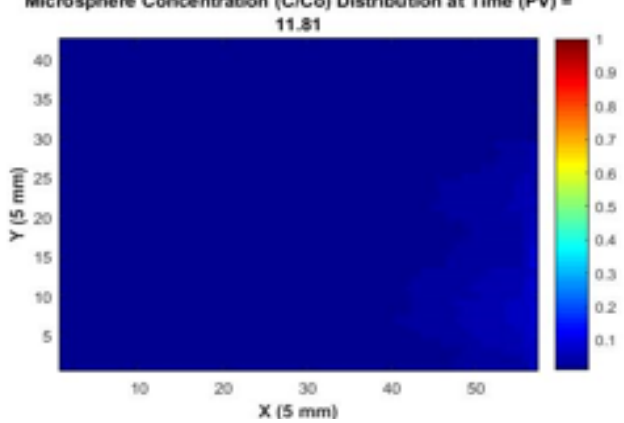

Figure 4.29 Unfavorable (left) and favorable (right) concentration distribution in middle fracture layer (layer 4) for $200 \mathrm{~nm}$ microspheres at $0.35 \mathrm{~mm} . \mathrm{s}^{-1}$ SD and $5 \mathrm{mM}$ IS. Flow Direction is left to right. 

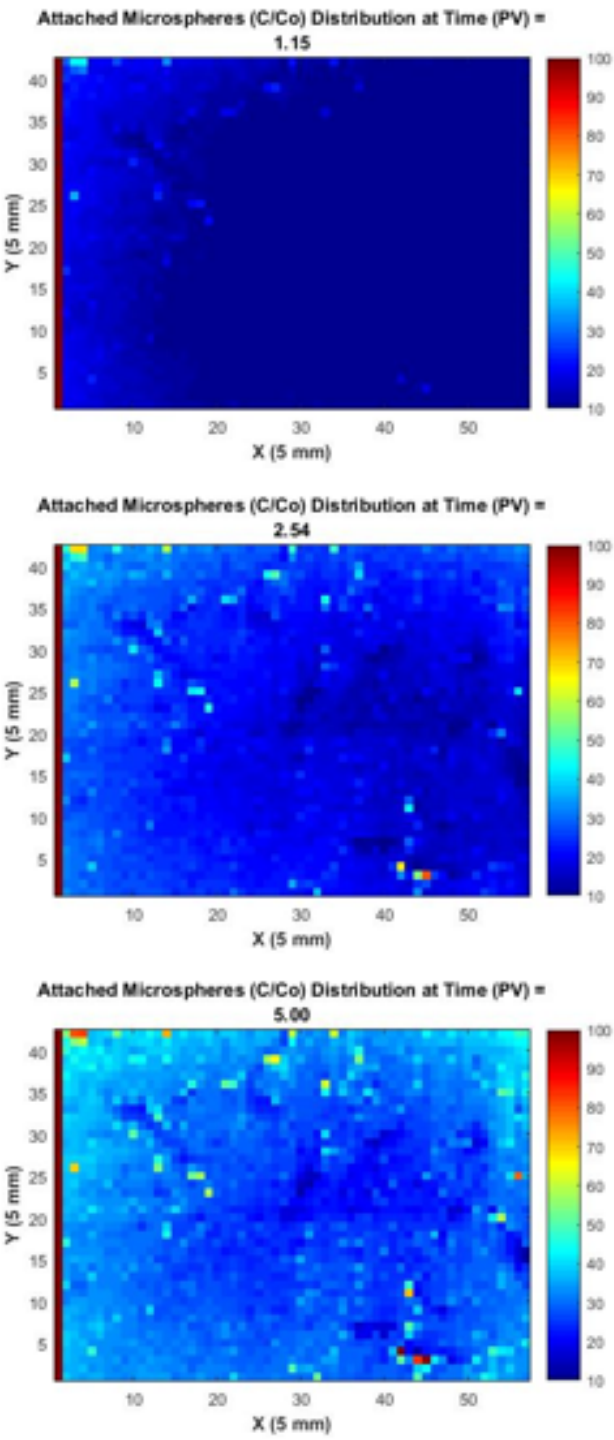

Attached Microspheres (C/Co) Distribution at Time (PV) =

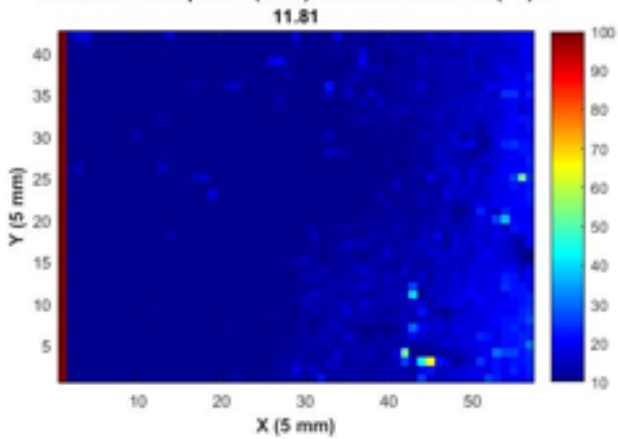

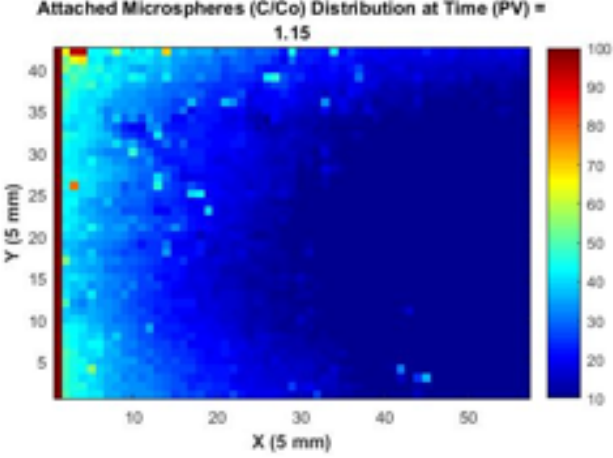

Attached Microspheres (C/Co) Distribution at Time $(\mathrm{PV})=$

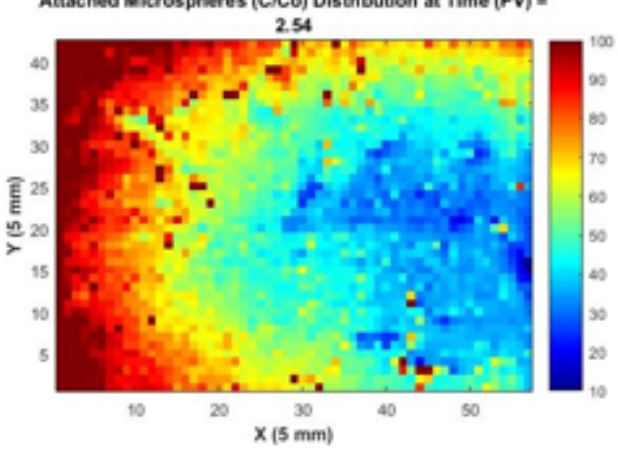

Attached Microspheres (CJCo) Distribution at Time (PV) =

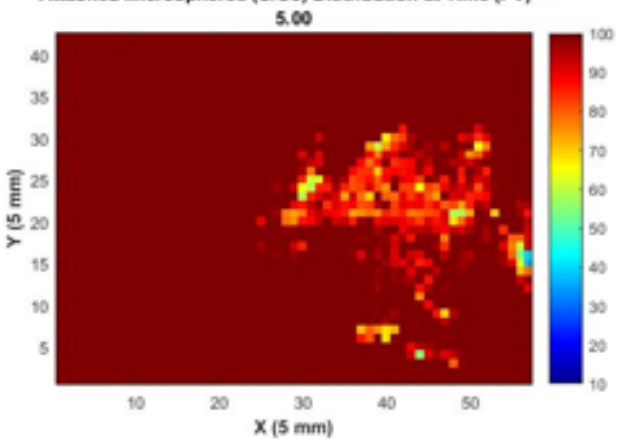

Attached Microspheres (C/Co) Distribution at Time (PV) =

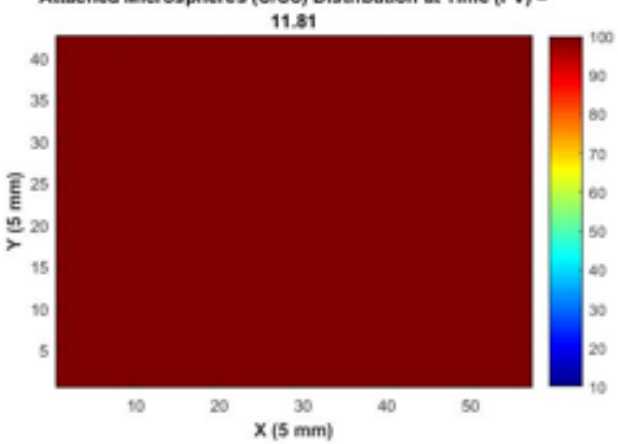

Figure 4.30 Unfavorable (left) reversible attachment (layer 3) and favorable (right) irreversible attachment (layer 5) attached microsphere distribution for $200 \mathrm{~nm}$ microspheres at $0.35 \mathrm{~mm} . \mathrm{s}^{-1} \mathrm{SD}$ and $5 \mathrm{mM}$ IS. Flow direction is left to right. 
Figure 4.29 and 4.30 show how the different attachment conditions impacted the transport of the $200 \mathrm{~nm}$ microspheres. In the concentration distribution (Figure 4.29), unfavorable attachment shows higher $\mathrm{C} / \mathrm{C}_{\mathrm{o}}$ values and a longer period of time with visible concentration, which is consistent with more tailing. The differences become even more apparent when examining the attached microsphere distribution in Figure 4.30. The favorable attachment conditions show significantly higher attachment than the unfavorable conditions and no noticeable decrease in attached micropsheres after the flush is started at 9.4 PV. The unfavavorable conditions show a clear decrease in attached microspheres after the flush at 9.4 PV, which is consistent with reversible attachment. 


\section{Chapter 5 \\ Discussion}

\section{Discussion}

\subsection{Solute Transport}

Bromide was used as a conservative tracer in this study and analyzed at specific discharges of 0.35 and $0.70 \mathrm{~mm} \cdot \mathrm{s}^{-1}$. The mass recovery for all tests was between 93 and $97 \%$ with a peak $\mathrm{C} / \mathrm{C}_{\mathrm{o}}$ close to 1 . The bromide transport was slower than both microsphere sizes for all conditions tested, which is consistent with several results from the literature [31], [139], [153], [154]. The results showed no impact from changing specific discharge or ionic strength conditions, which was expected for a conservative tracer. The overall shape of the BTC stayed very similar and the mean residence time decreased almost linearly with increasing specific discharge. The solute being in the fracture for a longer time (due to a lower SD) should provide more opportunity for diffusion into immobile areas such as the matrix or stagnation zones. The result of more diffusion into immobile zones would be a more sloped BTC plateau and a longer tailing section due to solute slowly diffusing back into the mobile fracture flow during flushing. The likely reason that this change in BTC shape was not observed in this study was that the change in specific discharge from $0.35 \mathrm{~mm} . \mathrm{s}^{-1}$ to 0.70 mm.s ${ }^{-1}$ was not significant enough to impact the shape of the BTC. The shape may have been affected if a larger difference in specific discharge was tested by including a trial at a much lower flow rate, which would result in a lower Peclet number and more diffusion-dominated transport.

The importance of immobile zones and matrix porosity on solute transport is shown clearly in both the experimental and modeling results. Comparing the bromide and microsphere BTCs, the effects of matrix diffusion can be seen in the increased tailing and longer retention time of the bromide compared to the microspheres. Bromide has a higher diffusion coefficient than both the microsphere sizes, which results in more diffusion into stagnant water areas and the matrix. Differentiating matrix diffusion, diffusion into stagnant flow zones, and dispersion can be very challenging in fractured rock [123], but it is evident when modeling the experimental results that factors such as matrix porosity and immobile water content have a major impact on transport. In modeling the bromide transport with Hydrus-1D with a dual porosity model, one of the primary factors in fitting the shape of the BTC was to select the right fraction of immobile water. The immobile water content that provided the best fit was $25 \%$, but the model does not provide any 
information on the relative contributions of matrix porosity and stagnation zones to the immobile water content. The matrix porosity determined from SEM-BSE analysis was $10.8 \pm 2.5 \%$. There was evidence of cracks and fissures on the fracture surface developed during the fracturing process that have the potential to be stagnation zones. The $25 \%$ immobile water content is likely a combination of the matrix porosity, fracture surface cracks and fissures, and low aperture no flow areas.

The 3D model (Compsim) required the matrix porosity to be fit to get the correct BTC shape. The outer matrix was set at $10 \%$ to match the SEM-BSE results while the inner matrix layer had to be set at a higher value (25\%). The requirement for a higher inner matrix porosity is more evidence that the cracks and fissures on the fracture surface are contributing to the immobile water content.

\subsection{Microsphere Transport}

\subsubsection{Fracture Properties Impact}

There are several fracture and sandstone properties that were important to the transport of microspheres. The zeta potential of the sandstone was measured and it was found to be negative under all solution conditions used in these transport tests. The result of this is that the positively charged AML microspheres will generate favorable conditions while the negatively charged CML microspheres will generate unfavorable conditions. The zeta potential of the sandstone should be affected by the ionic strength and $\mathrm{pH}$ of the solutions; studies show higher ionic strength and lower $\mathrm{pH}$ both result in a less negative sandstone zeta potential [16]. The consequence of a less negative sandstone zeta potential for unfavorable attachment conditions is that the electrostatic repulsive forces between the negatively charged sandstone surface and CML microspheres are not as strong, which could lead to more deposition. Under favorable attachment conditions, the less negative zeta potential would have the opposite effect, leading to less deposition due to reduced electrostatic attractive forces. The experimental results showed that under favorable attachment conditions the microsphere transport was not significantly impacted by increasing the ionic strength, while under unfavorable conditions the microsphere recovery was dramatically reduced.

The zeta potential of the sandstone is negative under all solution conditions tested, but these results only represent the average zeta potential of the sample. There may be some positively charged 
sites on the sample despite the overall zeta potential being negative. Surface charge heterogeneities have been cited as an explanation for deviation from expected transport behavior under unfavorable conditions [7]. The mineral analysis of the sandstone revealed that the sample contained small concentrations of iron and titanium oxide which may have a positive zeta potential under some of the tested solution conditions. Based on a review of the literature by Kosmulski (2009) [155], the reported range for the point of zero charge (PZC) of iron oxide $\left(\mathrm{Fe}_{2} \mathrm{O}_{3}\right)$, titanium oxide $\left(\mathrm{TiO}_{2}\right)$, and aluminum oxide is 7.6-9.1 (synthetic), 5.1-6.4, and 8.5-9.0 respectively. The reported PZC of the metal oxides is clearly in a range where metal oxide impurities would result in some positively charged sites at both $\mathrm{pH} 8$ and $\mathrm{pH} 6$. The lower $\mathrm{pH}$ of the favorable attachment tests $(\mathrm{pH} 6)$ would make it more likely for some of these impurities to be positively charged, although the existence of a small number of positively charged sites is not expected to be as significant for favorable conditions.

Positively charged attachment sites can have a major impact on transport even if the zeta potential results suggest the overall conditions are still unfavorable. This phenomenon was noted by Elimelech et al. (2000) [83] when they discovered that colloid deposition kinetics were controlled by the degree of patchwise chemical heterogeneity and not by the measured zeta potential of the porous media. The same observation can be made from this study in fractured media when the effect of attached positively charged AML microspheres on subsequent CML microsphere transport tests is examined. Performing favorable attachment tracer tests resulted in cationic AML microspheres being attached to the sandstone surface which created positively charged impurities on the overall anionic sandstone surface. The potential interference of these attached AML microspheres was the reason behind completing all unfavorable attachment experiments prior to starting the favorable attachment experiments. After the favorable attachment experiments were completed, an unfavorable attachment tracer test was run to analyze the impact of attached AML microspheres on CML microsphere transport. Figure 5.1 and 5.2 present a comparison between a CML microsphere transport test that occurred before and after the AML microsphere transport tests for $200 \mathrm{~nm}$ and $1000 \mathrm{~nm}$ particle sizes. 
Particle Size: 200 nm
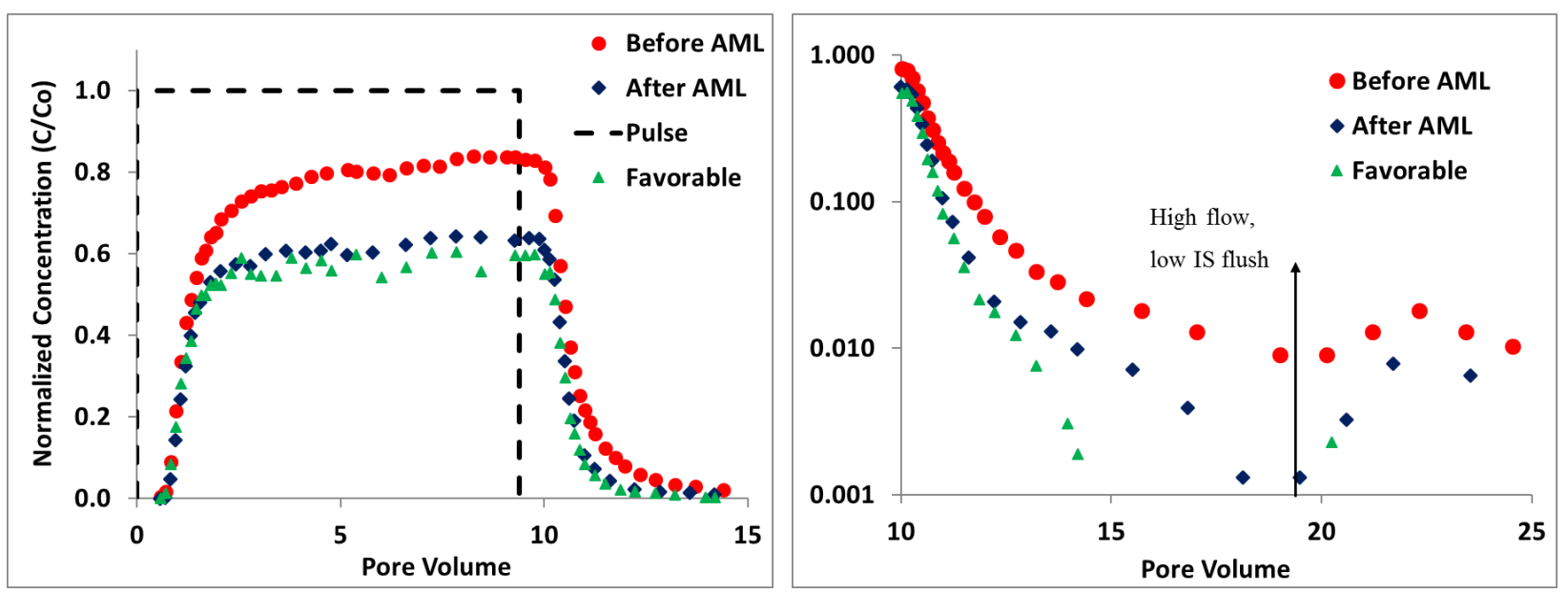

Figure 5.1 CML microsphere transport test at $0.35 \mathrm{~mm} . \mathrm{s}^{-1} \mathrm{SD}$ and $5 \mathrm{mM}$ IS for $200 \mathrm{~nm}$ particle size before and after AML microsphere transport tests

\section{Particle Size: 1000nm}
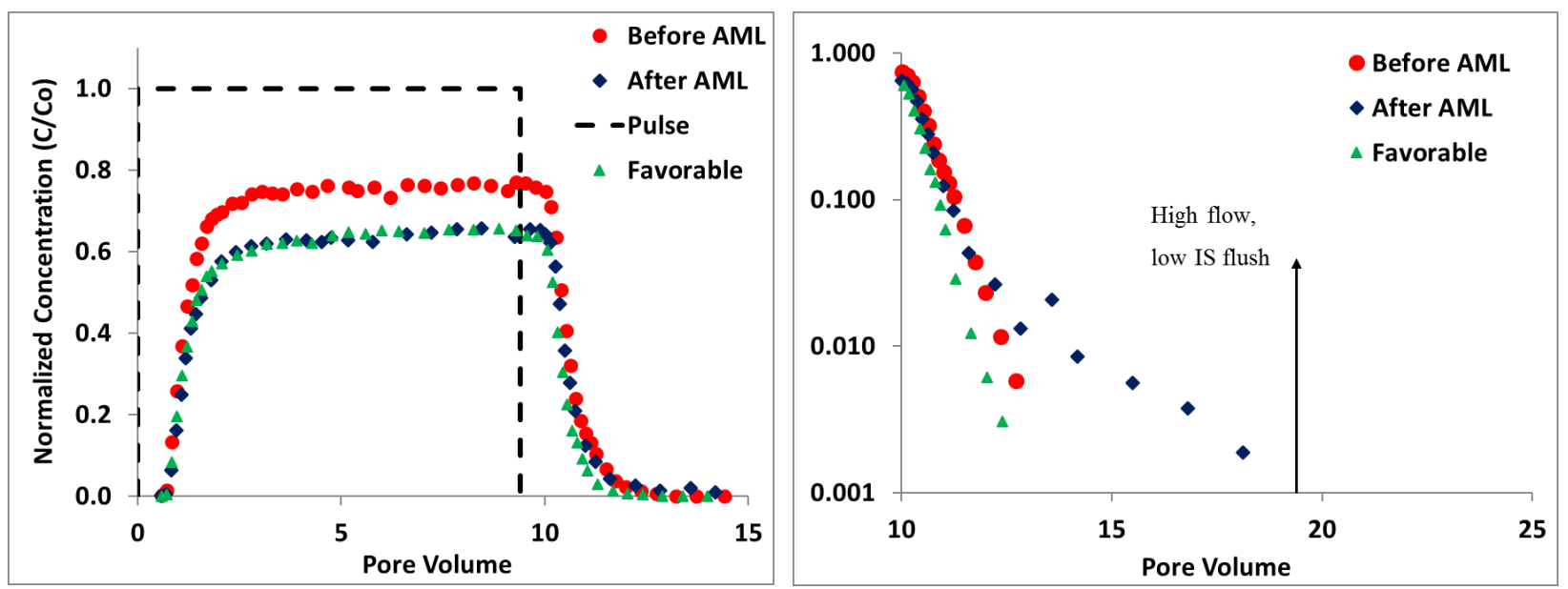

Figure 5.2 CML microsphere transport test at $0.35 \mathrm{~mm} . \mathrm{s}^{-1} \mathrm{SD}$ and $5 \mathrm{mM}$ IS for $1000 \mathrm{~nm}$ particle size before and after AML microsphere transport tests

Figure 5.1 and 5.2 show that the presence of attached positively charged microspheres on the fracture surface significantly increases the retention of the CML microspheres. For both microsphere sizes the mass recovery was similar to favorable attachment conditions. There is still evidence of unfavorable attachment in the "After AML" BTCs, because both particle sizes show more tailing than is present under favorable conditions. The spike in concentration for $200 \mathrm{~nm}$ 
microspheres after the high flow, low ionic strength flush also shows the presence of a secondary minimum, which would not exist under favorable conditions. The attached AML microspheres did not have the same effect on favorable attachment tests as they did on the unfavorable tests. The minimal impact of attached AML microspheres on subsequent favorable attachment tests was confirmed by repeating the first favorable attachment test at the end of all experiments and finding no significant changes in the results. The favorable attachment experiments not being impacted by previously attached AML microspheres is evidence that the overall conditions of the fracture were not changed (i.e. the sandstone still had an overall negative zeta potential). Positively charged attachment sites resulting in unfavorable attachment so closely resembling favorable attachment despite the overall conditions remaining unfavorable is an important observation. The assumption that the overall zeta potential of the collector media can determine the transport behavior of colloids through fractured media may lead to poor predictions in the presence of surface charge heterogeneities.

The effect of blocking was investigated by running multiple unfavorable attachment tests after the completion of the favorable attachment tests. As discussed previously, positively charged AML microspheres on the sandstone surface created favorable attachment sites for the anionic CML microspheres and led to a dramatic decrease in recovery. By running multiple tracer tests with 200 nm CML microspheres, the favorable attachment sites were eventually filled and blocked for further attachment. The results of this process of running multiple CML microsphere transport tests to block the favorable attachment sites is shown in Figure 5.3. 

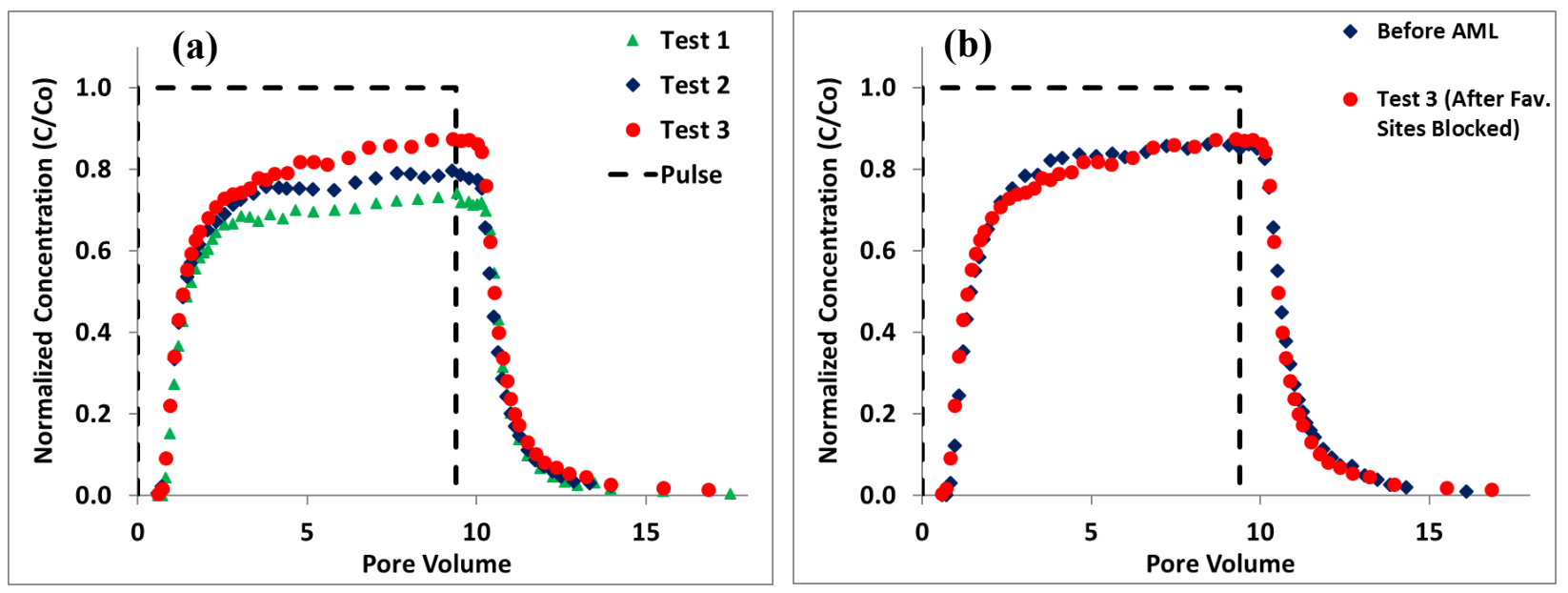

Figure 5.3 (a) 3 consecutive $200 \mathrm{~nm}$ CML transport tests showing increasing recovery as favorable sites are filled. (b) Comparing $200 \mathrm{~nm}$ BTCs before attached AML microspheres and after favorable sites are filled

The BTCs in Figure 5.3 (a) clearly show an increasing trend in recovery as the favorable attachment sites created by the attached AML microspheres are filled. The CML microspheres attach to the positively charged AML microspheres on the sandstone surface and block the site by repelling future negatively charged CML microspheres from attaching to that site. The BTCs in Figure 5.3 (b) indicate that after enough $200 \mathrm{~nm}$ CML microsphere transport tests were run the favorable attachment sites became filled and the results resembled the test prior to the AML microsphere experiments. Further evidence of blocking can be seen in the steep slope of the BTC plateau for Test 3, which indicates high initial attachment followed by increased recovery as the favorable sites are blocked.

\subsubsection{Specific Discharge Impact}

The overall impact of specific discharge was not significant in this study for either favorable or unfavorable attachment. Studies have shown that recovery generally increases with increasing specific discharge [121], [149], although this is not true in all cases as noted by Rodrigues et al. (2013) [144]. The specific discharge did show an impact for one tested condition in this study, which was for $200 \mathrm{~nm}$ microspheres under unfavorable attachment conditions at higher ionic strength $(10 \mathrm{mM})$. The higher specific discharge of $0.70 \mathrm{~mm} \cdot \mathrm{s}^{-1}$ resulted in the recovery of CML microspheres increasing from $65 \%$ to $74 \%$. The impact of SD was more significant for the higher 
ionic strength conditions because the reduced mean residence time would provide less time for Brownian motion to transport colloids to the near-surface domain and facilitate attachment in the secondary minimum. The shear force would also be increased for the higher specific discharge, which may be more significant at higher ionic strength due to more colloids having a weak potentially reversible attachment in the secondary minimum. The result shows that if a broader range of specific discharge conditions was tested it is likely that the trend of increasing recovery with increasing specific discharge would have been found. Further tests to investigate specific discharge were not completed because the link between specific discharge and mass recovery has been well established, including by a previous study with this exact fracture system [146].

\subsubsection{Ionic Strength Impact}

Similar to specific discharge, the impact of ionic strength on colloid transport through fractured rock under unfavorable attachment conditions has been well established by previous studies [25], [32], [142], [156]. An increase in ionic strength leads to more microspheres being retained in the fracture, with the impact of divalent ions (not tested in this study) being more significant than monovalent ions. The main reason for the increase in retention is that particles become trapped in a zone near the surface of the collector known as the secondary minimum. An increase in ionic strength causes the depth of this energy well to increase and the separation distance from the collector surface to decrease. The effect of the increase in the depth of the secondary minimum at higher ionic strength is shown by examining the change in the tailing behavior of the $200 \mathrm{~nm}$ microspheres at $10 \mathrm{mM}$ ionic strength. The $10 \mathrm{mM}$ ionic strength BTC shows less tailing because the microspheres trapped in the deeper secondary minimum are retained more strongly and detach less. The impact of ionic strength in this study followed the trends outlined in the literature with the recovery of 200 and $1000 \mathrm{~nm}$ microspheres both decreasing for the higher ionic strength condition.

The high flow, low ionic strength flush at the end of the tracer test caused a small release of the $200 \mathrm{~nm}$ microspheres, which shows evidence that a secondary minimum exists. The spike in concentration during the high flow, low ionic strength flush is not large enough to account for most microspheres retained in the fracture, which is evidence that many of the microspheres must be irreversibly attached despite the unfavorable attachment conditions. Another interesting observation is that despite an $18 \%$ decrease in mass recovery with for the higher ionic strength 
condition the amount $200 \mathrm{~nm}$ CML microspheres released during the flush is not significantly greater than for the low ionic strength condition. The same scenario occurs for the $1000 \mathrm{~nm}$ microspheres, which see a decrease in mass recovery with the increased in ionic strength, but no particles released when the secondary minimum was eliminated. The conclusion can be made that the lower recovery at increased ionic strength must not be solely due to an increased retention in the secondary minimum. There are a few theories that could explain this observation: the decrease in zeta potential caused by higher ionic strength leads to less repulsive interaction between the colloid and collector, the microspheres initially attached in the secondary minimum become irreversibly attached, or the secondary minimum is not completely eliminated due to the flush having a $1 \mathrm{mM}$ ionic strength. The decrease in zeta potential does likely have some impact on attached microspheres, but even at $10 \mathrm{mM}$ ionic strength the zeta potential of the microspheres is still sufficiently negative to have a large energy barrier to attachment in the primary minimum. For a study in porous media, Kuznar and Elimelech (2007) [59] attributed the incomplete release of microspheres during a low ionic strength flush to microspheres that were initially trapped in the secondary minimum jumping to the primary minimum. The same theory can be applied to this study; more microspheres being trapped in the secondary minimum at higher ionic strength would lead to more microspheres jumping into the primary minimum and a lower overall recovery. CML microspheres can become irreversibly attached because they translate along the collector surface and become trapped in a stagnant flow zone, or because the polymers extending from the microsphere surface are able to reach through the primary energy barrier when the secondary minimum gets closer to the collector surface [59].

Ionic strength had a negligible impact for both microsphere sizes under favorable attachment conditions. The result is consistent with favorable attachment having no barrier to attachment and therefore no reversible attachment in the secondary minimum. The main impact that increasing ionic strength has on favorable attachment is that it reduces the zeta potential for both the colloid and collector which leads to a decrease in the magnitude and range of attractive double layer forces. A study in porous media by Elimelech (1991) [110] showed that the deposition rate of colloids under favorable attachment conditions increased when the ionic strength was reduced, which opposes the trends observed for unfavorable attachment. A larger increase in ionic strength for this study likely would have produced a similar trend to that obtained by Elimelech (1991) [110], but the ionic strength was kept low to ensure that the colloids remained stable. 


\subsubsection{Particle Size Impact}

The two particle sizes tested in this study were $200 \mathrm{~nm}$ and $1000 \mathrm{~nm}$ in diameter. Studies have suggested that an optimal particle size can be determined for transport through a fractured system, with $500 \mathrm{~nm}$ being a common determination [32], [140]. The optimal particle size could not be determined for this study because only two particle sizes were tested. The optimal size probably falls between 200 and $1000 \mathrm{~nm}$ because the recovery of these two sizes is relatively similar so there is likely a peak recovery somewhere in between.

For unfavorable conditions at low ionic strength $(5 \mathrm{mM})$, the $200 \mathrm{~nm}$ microspheres had a higher peak concentration and mass recovery than the $1000 \mathrm{~nm}$ microspheres. When the ionic strength was increased, this was reversed and the $1000 \mathrm{~nm}$ microspheres had the higher mass recovery and peak concentration. At high specific discharge $(10 \mathrm{mM})$ the smaller microspheres showed increased recovery when the specific discharge was increased, while the larger microspheres still showed no impact from specific discharge. When the conditions were changed to favorable (AML microspheres) the decrease in recovery was more significant for the smaller microspheres than it was for the larger microspheres. All these observations indicated that there was an overall trend of the larger microspheres being less impacted by changing the conditions of the test (specific discharge, ionic strength, and attachment conditions), with Brownian motion being the likely cause. Brownian motion would cause increased particle collisions and attachment for the smaller microspheres, which would lead to smaller microspheres getting closer to the collector surface and becoming more likely to be trapped in the secondary minimum. The increase in secondary minimum attachment would also explain the higher amount of tailing for the $200 \mathrm{~nm}$ microspheres because of higher detachment during the particle-free flush.

The shape of the BTCs for the 200 and $1000 \mathrm{~nm}$ colloids under unfavorable attachment conditions show some distinct differences. One noteworthy difference being that the peak of the $200 \mathrm{~nm}$ BTC rises as time passes, but for the larger $1000 \mathrm{~nm}$ microspheres it plateaus and is mostly flat. The larger microspheres also have a consistently shorter residence time than the smaller microspheres. These differences can be attributed to macro dispersion caused by some of the smaller colloids entering slower moving flow paths while the larger colloids stay mostly in the faster moving streamlines. The $200 \mathrm{~nm}$ microspheres have a higher diffusion coefficient than the $1000 \mathrm{~nm}$ microspheres $\left(2.25 \times 10^{-12}\right.$ vs $\left.4.5 \times 10^{-13} \mathrm{~m}^{2} \cdot \mathrm{s}^{-1}\right)$ so they are more likely to diffuse into the slower 
moving areas of the fracture. The size exclusion effect keeps the larger microspheres from entering slower moving small aperture regions of the fracture and it has also been show by James and Chrysikopoulos (2003) [157] that the finite size of a particle excludes it from the slower moving portions of the parabolic velocity profile that develops in a fracture. The charge exclusion effect is also a factor in keeping the larger microspheres more in the center of the parabolic velocity profile because they have a more negative zeta potential and therefore stronger double layer repulsive forces than the smaller microspheres. Under favorable attachment conditions the $1000 \mathrm{~nm}$ microspheres had a higher recovery than the $200 \mathrm{~nm}$ microspheres for all ionic strength and specific discharge conditions despite the larger microspheres having a more positive zeta potential. The larger microspheres staying more in the center of the parabolic velocity profile away from the collector surface explains the higher recovery of the $1000 \mathrm{~nm}$ microspheres under favorable conditions.

\subsubsection{Comparing Favorable and Unfavorable Attachment}

Examining the favorable attachment BTCs can provide a better understanding of the unfavorable attachment. Under favorable attachment conditions both microsphere sizes show similar amounts of tailing, whereas under unfavorable attachment conditions the smaller microspheres show more tailing. The fact that microsphere size does not significantly impact tailing when attachment is irreversible (favorable attachment) suggests that microsphere detachment and re-entrainment is a major contributor to the increased tailing for the smaller microspheres under unfavorable conditions. Of course, macrodispersion would also play a role in the increased tailing of the smaller microspheres, and the effect would be reduced under favorable conditions because the microspheres that enter slower moving flow paths would likely be retained in the fracture.

The reduction in mass recovery under favorable attachment conditions is not as significant as would be expected with no barrier to attachment. A study in porous media by Johnson and Li (2005) [158] showed that there was a close to 4 magnitude difference in peak normalized concentration between favorable and unfavorable attachment BTCs. The higher recovery under favorable attachment conditions in this study compared to in the study by Johnson and Li (2005) [158] is likely because differences in geometry of the fluid conduit cause transport and retention in fractured media to be significantly different than porous media [19]. In fractured media colloids are transported through large highly conductive pathways which is likely to facilitate further 
transport. The increased fluid velocity would result in higher physical shear forces which may contribute to a higher than anticipated recovery. Transport through fractures would also lead to less colloid collector interactions and therefore less opportunity for attachment because of the tendency for the particles to stay in the center of fluid flow away from the fracture walls. The colloids tend to stay in the center of the fracture flow due to size exclusion and low diffusion coefficients. Testing a smaller microsphere size (e.g. $20 \mathrm{~nm}$ ) may have resulted in a more drastic decrease in recovery under favorable conditions because of diffusion into slower moving zones and increased Brownian motion leading to more interactions with the collector. Under favorable conditions all collisions with the fracture surface should result in attachment (sticking efficiency $=1.0$ ), so the amount of colloid collector interaction would be the controlling factor for retention. The higher than anticipated recovery is an important observation because it demonstrates that if fractures are present under favorable attachment conditions in the field colloids may be transported greater distances than assumed.

\subsubsection{Comparison to Transport in Dolomite Fracture}

Similar transport tests to the ones performed in this study were carried out by Dr. Pulin Mondal and presented in both his thesis [149] and two research papers [25], [142]. The fracture set up and procedure used for those tests was adapted for this work, so a logical comparison could be made between Dr. Mondal's transport results in two dolomite fractures and the sandstone transport results from this study. The comparison is kept to the $200 \mathrm{~nm}$ CML microspheres because this is the only common microsphere between the two studies. The studies will be referred to as Mondal and Spanik for this section. The same specific discharges were used for both studies ( 0.35 and 0.70 $\mathrm{mm} \cdot \mathrm{s}^{-1}$ ) and the ionic strength conditions were comparable ( $3 \mathrm{mM}$ and $12 \mathrm{mM}$ for Mondal; $5 \mathrm{mM}$ and $10 \mathrm{mM}$ Spanik).

Both dolomite fractures for Mondal had a lower equivalent hydraulic aperture (130 $\mu \mathrm{m}$ for F1 and $110 \mu \mathrm{m}$ for F2) than the sandstone fracture $(311 \mu \mathrm{m})$. The bulk matrix porosity determined by SEM-BSE analysis was $10.3 \%$ for Mondal fracture F1, which was similar to the $10.8 \%$ porosity of the sandstone fracture. Mondal fracture F2 had a lower porosity of $6.2 \%$. Despite the sandstone and Mondal fracture F1 having more similar porosity, the bromide transport results for Mondal fracture F2 and the sandstone showed more resemblance. Fracture F1 had a longer mean residence time and more tailing than either fracture F2 or the sandstone. A likely explanation for this is that 
the aperture distribution of F1 shows more potential stagnant water zones, so even though the porosity is similar to the sandstone the overall immobile water content is probably higher for this fracture than the two others. A higher immobile water content would result in a longer BTC tail due to diffusion from the immobile zones back into the fracture flow during the flushing period. The aperture distribution of fracture F1 would also result in more flow channeling and increased macrodispersion compared to the other two fractures. The aperture distribution of the sandstone appears to be more similar to fracture F2, which results in the tailing of the bromide BTC also being more comparable.

The trends in microsphere recovery for the $200 \mathrm{~nm}$ CML microspheres are comparable for both studies. Both fractures from Mondal had a significant decrease in recovery when the ionic strength was increased from 3 to $12 \mathrm{mM}$; the same effect was observed in the sandstone fracture. In both studies, the significant decrease would not be fully accounted for by attachment in the reversible secondary minimum (shown by a low ionic strength flush), and must have involved some microspheres becoming irreversibly attached. The largest drop in recovery with increased ionic strength happened in fracture F2, but it is difficult to determine why this is because of the large number of factors involved (aperture, roughness, zeta potential, etc.). Another similar trend is that the $200 \mathrm{~nm}$ microsphere recovery is not significantly impacted by increasing specific discharge from 0.35 to $0.70 \mathrm{~mm} . \mathrm{s}^{-1}$ in either fracture. The comparison shows that despite differences in the fracture material and aperture between the two studies several similar trends could still be identified.

\subsection{Hydrus-1D Parameter Estimation}

The modeling with Hydrus-1D helped to identify the parameters that impact colloid transport. The BTCs were fit using a two-site kinetic non-equilibrium model which incorporated attachment and detachment. A good fit was found for all microsphere BTCs $\left(\mathrm{R}^{2}>98.5 \%\right)$ by assigning site 1 as an irreversible attachment site (low detachment coefficient) and site 2 as a reversible attachment site (high detachment coefficient). Having a reversible and irreversible attachment site coincides with the existence of a primary and secondary minimum for unfavorable attachment conditions. The difference between favorable and unfavorable attachment were primarily controlled by the magnitude of the two attachment coefficients. For favorable attachment, $\mathrm{K}_{\text {att1 }}$ (irreversible 
attachment site) was higher and $\mathrm{K}_{\mathrm{att} 2}$ (reversible attachment site) was lower than for unfavorable attachment. This is logical given that irreversible attachment should be a more significant retention mechanism under favorable conditions. Another interesting observation is that the higher value of $\mathrm{K}_{\text {det1 }}$ (irreversible attachment site) for the $200 \mathrm{~nm}$ microspheres under unfavorable conditions appears to be the primary controlling factor for why this case has the most tailing. An explanation for this could be that the higher detachment coefficient for site 1 can account for the slow release of microspheres back into the fluid that would cause the tailing. An increase in ionic strength under unfavorable attachment conditions resulted in a higher value of $\mathrm{K}_{\text {att1 }}$ (irreversible attachment site). This fits with the theory of higher ionic strength leading to more microspheres that were initially attached in the secondary minimum jumping into the primary minimum and becoming irreversibly attached (as discussed in Section 5.2.3). Including the effect of blocking only noticeably improved the result for the smaller CML microspheres, potentially due to their initial concentration being higher than the larger microspheres.

\subsection{Compsim Modeling}

In addition to the Hydrus-1D parameter estimation, the microsphere transport was also modeled using Compsim, which was developed by Sleep and Sykes (1993) [151]. The $200 \mathrm{~nm}$ microspheres were modeled under both favorable and unfavorable attachment conditions to identify changes in the fitting parameters. The model has four attachment sites that each have an attachment and detachment coefficient. The two attachment sites in the inner and outer matrix were not adjusted in the fitting. This was done to limit the complexity of the fit, and because adjusting the attachment and detachment coefficients in the matrix had less impact on the fit due to less microsphere transport occurring in the matrix. The attachment and detachment coefficients for the top ( $\mathrm{K}_{\mathrm{aw} 1}$ and $\left.\mathrm{K}_{\mathrm{dw} 1}\right)$ and bottom $\left(\mathrm{K}_{\mathrm{aw} 2}\right.$ and $\left.\mathrm{K}_{\mathrm{dw} 2}\right)$ of the fracture flow were used to fit the data. The fit obtained from the model was good, although it slightly underestimated the tailing of the $200 \mathrm{~nm}$ anionic CML microspheres. The fit likely could have been improved by employing a smaller $1 \mathrm{~mm}$ x 1 $\mathrm{mm}$ grid block size instead of the $5 \mathrm{~mm}$ x $5 \mathrm{~mm}$ that was used. A smaller grid block size was not used because of the added computational expense that it would cause.

The main difference between fitting the favorable and unfavorable attachment BTCs was in which

attachment sites were set to be reversible or irreversible. The favorable attachment BTC was fit by 
making both attachment sites irreversible, which limited the tailing on the BTC. The unfavorable attachment BTC was fit in a similar manner to the Hydrus-1D fit, by setting one site to be irreversible and the other site to be reversible. The irreversible attachment site allowed the longer tail of the unfavorable attachment BTC to be fit.

The fitted value for sticking efficiency was higher for favorable attachment, but there was not as much separation between favorable and unfavorable attachment as would be expected. The result corresponds with the less than anticipated difference in mass recovery between favorable and unfavorable attachment that was discussed in Section 5.2.5. Favorable attachment should have a sticking efficiency close to 1 (all collisions result in attachment), but the fitted results from Compsim for this study show a much lower value. An example of sticking efficiency values from the literature in a study in porous media by Tufenkji and Elimelech (2004) [7] showed the sticking efficiency increased from 0.019 under unfavorable conditions to 0.68 under favorable conditions. The model is set up in Compsim to treat the fracture as an equivalent porous media, so comparing the sticking efficiency to a real porous media system is not a fair comparison. The collector diameter that is set in Compsim cannot be physically defined like it is in porous media, which means that that the model does not provide a unique fit and could be one of the factors for why the sticking efficiency is low. For example, a higher sticking efficiency could be found if the collector diameter was initially set to a higher value. More work needs to be done to find an equation for the collector diameter based on fracture characteristics to make the model more easily applied for fractured systems.

Although the fit of the model in Hydrus-1D appears to be better, the 3D Compsim model holds more value for application in contamination and remediation projects. The Hydrus-1D model is valuable for estimating transport parameters and comparing scenarios, but it does not provide the same depth of information that is obtained from the Compsim model. The Compsim model is based on the measured aperture distribution of the fracture, which can help to identify stagnant water zones and preferential flow paths. The movement of a contaminant over time through the fracture can be visualized, and high attachment areas of the fracture can be identified. In a scenario where a colloidal remediation agent is being applied, knowledge of how it will travel through the fracture and which areas it might not be able to reach would be very important for developing an effective remediation plan. 


\section{Chapter 6 \\ Conclusions}

\section{Conclusions}

In this investigation, several experiments were carried out, with the primary goal of comparing the transport of microspheres through fractured rock under favorable and unfavorable attachment conditions. Parameters that affected the transport of microspheres under favorable and unfavorable attachment such as specific discharge and ionic strength were also investigated. The comparisons were supported by modeling the experimental results with both 1D (Hydrus-1D) and 3D (Compsim) groundwater modeling software. Important observations from this study and recommendations for future work are presented in this section.

\subsection{Important Observations}

1. Ionic strength has a major impact on unfavorable attachment transport tests, but a limited impact on favorable attachment transport tests. The difference is attributed to the existence of a secondary minimum under unfavorable conditions that is not present under favorable conditions. The existence of the secondary minimum under unfavorable conditions was confirmed by the release of microspheres with a low ionic strength flush, which did not occur under favorable conditions.

2. The number of microspheres released with the low ionic strength flush was not large enough to account for the decrease in attachment that was observed when the ionic strength was increased. This shows that microspheres initially attached in the secondary minimum can jump into the primary minimum and become irreversibly attached.

3. Larger microspheres are not as highly impacted by changes in ionic strength, specific discharge, and attachment conditions. Larger microspheres would be subject to less Brownian motion so they stay more in the center of the parabolic fracture flow and have less opportunity to become trapped in the primary or secondary minimum.

4. The decrease in recovery from unfavorable to favorable attachment was not as significant as would be anticipated. Transport through fractures results in less interaction between 
colloids and collectors than in porous media, particularly for the particle sizes and high specific discharge used in these tests. This is an important observation because it shows that colloids can be mobile in fractures even under favorable attachment conditions.

5. The presence of positively charged sites on the sandstone surface can have a major impact on the transport of anionic microspheres even if the overall attachment conditions remain unfavorable. Cationic microspheres retained on the surface of the sandstone caused anionic microsphere transport tests to closely resemble favorable attachment. This shows the importance of surface charge heterogeneity in colloid transport through fractured rock.

6. Hydrus-1D and Compsim were both effective tools for modeling the experimental results. The primary difference in modeling favorable and unfavorable attachment with both models was the reversibility of attachment. Unfavorable attachment required one attachment site to be reversible (high detachment coefficient) to fit the tail of the BTC.

7. Although a better fit for the experimental data was obtained from Hydrus-1D, Compsim provides more valuable information such as potential stagnation zones, high attachment areas, and preferential flow paths.

\subsection{Recommendations for Future Work}

A list of recommendations for future work to be carried out after this investigation is provided here. The work on modeling is likely where the more interesting future investigations will be because a lot of experimental data has already been obtained by this study and the work of Mondal (2012) [149] and Rrokaj (2015) [146].

\subsubsection{Experimental}

1. More favorable attachment tests using smaller microspheres (e.g. $20 \mathrm{~nm}$ ) to get a more complete idea of the impact of particle size on transport under favorable conditions. A smaller microsphere size may also lead to more separation between favorable and unfavorable transport results.

2. Perform transport tests at a lower specific discharge (e.g. $0.15 \mathrm{~mm} . \mathrm{s}^{-1}$ ) to observe whether the cationic microspheres are retained to a greater extent due to the longer mean residence time. 
3. Run favorable attachment tracer tests in the dolomite fracture used in Mondal (2012) [149] to investigate any deviations from the trends observed in this study due to the different fracture.

4. Perform microsphere attachment visualization experiments using a miniature fracture system. The goal of this study would be to observe how the anionic microspheres attach to the retained cationic microspheres on the fracture surface.

\subsubsection{Modeling}

1. Improve the fit of the Compsim model for colloid transport. Investigate the impact of the two attachment zones (inner and outer matrix) to see if the adjustment of these attachment and detachment coefficients can improve the fit.

2. Improve the fit for the bromide transport model in Compsim. Investigate the factors that are leading to the fit for Bromide not being as good as the fit for the microspheres.

3. Use Compsim to model both particle sizes under all specific discharge, ionic strength, and attachment conditions.

4. Utilize all of the experimental data obtained from the three fractures (two dolomite and one sandstone) to develop an equation for the equivalent fracture collector diameter to be used in Compsim. 


\section{References}

[1] Environment and Climate Change Canada, "Groundwater." [Online]. Available: https://www.ec.gc.ca/eau-water/default.asp?lang=En\&n=300688DC-1. [Accessed: 04Apr-2017].

[2] USGS, "Ground Water," $1999 . \quad$ [Online]. Available: https://pubs.usgs.gov/gip/gw/gw_b.html. [Accessed: 09-Aug-2017].

[3] M. W. Priddle, R. E. Jackson, and J. P. Mutch, "Contamination of the Sandstone Aquifer of Prince Edward Island, Canada by Aldicarb and Nitrogen Residues," Groundwater Monitoring \& Remediation, vol. 9, no. 4. pp. 134-140, 1989.

[4] M. Elimelech, "Effect of Particle Size on the Kinetics of Particle Deposition under Attractive Double Layer Interactions," Journal of Colloid and Interface Science, vol. 164, no. 1. pp. 190-199, 1994.

[5] L. Cai, M. Tong, X. Wang, and H. Kim, "Effect of different-sized colloids on the transport and deposition of titanium dioxide nanoparticles in quartz sand," Environ. Pollut., vol. 208, pp. 637-644, 2015.

[6] J. F. McCarthy and L. D. McKay, "Colloid Transport in the Subsurface," Vadose Zo. J., vol. 3, no. 2, p. 326, 2004.

[7] N. Tufenkji and M. Elimelech, "Deviation from colloid filtration theory in the presence of repulsive electrostatic interactions: Implications to microbial transport," no. 21, p. ENVR095, 2004.

[8] USGS, "Sandstone aquifers." [Online]. Available: https://water.usgs.gov/ogw/aquiferbasics/sandstone.html. [Accessed: 22-Jun-2017].

[9] P. G. Cook, “A Guide To Regional Flow in Fractured Rock Aquifers,” 2003.

[10] T. B. Boving and P. Grathwohl, "Tracer diffusion coefficients in sedimentary rocks: Correlation to porosity and hydraulic conductivity," J. Contam. Hydrol., vol. 53, no. 1-2, pp. 85-100, 2001.

[11] J. Maxwell, "Influence of depth, temperature, and geologic age on porosity of quartzose sandstone," Am. Assoc. Pet. Geol. Bull., 1964.

[12] M. Ramm and K. Bjorlykke, "Porosity/depth trends in reservoir sandstones: assessing the quantitative effects of varying pore-pressure, temperature and mineralogy: Norwegian shelf data," Clay Miner., vol. 29, pp. 475-490, 1994.

[13] K. K. Mohan, R. N. Vaidya, M. G. Reed, and H. S. Fogler, "Water sensitivity of sandstones containing swelling and non-swelling clays," Colloids Surfaces A Physicochem. Eng. Asp., vol. 73, no. C, pp. 237-254, 1993.

[14] F. Domenico, P.A., and Schwarz, Physical and chemical hydrogeology, 2nd ed. New York: John Wiley \& Sons, 1998.

[15] M. Z. Jaafar, A. M. Nasir, and M. F. Hamid, "Measurement of Isoelectric Point of Sandstone and Carbonate Rock for Monitoring Water Encroachment," J. Appl. Sci., vol. 14, no. 23, 
pp. 3349-3353, 2014.

[16] J. Vinogradov and M. D. Jackson, "Zeta potential in intact natural sandstones at elevated temperatures," Geophys. Res. Lett., vol. 42, no. 15, pp. 6287-6294, 2015.

[17] R. Kretzschmar and H. Sticher, "Colloid transport in natural porous media: influence of surface chemistry and flow velocity," Phys. Chem. Earth, vol. 23, no. 2, pp. 133-139, 1998.

[18] J. Wan and J. L. Wilson, "Visualization of the role of the gas water interface on the fate and transport of colloids in porous media," Water Resour. Res., vol. 30, no. 1, pp. 11-23, 1994.

[19] R. B. Knapp, M. L. Chiarappa, and W. B. Durham, "An experimental exploration of the transport and capture of abiotic colloids in a single fracture," Water Resour. Res., vol. 36, no. 11, pp. 3139-3149, 2000.

[20] P. W. Reimus, "The Use of Synthetic Colloids in Tracer Transport Experiments in Saturated Rock Fractures," Modal Anal., 1995.

[21] J. N. Ryan and M. Elimelech, "Colloid mobilization and transport in groundwater," Colloids Surfaces A Physicochem. Eng. Asp., vol. 107, no. 95, pp. 1-56, 1996.

[22] C. Degueldre, B. Baeyens, W. Goerlich, J. Riga, J. Verbist, and P. Stadelmann, "Colloids in water from a subsurface fracture in granitic rock, Grimsel Test Site, Switzerland," Geochim. Cosmochim. Acta, vol. 53, no. 3, pp. 603-610, 1989.

[23] W. Zhang, X. Tang, N. Weisbrod, and Z. Guan, "A review of colloid transport in fractured rocks," J. Mt. Sci., vol. 9, no. 6, pp. 770-787, 2012.

[24] J. McCarthy and C. Degueldre, "Sampling and characterization of groundwater colloids for studying their role in the subsurface transport of contaminants," Environ. Part., 1993.

[25] P. K. Mondal and B. E. Sleep, "Colloid Transport in Dolomite Rock Fractures: Effects of Fracture Characteristics, Speci fi c Discharge, and Ionic Strength," Environ. Sci. Technol., vol. 46, no. August, pp. 9987-9994, 2012.

[26] M. W. Hahn and C. R. O'Melia, "Deposition and Reentrainment of Brownian Particles in Porous Media under Unfavorable Chemical Conditions: Some Concepts and Applications," Environ. Sci. Technol., vol. 38, no. 1, pp. 210-220, 2004.

[27] D. Backhus, J. Ryan, D. Groher, and J. MacFarlane, "Sampling Colloids and ColloidAssociated Contaminants in Ground Water," Ground Water, 1993.

[28] T. Tosco, A. Tiraferri, and R. Sethi, "Ionic Strength Dependent Transport of Microparticles in Saturated Porous Media: Modeling Mobilization and Immobilization Phenomena under Transient Chemical Conditions," Environ. Sci. Technol., vol. 43, pp. 4425-4431, 2009.

[29] L. M. Mcdowell-boyer, J. R. Hunt, and N. Itar, "Particle Transport Through Porous Media," vol. 22, no. 13, pp. 1901-1921, 1986.

[30] B. R. Magee, L. W. Lion, and A. T. Lemley, "Transport of dissolved organic macromolecules and their effect on the transport of phenanthrene in porous media," Environ. Sci. Technol., vol. 25, no. 2, pp. 323-331, 1991.

[31] P. Reimus, B. Robinson, H. Nuttall, and R. Kale, "Simultaneous transport of synthetic colloids and a nonsorbing solute through single saturated natural fractures," 1994. 
[32] J. F. McCarthy, L. D. McKay, and D. D. Bruner, "Influence of ionic strength and cation charge on transport of colloidal particles in fractured shale saprolite," Environ. Sci. Technol., vol. 36, no. 17, pp. 3735-3743, 2002.

[33] L. D. McKay, R. W. Gillham, and J. A. Cherry, "Field experiments in a fractured clay till: 2. Solute and colloid transport," Water Resour. Res., vol. 29, no. 12, pp. 3879-3890, 1993.

[34] R. Kretzschmar, M. Borkovec, D. Grolimund, and M. Elimelech, "Mobile Subsurface Colloids and Their Role in Contaminant Transport," Adv. Agron., vol. 66, no. C, pp. 121193, 1999.

[35] Helmholtz, "Ueber einige Gesetze der Vertheilung elektrischer Ströme in körperlichen Leitern mit Anwendung auf die thierisch- elektrischen Versuche," Ann. der Phys. und Chemie, vol. 165, no. 6, pp. 211-233, 1853.

[36] D. L. Chapman, "A contribution to the theory of electrocapillarity," Philos. Mag. Ser. 6, vol. 25, no. 148, pp. 475-481, 1913.

[37] M. Gouy, "Sur la constitution de la charge électrique à la surface d'un électrolyte," J. Phys. Théorique Appliquée, vol. 9, no. 1, pp. 457-468, 1910.

[38] O. Stern, "The theory of the electrolytic double-layer," Z. Elektrochem, 1924.

[39] E. Olson, "Zeta Potential and Colloid Chemistry.," J. GXP Compliance, vol. 16, no. 1, pp. 81-96, 2012.

[40] B. E. Logan, "Coagulation in Natural and Engineered Systems," Environ. Transp. Process., pp. $362-407,2012$.

[41] B. Berkowitz, "Characterizing flow and transport in fractured geological media: A review," Adv. Water Resour., vol. 25, no. 8-12, pp. 861-884, 2002.

[42] D. J. Shaw, "Colloid \& Surface Chemistry," p. 315, 1992.

[43] M. Elimelech, J. Gregory, X. Jia, R. A. Williams, J. Gregory, X. Jia, and R. A. Williams, "Chapter 2 - Electrical properties of interfaces," Part. Depos. Aggreg., pp. 9-32, 1995.

[44] D. C. Grahame, "The electrical double layer and the theory of electrocapillarity.," Chem. Rev., pp. 441-501, 1947.

[45] B. Derjaguin and L. Landau, "The theory of stability of highly charged lyophobic sols and coalescence of highly charged particles in electrolyte solutions," Acta Physicochim. URSS, 1941.

[46] V. E. J. W. and O. J.Th.G., "Theory of the stability of lyophobic colloids.," The Journal of physical and colloid chemistry, vol. 51, no. 3. pp. 631-636, 1948.

[47] F. London, "The general theory of molecular forces," Trans. Faraday Soc., vol. 33, no. 8, p. $8 \mathrm{~b}, 1937$.

[48] H. C. Hamaker, "The London-van der Waals attraction between spherical particles," Physica, vol. 4, no. 10, pp. 1058-1072, 1937.

[49] E. M. Lifshitz, "The theory of molecular attractive forces between solids," Sov. Phys. JETP, vol. 2, no. 1, pp. 73-83, 1956. 
[50] E. S. Sabisky and C. H. Anderson, "Verification of the Lifshitz theory of the van der Waals potential using liquid-helium films," Phys. Rev. A, vol. 7, no. 2, pp. 790-806, 1973.

[51] J. van der Lee, E. Ledoux, G. de Marsily, M. D. de Cayeux, H. van de Weerd, B. Fraters, J. Dodds, E. Rodier, M. Sardin, and A. Hernández, A bibliographical review of colloid transport through the geosphere: Topical Report. 1994.

[52] J. N. Israelachvili, Van der Waals Forces between Particles and Surfaces. 2011.

[53] J. Gregory, "Approximate expressions for retarded van der waals interaction," J. Colloid Interface Sci., vol. 83, no. 1, pp. 138-145, 1981.

[54] N. Tufenkji and M. Elimelech, "Breakdown of colloid filtration theory: Role of the secondary energy minimum and surface charge heterogeneities," Langmuir, vol. 21, no. 3, pp. 841-852, 2005.

[55] J. N. Israelachvili, Van der Waals Forces between Particles and Surfaces. 2011.

[56] W. Stumm and J. J. Morgan, Aquatic chemistry: chemical equilibria and rates in natural waters. Wiley, 1996.

[57] D. Grasso, K. Subramaniam, M. Butkus, K. Strevett, and J. Bergendahl, "A review of nonDLVO interactions in environmental colloidal systems," Rev. Environ. Sci. Biotechnol., vol. 1, no. 1, pp. 17-38, 2002.

[58] I. L. Molnar, W. P. Johnson, J. I. Gerhard, C. S. Willson, and D. M. O'Carroll, "Predicting colloid transport through saturated porous media: A critical review," Water Resour. Res., vol. 51, no. 9, pp. 6804-6845, Sep. 2015.

[59] Z. A. Kuznar and M. Elimelech, "Direct microscopic observation of particle deposition in porous media: Role of the secondary energy minimum," Colloids Surfaces A Physicochem. Eng. Asp., vol. 294, no. 1-3, pp. 156-162, 2007.

[60] G. Litton and T. Olson, "Particle size effects on colloid deposition kinetics: evidence of secondary minimum deposition," Colloids and Surfaces, vol. 107, pp. 273-283, 1996.

[61] S. Bhattacharjee, C.-H. Ko, and M. Elimelech, "DLVO Interaction between Rough Surfaces," Langmuir, vol. 14, no. 26, pp. 3365-3375, 1998.

[62] M. B. Seymour, G. Chen, C. Su, and Y. Li, "Transport and retention of colloids in porous media: Does shape really matter?," Environ. Sci. Technol., vol. 47, no. 15, pp. 8391-8398, 2013.

[63] G. Chen and S. L. Walker, "Role of solution chemistry and ion valence on the adhesion kinetics of groundwater and marine bacteria," Langmuir, vol. 23, no. 13, pp. 7162-7169, 2007.

[64] J. N. Israelachvili, Solvation, Entropic, Structural, and Hydration Forces. 2011.

[65] R. M. Pashley, "DLVO and hydration forces between mica surfaces in $\mathrm{Li}+, \mathrm{Na}+, \mathrm{K}+$, and $\mathrm{Cs}+$ electrolyte solutions: A correlation of double-layer and hydration forces with surface cation exchange properties," J. Colloid Interface Sci., vol. 83, no. 2, pp. 531-546, 1981.

[66] J. N. Israelachvili and R. . Pashley, "Measurement of the hydrophobic interaction between two hydrophobic surfaces in aqueous electrolyte solutions," J. Colloid Interface Sci., vol. 
98, no. 2, pp. 500-514, 1984.

[67] V. Morales, J. A. Anta, and S. Lago, "Integral equation prediction of reversible coagulation in charged colloidal suspensions," Langmuir, vol. 19, no. 2, pp. 475-482, 2003.

[68] K. K. Yao, M. M. T. Habibian, and C. C. R. O'Melia, "Water and Waste Water Filtration: Concepts and Applications," Environ. Sci. Technol., vol. 5, no. 11, pp. 1105-1112, 1971.

[69] M. (Menachem) Elimelech, Particle deposition and aggregation : measurement, modelling, and simulation. Butterworth-Heinemann, 1998.

[70] H. Yuan and A. A. Shapiro, Colloid Transport and Retention: Recent Advances in Colloids Filtration Theory, vol. 17, no. S2. 2011.

[71] J. McCarthy and L. D. McKay, "Colloid Transport in the Subsurface : Past, Present , and Future Challenges," Vadose Zo. J., no. 3, pp. 326-337, 2004.

[72] R. Rajagopalan and C. Tien, "Trajectory analysis of deep bed filtration with the sphere in cell porous media model," AIChE J., vol. 22, no. 3, pp. 523-533, 1976.

[73] N. Tufenkji and M. Elimelech, "Correlation Equation For Predicting Single-Collector Eficiency in Physiochemical Filtration in Saturated Porous Media," Environ. Sci. Technol., vol. 38, no. 2, pp. 529-536, 2004.

[74] W. Long, H. Huang, J. Serlemitsos, E. Liu, A. H. Reed, and M. Hilpert, "Pore-scale study of the collector efficiency of nanoparticles in packings of nonspherical collectors," Colloids Surfaces A Physicochem. Eng. Asp., vol. 358, no. 1-3, pp. 163-171, 2010.

[75] W. Long and M. Hilpert, "A correlation for the collector efficiency of Brownian particles in clean-bed filtration in sphere packings by a Lattice-Boltzmann method," Environ. Sci. Technol., vol. 43, no. 12, pp. 4419-4424, 2009.

[76] H. Ma, M. Hradisky, and W. P. Johnson, "Extending applicability of correlation equations to predict colloidal retention in porous media at low fluid velocity," Environ. Sci. Technol., vol. 47 , no. $5,2013$.

[77] H. Ma, J. Pedel, P. Fife, and W. P. Johnson, "Hemispheres-in-cell geometry to predict colloid deposition in porous media," Environ. Sci. Technol., vol. 43, no. 22, pp. 8573-8579, 2009.

[78] K. E. Nelson and T. R. Ginn, "New collector efficiency equation for colloid filtration in both natural and engineered flow conditions," Water Resour. Res., vol. 47, no. 5, pp. 1-17, 2011.

[79] M. Huilian and W. P. Johnson, "Colloid retention in porous media of various porosities: Predictions by the hemispheres-in-cell model," Langmuir, vol. 26, no. 3, pp. 1680-1687, 2010.

[80] J. Happel, "Viscous flow in multiparticle systems: Slow motion of fluids relative to beds of spherical particles," AIChE J., vol. 4, no. 2, pp. 197-201, 1958.

[81] I. L. Molnar, J. I. Gerhard, C. S. Willson, and D. M. O'Carroll, “The impact of immobile zones on the transport and retention of nanoparticles in porous media," Water Resour. Res., vol. 51, no. 11, pp. 8973-8994, 2015. 
[82] J. F. Schijven, W. Hoogenboezem, S. M. Hassanizadeh, and J. H. Peters, "Modeling removal of bacteriophages MS2 and PRD1 by dune recharge at Castricum, Netherlands," Water Resour. Res., vol. 35, no. 4, pp. 1101-1111, 1999.

[83] M. Elimelech, M. Nagai, C. H. Ko, and J. N. Ryan, "Relative insignificance of mineral grain zeta potential to colloid transport in geochemically heterogeneous porous media," Environ. Sci. Technol., vol. 34, no. 11, pp. 2143-2148, 2000.

[84] L. Song, P. R. Johnson, and M. Elimelech, "Kinetics of colloid deposition onto heterogeneously charged surfaces in porous media," Environ. Sci. Technol., vol. 28, no. 6, pp. 1164-1171, 1994.

[85] L. Song, P. R. Johnson, and M. Elimelech, "Kinetics of colloid deposition onto heterogeneously charged surfaces in porous media," Environ. Sci. Technol., vol. 28, no. 6, pp. 1164-1171, 1994.

[86] E. F. Pazmino, H. Ma, and W. P. Johnson, "Applicability of colloid filtration theory in sizedistributed, reduced porosity, granular media in the absence of energy barriers," Environ. Sci. Technol., vol. 45, no. 24, pp. 10401-10407, 2011.

[87] X. Li, T. D. Scheibe, and W. P. Johnson, "Apparent decreases in colloid deposition rate coefficients with distance of transport under unfavorable deposition conditions: A general phenomenon," Environ. Sci. Technol., vol. 38, no. 21, pp. 5616-5625, 2004.

[88] M. Tong and W. P. Johnson, "Colloid population heterogeneity drives hyperexponential deviation from classic filtration theory," Environ. Sci. Technol., vol. 41, no. 2, pp. 493-499, 2007.

[89] M. Turenkji, N; Elimeliech, "Reply to Comment on Breakdown of Colloid Filtration Theory: Role of the Secondary Energy Minimum and Surface Charge Heterogeneities," Langmuir, vol. 21, pp. 10896-10897, 2005.

[90] W. P. Johnson and X. Li, "Comment on Breakdown of Colloid Filtration Theory: Role of the Secondary Energy Minimum and Surface Charge Heterogeneities," Langmuir, vol. 21, p. 10895, 2005.

[91] O. Albinger, B. K. Biesemeyer, R. G. Arnold, and B. E. Logan, "Effect of bacterial heterogeneity on adhesion to uniform collectors by monoclonal populations," FEMS Microbiol. Lett., vol. 124, no. 3, pp. 321-326, 1994.

[92] N. Tufenkji, J. A. Redman, and M. Elimelech, "Interpreting deposition patterns of microbial particles in laboratory-scale column experiments," Environ. Sci. Technol., vol. 37, no. 3, pp. 616-623, 2003.

[93] S. F. Simoni, H. Harms, T. N. P. Bosma, and A. J. B. Zehnder, "Population heterogeneity affects transport of bacteria through sand columns at low flow rates," Environ. Sci. Technol., vol. 32, no. 14, pp. 2100-2105, 1998.

[94] M. W. Hahn, D. Abadzic, and C. R. O'Melia, "Aquasols: On the role of secondary minima," Environ. Sci. Technol., vol. 38, no. 22, pp. 5915-5924, 2004.

[95] J. A. Redman, S. L. Walker, and M. Elimelech, "Bacterial Adhesion and Transport in Porous Media: Role of the Secondary Energy Minimum," Environ. Sci. Technol., vol. 38, no. 6, pp. 1777-1785, 2004. 
[96] C. Shen, B. Li, Y. Huang, and Y. Jin, "Kinetics of coupled primary- and secondaryminimum deposition of colloids under unfavorable chemical conditions," Environ. Sci. Technol., vol. 41, no. 20, pp. 6976-6982, 2007.

[97] S. a. Bradford, S. R. Yates, M. Bettahar, and J. Simunek, "Physical factors affecting the transport and fate of colloids in saturated porous media," Water Resour. Res., vol. 38, no. 12, pp. 1-12, 2002.

[98] S. A. Bradford, S. Torkzaban, and S. L. Walker, "Coupling of physical and chemical mechanisms of colloid straining in saturated porous media," Water Res., vol. 41, no. 13, pp. 3012-3024, 2007.

[99] S. A. Bradford, J. Simunek, M. Bettahar, M. T. Van Genuchten, and S. R. Yates, "Modeling colloid attachment, straining, and exclusion in saturated porous media," Environ. Sci. Technol., vol. 37, no. 10, pp. 2242-2250, 2003.

[100] A. A. Porubcan and S. Xu, "Colloid straining within saturated heterogeneous porous media," Water Res., vol. 45, no. 4, pp. 1796-1806, 2011.

[101] O. Zvikelsky and N. Weisbrod, "Impact of particle size on colloid transport in discrete fractures," Water Resour. Res., vol. 42, no. 12, pp. 1-12, 2006.

[102] F. J. Leij, S. A. Bradford, Y. S. Wang, and A. Sciortino, "Langmuirian Blocking of Irreversible Colloid Retention: Analytical Solution, Moments, and Setback Distance," J. Environ. Qual., vol. 44, no. 5, pp. 1473-1482, 2015.

[103] S. A. Bradford, S. Torkzaban, and A. Shapiro, "A theoretical analysis of colloid attachment and straining in chemically heterogeneous porous media," Langmuir, vol. 29, no. 23, 2013.

[104] N. Seetha, M. S. Mohan Kumar, S. Majid Hassanizadeh, and A. Raoof, "Virus-sized colloid transport in a single pore: Model development and sensitivity analysis," J. Contam. Hydrol., vol. 164, pp. 163-180, 2014.

[105] I. L. Molnar, P. C. Sanematsu, J. I. Gerhard, C. S. Willson, and D. M. O'Carroll, "Quantified Pore-Scale Nanoparticle Transport in Porous Media and the Implications for Colloid Filtration Theory," Langmuir, vol. 32, no. 31, pp. 7841-7853, 2016.

[106] M. Elimelech and C. R. O'Melia, "Effect of electrolyte type on the electrophoretic mobility of polystyrene latex colloids," Colloids and Surfaces, vol. 44, no. C, pp. 165-178, 1990.

[107] K. Shellenberger and B. E. Logan, "Effect of molecular scale roughness of glass beads on colloidal and bacterial deposition," Environ. Sci. Technol., vol. 36, no. 2, pp. 184-189, 2002.

[108] S. Torkzaban and S. A. Bradford, "Critical role of surface roughness on colloid retention and release in porous media," Water Res., vol. 88, pp. 274-284, 2016.

[109] M. Elimelech, J. Gregory, X. Jia, R. A. Williams, J. Gregory, X. Jia, and R. A. Williams, "Theoretical predictions compared to experimental observations in particle deposition kinetics," Part. Depos. Aggreg. - Meas. Model. Simul., pp. 310-343, 1995.

[110] M. Elimelech, "Kinetics of capture of colloidal particles in packed beds under attractive bouble layer interactions," J. Colloid Interface Sci., vol. 146, no. 2, pp. 337-352, 1991.

[111] J. Bergendahl and D. Grasso, "Prediction of colloid detachment in a model porous media: 
Hydrodynamics," Chem. Eng. Sci., vol. 55, no. 9, pp. 1523-1532, 2000.

[112] C. Shen, V. Lazouskaya, H. Zhang, F. Wang, B. Li, Y. Jin, and Y. Huang, "Theoretical and experimental investigation of detachment of colloids from rough collector surfaces," Colloids Surfaces A Physicochem. Eng. Asp., vol. 410, pp. 98-110, 2012.

[113] K. L. Chen and M. Elimelech, "Aggregation and Deposition Kinetics of Fullerene (C60) Nanoparticles," Langmuir, vol. 22, no. 26, pp. 10994-11001, 2006.

[114] R. Detwiler, H. Rajaram, and R. Glass, "Solute transport in variable-aperture fractures," Water Resour. Res., vol. 36, no. 7, pp. 1611-1625, 2000.

[115] S. S. D. Foster, "The Chalk groundwater tritium anomaly - A possible explanation," $J$. Hydrol., vol. 25, no. 1-2, pp. 159-165, 1975.

[116] G. E. Grisak, J. F. Pickens, and J. A. Cherry, "Solute transport through fractured media: 2. Column study of fractured till," Water Resour. Res., vol. 16, no. 4, pp. 731-739, 1980.

[117] J. F. PANKOW, R. L. JOHNSON, J. P. HEWETSON, and J. A. CHERRY, “An evaluation of contaminant migration patterns at two waste disposal sites on fractured porous media in terms of the equivalent porous medium (EPM) model," J. Contam. Hydrol., vol. 1, no. 1-2, pp. 65-76, 1986.

[118] D. L. Rudolph, J. A. Cherry, and R. N. Farvolden, "Groundwater Flow and Solute Transport in Fractured Lacustrine Clay Near Mexico City," Water Resour. Res., vol. 27, no. 9, pp. 2187-2201, 1991.

[119] P. M. Jardine, W. E. Sanford, J. P. Gwo, O. C. Reedy, D. S. Hicks, J. S. Riggs, and W. B. Bailey, "Quantifying diffusive mass transfer in fractured shale bedrock," Water Resour. Res., vol. 35, no. 7, pp. 2015-2030, 1999.

[120] L. McKay, W. Sanford, and J. Strong, "Field-scale migration of colloidal tracers in a fractured shale saprolite," Groundwater, vol. 38, no. 1. pp. 139-147, 2000.

[121] N. Albarran, T. Missana, U. Alonso, M. García-Gutiérrez, and T. López, "Analysis of latex, gold and smectite colloid transport and retention in artificial fractures in crystalline rock," Colloids Surfaces A Physicochem. Eng. Asp., vol. 435, pp. 115-126, 2013.

[122] M. W. Becker and A. M. Shapiro, "Tracer transport in fractured crystalline rock: Evidence of nondiffusive breakthrough tailing," Water Resour. Res., vol. 36, no. 7, p. 1677, 2000.

[123] M. W. Becker, "Distinguishing Advection, Dispersion , and Diffusion in Fractured Bedrock," 2004 U.S. EPA/NGWAFractured Rock Conf. State Sci. Meas. Success Remediat., pp. 685-693, 2004.

[124] T. J. Callahan, P. W. Reimus, R. S. Bowman, and M. J. Haga, "Using multiple experimental methods to determine fracture/matrix interactions and dispersion of nonreactive solutes in saturated volcanic tuff," Water Resour. Res., vol. 36, no. 12, pp. 3547-3558, 2000.

[125] G. . Barenblatt, I. . Zheltov, and I. . Kochina, "Basic concepts in the theory of seepage of homogeneous liquids in fissured rocks [strata]," J. Appl. Math. Mech., vol. 24, no. 5, pp. 852-864, 1960.

[126] J. E. Warren and P. J. Root, "The Behavior of Naturally Fractured Reservoirs," Society of Petroleum Engineers. p., 1963. 
[127] H. H. . Gerke and M. T. Genuchten, "A dual porosity model for simulating the preferential movement of water and solutes in structures porous media," Water Resour. Res., vol. 29, no. 2, pp. 305-319, 1993.

[128] I. Miller and W. Dershowitz, "Dual Porosity Fracture Flow and Transport," Geophys. Res. Lett., vol. 22, no. 11, pp. 1441-1444, 1995.

[129] C. I. Ho, "Dual Porosity vs. Dual Permeability Models of Matrix Diffusion in Fractured Rock," in High-Level Radioactive Waste Conference, 2001.

[130] A. Cortis and J. Birkholzer, "Continuous time random walk analysis of solute transport in fractured porous media," Water Resour. Res., vol. 44, no. 6, pp. 1-11, 2008.

[131] M. Stoll, F. M. Huber, G. K. Darbha, E. Schill, and T. Schäfer, "Impact of gravity, collector surface roughness and fracture orientation on colloid retention kinetics in an artificial fracture," J. Colloid Interface Sci., vol. 475, no. April, pp. 171-183, 2016.

[132] M. Alaskar, K. Li, and R. Horne, "Silica Particles Mobility Through Fractured Rock," Arab. J. Sci. Eng., vol. 40, no. 4, pp. 1205-1222, 2015.

[133] and R. W. H. Matthew W. Becker, David W. Metge, Samantha A. Collins, Allen M. Shapiro, "Bacterial Transport Experiments in Fractured Crystalline Bedrock," Groundwater, vol. 41, no. 5, pp. 682-689, 2003.

[134] C. V Chrysikopoulos and C. Masciopinto, "Field Study of Pathogen Transport in a Fractured Aquifer," Geophys. Res. Abstr., vol. 9, 2007.

[135] W. Zhang, X. Y. Tang, N. Weisbrod, P. Zhao, and B. J. Reid, "A coupled field study of subsurface fracture flow and colloid transport," J. Hydrol., vol. 524, pp. 476-488, 2015.

[136] A. Abdel-salam and C. V Chrysikopoulos, "Analytical solutions for one-dimensional colloid transport in saturated fractures A. Abdel-Salam \& C. V. Chrysikopoulos, Advances in Water Resources, 17(5), 1994, pp 283-296," Int. J. Rock Mech. Min. Sci. Geomech. Abstr., vol. 32, no. 7, p. 318, 1995.

[137] S. C. James and C. V. Chrysikopoulos, "Monodisperse and polydisperse colloid transport in water-saturated fractures with various orientations: Gravity effects," Adv. Water Resour., vol. 34, no. 10, pp. 1249-1255, 2011.

[138] Q. Zheng, S. E. Dickson, and Y. Guo, "Differential transport and dispersion of colloids relative to solutes in single fractures," J. Colloid Interface Sci., vol. 339, no. 1, pp. 140$151,2009$.

[139] M. W. Becker, P. W. Reimus, and P. Vilks, "Transport and Attenuation of CarboxylateModified Latex Microspheres in Fractured Rock Laboratory and Field Tracer Tests," Ground Water, vol. 37, pp. 387-395, 1999.

[140] D. H. Cumbie and L. D. McKay, "Influence of diameter on particle transport in a fractured shale saprolite," J. Contam. Hydrol., vol. 37, no. 1-2, pp. 139-157, 1999.

[141] R. W. Harvey, D. W. Metge, A. M. Shapiro, R. A. Renken, C. L. Osborn, J. N. Ryan, K. J. Cunningham, and L. Landkamer, "Pathogen and chemical transport in the karst limestone of the Biscayne aquifer: 3. Use of microspheres to estimate the transport potential of Cryptosporidium parvum oocysts," Water Resour. Res., vol. 44, no. 8, pp. 1-12, 2008. 
[142] P. K. Mondal and B. E. Sleep, "Virus and virus-sized microsphere transport in a dolomite rock fracture," Water Resour. Res., vol. 49, no. 2, pp. 808-824, 2013.

[143] C. Neukum, A. Braun, and R. Azzam, "Transport of stabilized engineered silver (Ag) nanoparticles through porous sandstones," J. Contam. Hydrol., vol. 158, pp. 1-13, 2014.

[144] S. N. Rodrigues, S. E. Dickson, and J. Qu, "Colloid retention mechanisms in single, saturated, variable-aperture fractures," Water Res., vol. 47, no. 1, pp. 31-42, 2013.

[145] D. B. B. P.Vilks, L.H. Frost, "Field-scale colloid migration experiments in a granite fracture," Contam. Hydrol., no. 26, pp. 203-214, 1997.

[146] E. Rrokaj, "Nano-scale Colloid Particle Transport in Variable-Aperture Sandstone Rock Fracture," ProQuest Diss. Theses, p. 103, 2015.

[147] H. Abelin, I. Neretnieks, S. Tunbrant, and L. Moreno, "Final Report of the Migration in a Single Fracture - Experimental results and evaluation," 1985.

[148] Y. W. Tsang, "Usage of 'Equivalent Apertures' for Rock Fractures as Derived From Hydraulic and Tracer Tests," Water Resour. Res., vol. 28, no. 5, pp. 1451-1455, 1992.

[149] P. K. Mondal, "Virus and virus-sized particle transport in variable aperture rock fractures," 2012.

[150] J. Šimůnek, a M. Šejna, H. Saito, M. Sakai, and M. T. Van Genuchten, "The HYDRUS1D Software Package for Simulating the Movement of Water, Heat, and Multiple Solutes in Variably Saturated Media, Version 4.17, HYDRUS Software Series 3," no. June, p. 343, 2013.

[151] B. E. Sleep and J. F. Sykes, "Compositional simulation of groundwater contamination by organic compounds: 1. Model development and verification," Water Resour. Res., vol. 29, no. 6, pp. $1697-1708,1993$.

[152] Invitrogen, “Working With FluoSpheres ${ }^{\circledR}$ Fluorescent Microspheres,” Manual, 2001.

[153] and S. L. J. Roger C. Bales, Charles P. Gerba, Gerald H. Grondin, "Bacteriophage Transport in a Sandy Soil and Fractured Tuff," Appl. Environ. Microbiol., vol. 55, no. 8, pp. 2061-2067, 1989.

[154] D. R. Champ and J. Schroeter, "Bacterial transport in fractured rock. A field-scale tracer test at the Chalk River nuclear laboratories," Water Sci. Technol., vol. 20, no. 11-12, pp. 81-87, 1988.

[155] M. Kosmulski, "Compilation of PZC and IEP of sparingly soluble metal oxides and hydroxides from literature," Adv. Colloid Interface Sci., vol. 152, no. 1-2, pp. 14-25, 2009.

[156] J. F. McCarthy, "Colloid transport and retention in fractured media," pp. 1-13, 1999.

[157] C. V. Chrysikopoulos and S. C. James, "Transport of neutrally buoyant and dense variably sized colloids in a two-dimensional fracture with anisotropic aperture," Transp. Porous Media, vol. 51, no. 2, pp. 191-210, 2003.

[158] X. Li and W. P. Johnson, "Nonmonotonic variations in deposition rate coefficients of microspheres in porous media under unfavorable deposition conditions," Environ. Sci. Technol., vol. 39, no. 6, pp. 1658-1665, 2005. 
[159] L. W. Gelhar, Stochastic subsurface hydrology. Prentice-Hall, 1993.

[160] G. Grasselli, J. Wirth, and P. Egger, "Quantitative three-dimensional description of a rough surface and parameter evolution with shearing," Int. J. Rock Mech. Min. Sci., vol. 39, no. 6, pp. 789-800, 2002. 


\section{Appendices}

\section{Appendix A: Rock Fracture Properties from Rrokaj (2015) [146]}

All the results from Appendix A are taken from the thesis work of Ertiana Rrokaj. The analysis was performed prior to this investigation during the initial set up of the sandstone fracture system.

\section{A.1 Aperture Distribution Data and Correlation Length}

The aperture data was analyzed using Origin 9.1 software. Figure A.1 shows the aperture distribution of the fracture, and a semi-variogram used to determine the correlation length of the fracture. The correlation length is the distance after which apertures become independent of one another. The correlation length can be related to the dispersivity of a tracer through a fracture [159], and for the sandstone fracture it was determined to be 30 and $18 \mathrm{~mm}$ for the $\mathrm{x}$ and $\mathrm{y}$ direction, respectively.

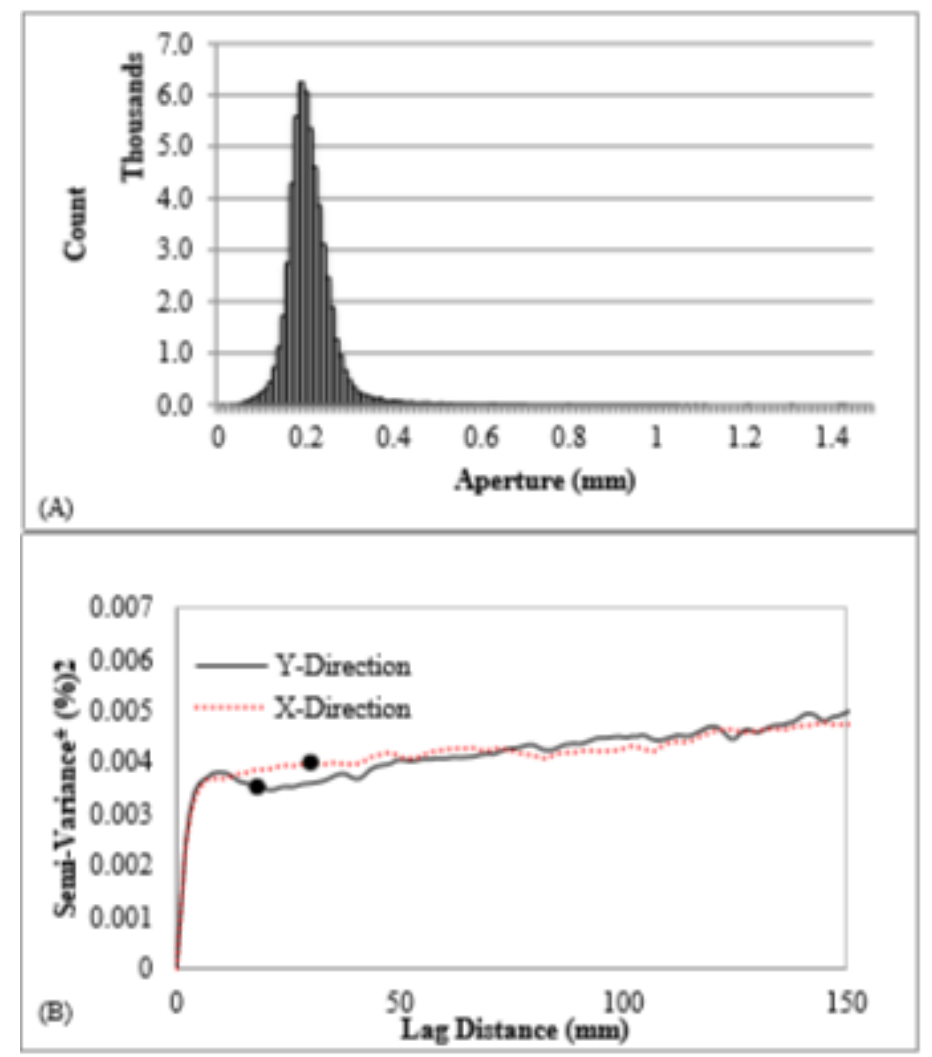

Figure A-1(A) Aperture data distribution. (B) Semi-Variogram of aperture data in $x$ and $y$ directions 


\section{A.2 Fracture Surface Images}

SEM images were taken of the sandstone surface to identify potential areas of flow stagnation and colloid attachment areas. Figure A-2 identifies some fissures on the fracture surface that have the potential to be high colloid deposition sites.
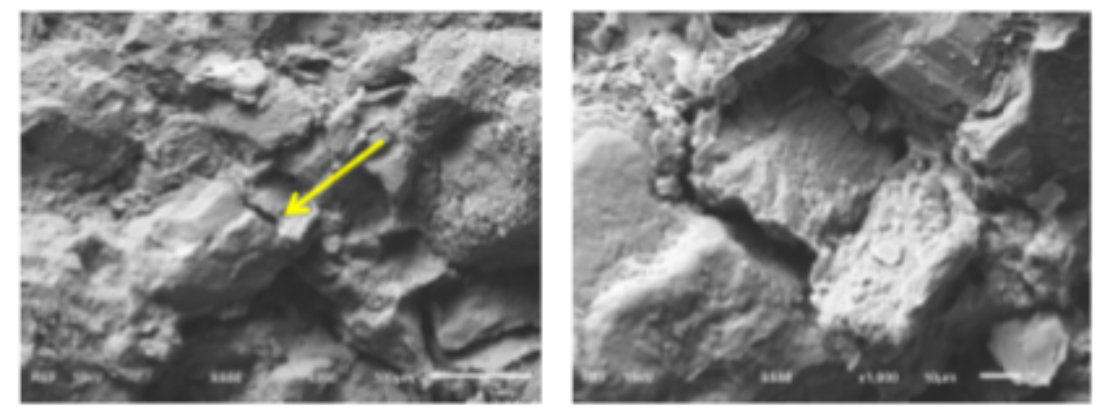

Figure A-2 SEM images of fracture fissures forming channels on surface

\section{A.3 Fracture Surface Roughness}

The fracture surface roughness was quantified using the Rock Surface Roughness Estimator software, which was developed by Grasselli et al. (2002) [160]. The maximum and minimum roughness values of the bottom fracture are 8.47 and 8.00. The roughness anisotropy (ratio of maximum to minimum roughness) is 1.06 . Figure A-3 presents a polar plot of the roughness anisotropy of the bottom plate of the fractured rock block. The direction angle of $0^{\circ}$ represents the water flow direction during the transport tests. The figure shows that the roughness along the long distance is slightly higher than along the short distance. 


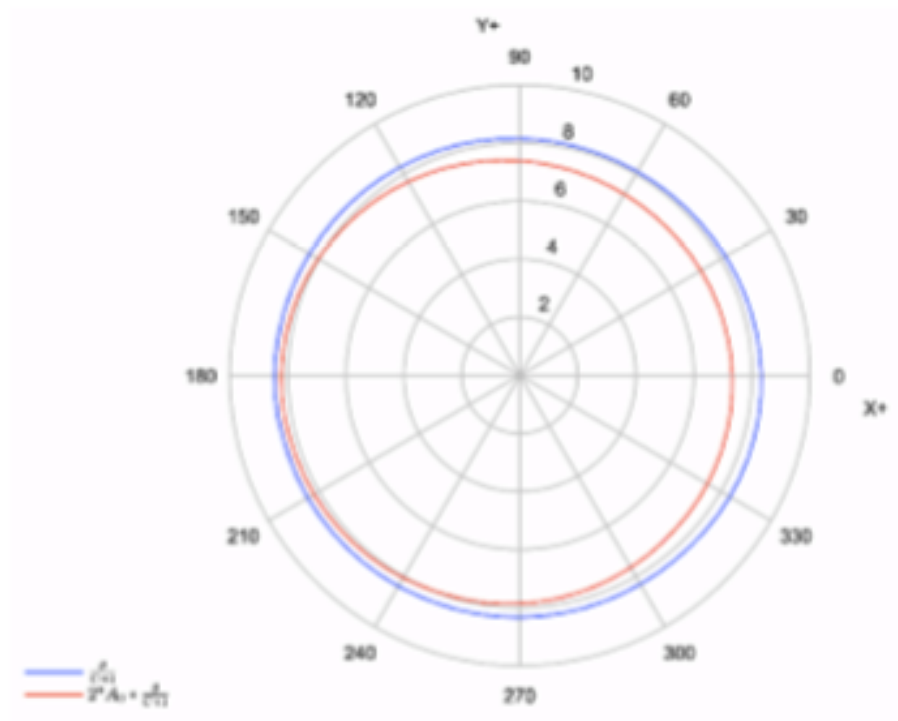

Figure A-3 Polar plot of fracture surface roughness for bottom plate

\section{A.4 Surface Element Mapping}

X-ray fluorescence spectroscopy (XRF) was used to quantify the mineral composition of the sandstone. The results are presented in Table A-1.

Table A-1 XRF analysis sandstone elemental concentrations in oxide form

\begin{tabular}{|c|c|c|c|}
\hline Compound & Concentration (\%) & Compound & Concentration (\%) \\
\hline $\mathrm{CO}_{2}$ & 15.463 & $\mathrm{MnO}$ & 0.06 \\
\hline $\mathrm{Na}_{2} \mathrm{O}$ & 2.063 & $\mathrm{Fe}_{2} \mathrm{O}_{3}$ & 2.641 \\
\hline $\mathrm{MgO}$ & 5.587 & $\mathrm{Ni}$ & 0.006 \\
\hline $\mathrm{Al}_{2} \mathrm{O}_{3}$ & 11.721 & $\mathrm{Cu}$ & 0.001 \\
\hline $\mathrm{SiO}_{2}$ & 50.798 & $\mathrm{Rb}$ & 0.007 \\
\hline $\mathrm{P}_{2} \mathrm{O}_{5}$ & 0.18 & $\mathrm{Sr}$ & 0.026 \\
\hline $\mathrm{SO}_{3}$ & 0.082 & $\mathbf{Y}$ & 0.002 \\
\hline $\mathrm{K}_{2} \mathbf{O}$ & 3.045 & $\mathbf{Z r}$ & 0.013 \\
\hline $\mathrm{CaO}$ & 7.814 & $\mathrm{Ba}$ & 0.11 \\
\hline $\mathrm{TiO}_{2}$ & 0.383 & $\mathrm{Cr}, \mathrm{Zn}_{\mathbf{n}}, \mathrm{Rh}$ & Traces \\
\hline
\end{tabular}


An SEM-EDS analysis was used on a few points of interest to identify potential mineral phases of the sandstone. Figure A-4 shows the results of this analysis. Potential positively charged areas such as titanium dioxide and iron oxide were identified.

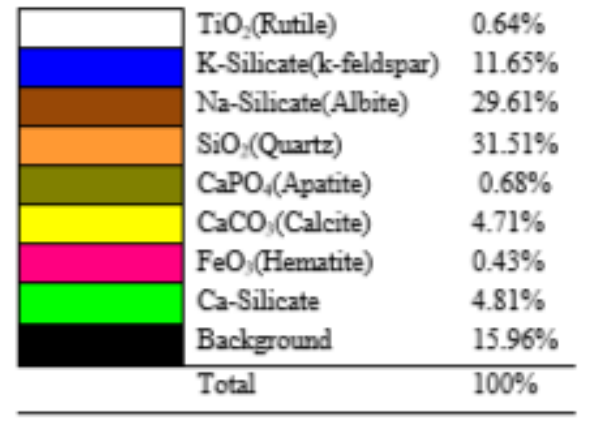

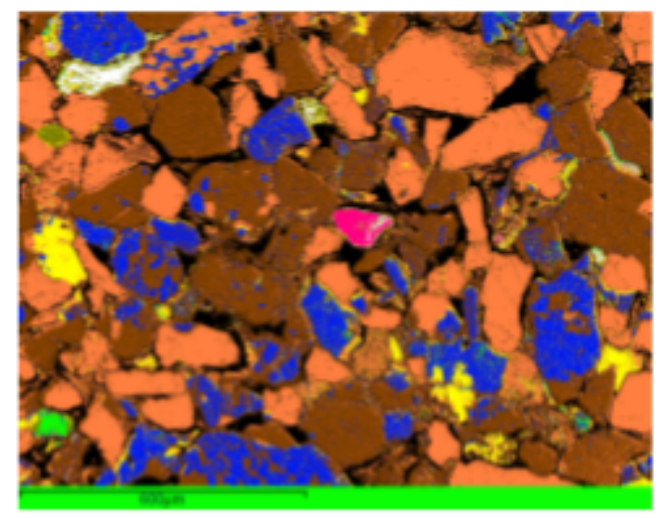

Figure A-4 Identification of mineral phases in sandstone sample

Figure A-5 shows the SEM-BSE analysis that was used to measure the porosity of the sandstone. The ratio of black to white pixels is used to calculate porosity. The average total porosity, as determined by this method was $10.8 \pm 2.5 \%$.
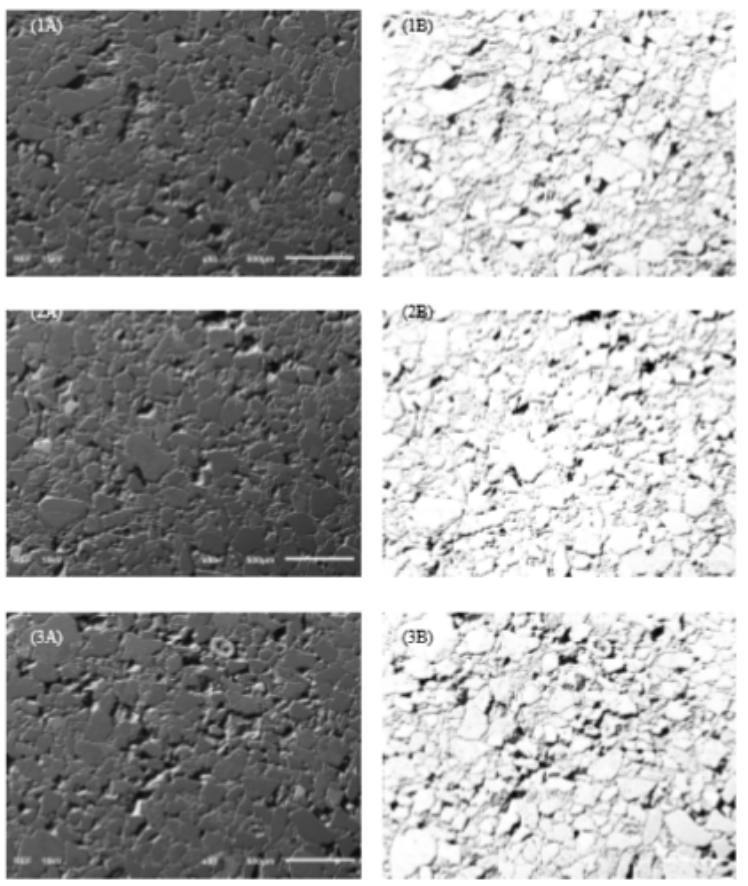

Figure A-5 SEM-BSE images (A) binary images (B) porosity measurement 


\section{Appendix B: Tracer Calibration Curves}

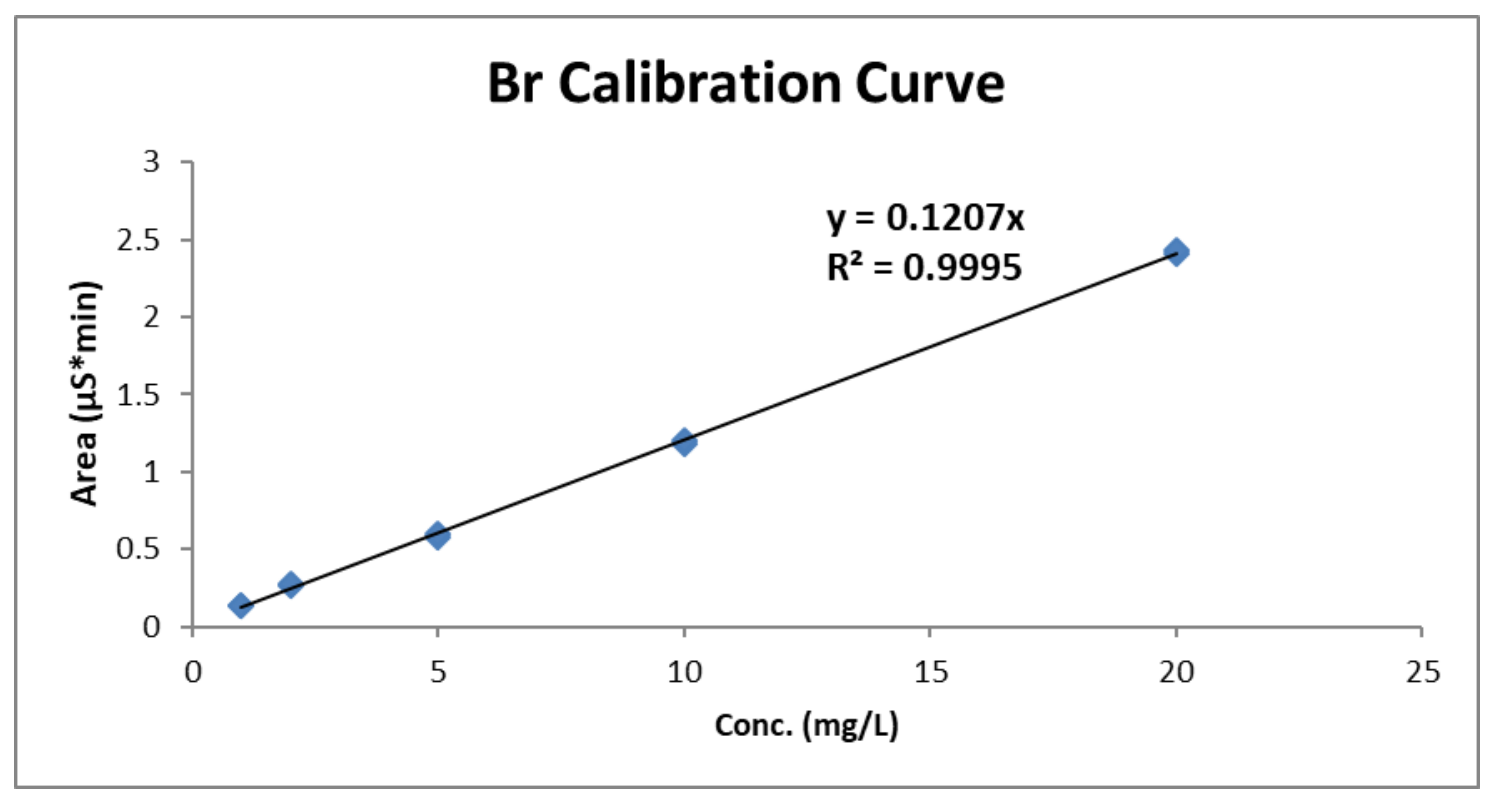

Figure B-1 Bromide calibration curve

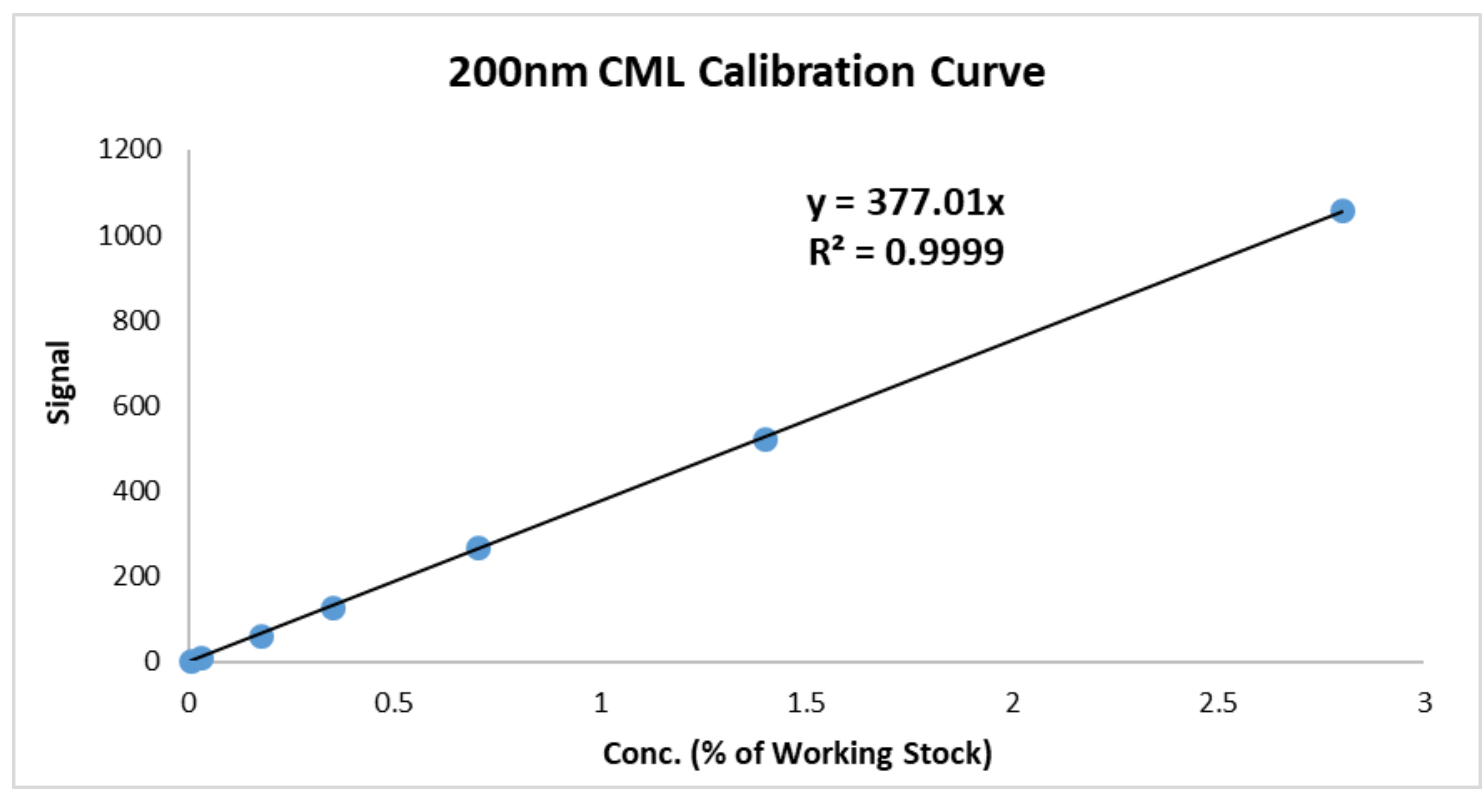

Figure B-2 $200 \mathrm{~nm}$ CML microsphere calibration curve 


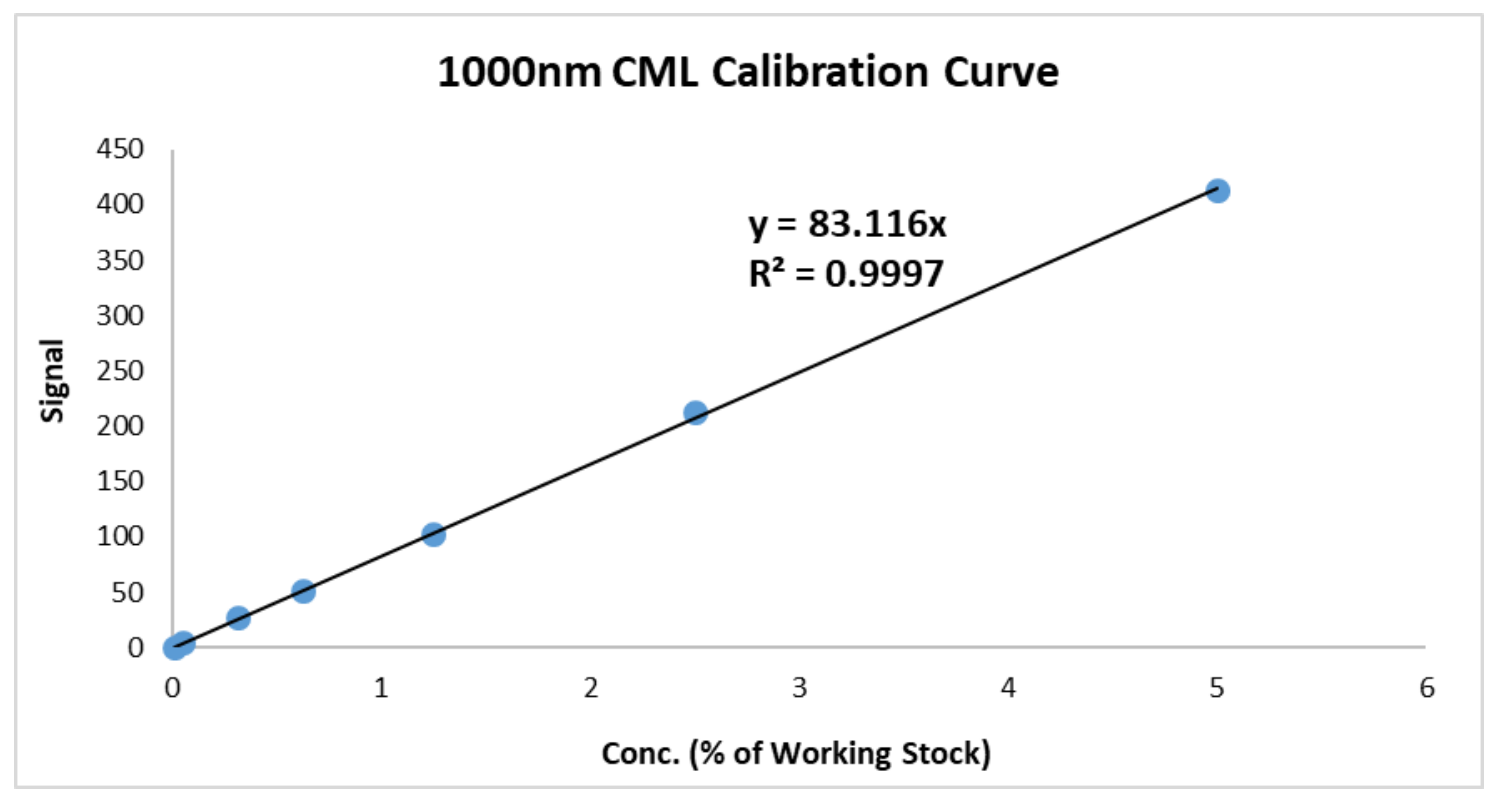

Figure B-3 $1000 \mathrm{~nm}$ CML microsphere calibration curve

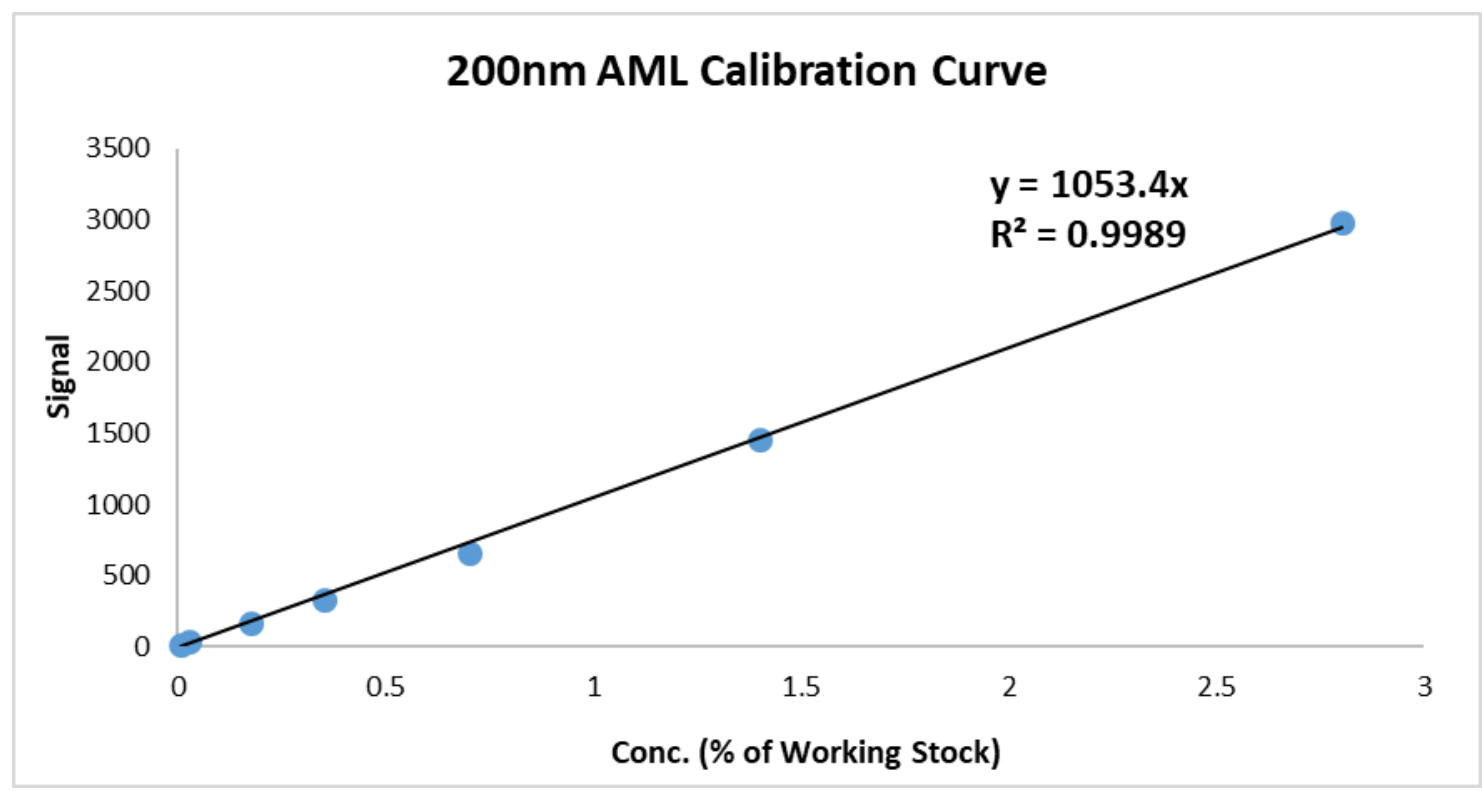

Figure B-4 200 nm AML microsphere calibration curve 


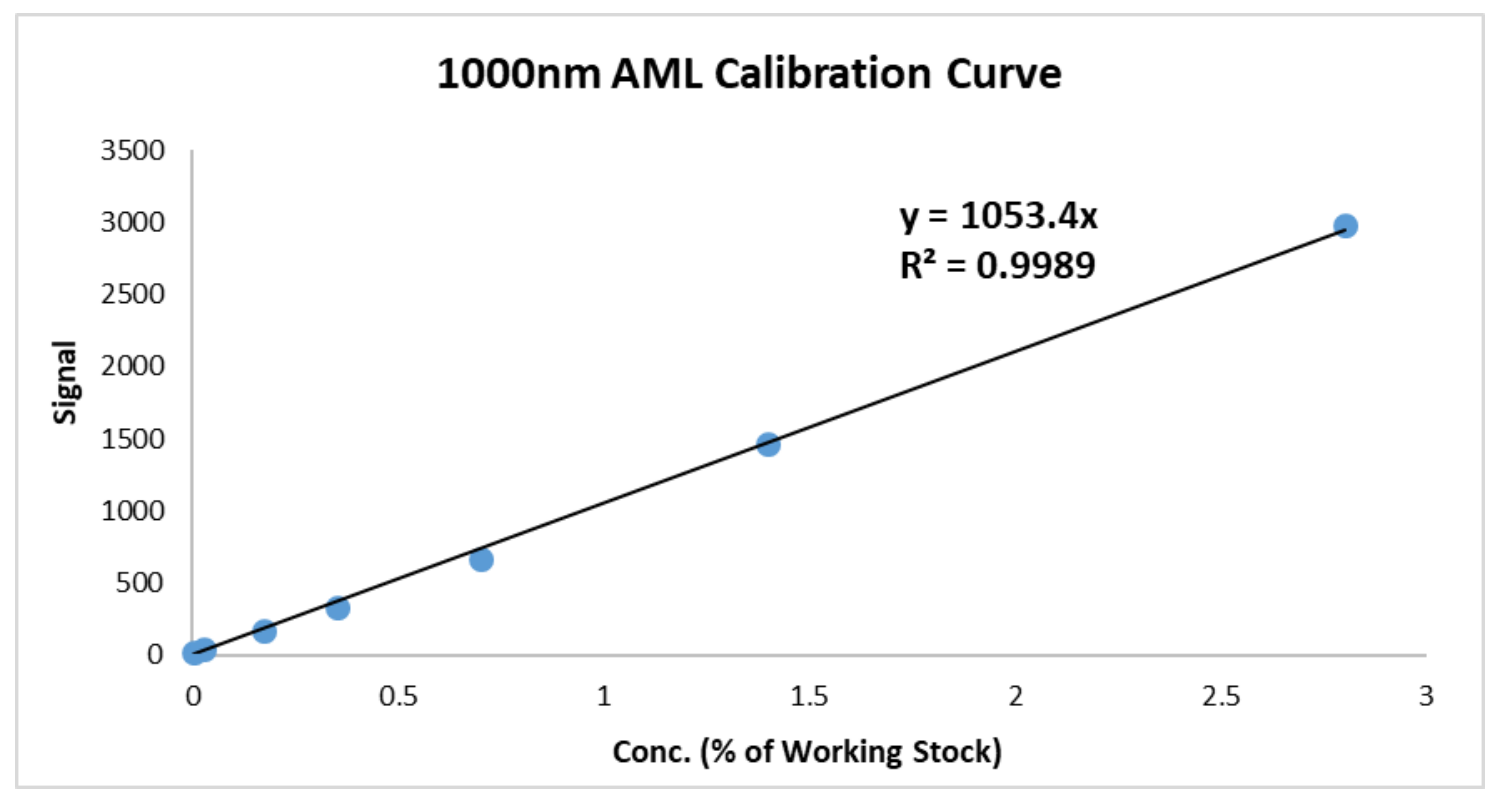

Figure B-5 $1000 \mathrm{~nm}$ AML microsphere calibration curve 